Portland State University

PDXScholar

Spring 6-16-2014

\title{
Complex Thermal Histories of $L$ Melt Breccias NWA 5964 and NWA 6580
}

Kristy Lee Schepker

Portland State University

Follow this and additional works at: https://pdxscholar.library.pdx.edu/open_access_etds

Part of the Geology Commons

Let us know how access to this document benefits you.

Recommended Citation

Schepker, Kristy Lee, "Complex Thermal Histories of L Melt Breccias NWA 5964 and NWA 6580" (2014). Dissertations and Theses. Paper 1835.

https://doi.org/10.15760/etd.1834

This Thesis is brought to you for free and open access. It has been accepted for inclusion in Dissertations and Theses by an authorized administrator of PDXScholar. Please contact us if we can make this document more accessible: pdxscholar@pdx.edu. 
Complex Thermal Histories of L Melt Breccias NWA 5964 and NWA 6580

by

Kristy Lee Schepker

A thesis submitted in partial fulfillment of the requirements for the degree of

Master of Science

in

Geology

Thesis Committee:

Alex Ruzicka, Chair

Melinda Hutson

Richard Hugo

Portland State University

2014 


\begin{abstract}
To constrain the thermal histories of two complex L chondrite melt breccia samples (NWA 5964 and NWA 6580) we compare textures and chemical compositions of metal and sulfide to L melt rock (NWA 6454 and NWA 6579) and strongly shocked (shock stage S6) (NWA 4860) samples. The inferred thermal histories can be used to evaluate formation settings on the L chondrite parent body. The L melt samples probably formed as different melt units within warm but largely unmelted material relatively close to the surface of the parent body, and the same is true for the S6 sample, except it experienced less melting. The breccia samples likely formed deeper, below different impact craters, by the injection of shock melt into a cooler chondritic basement. Carbide grains in the melt breccias could have formed by a contact metamorphic process caused by heating of the chondritic basement in proximity to the melt. Within the melt regions of the various samples, inferred cooling rates are on the order of $1-10{ }^{\circ} \mathrm{C} / \mathrm{sec}$, whereas in the chondritic portions of the melt breccias, the inferred cooling rates are many orders of magnitude slower, $\sim 1-100{ }^{\circ} \mathrm{C} / \mathrm{My}$. The complex intergrowths of metal and $\mathrm{FeS}$ (hereafter referred to as dendritic grains) within the melt are recording cooling rates above the metal-sulfide eutectic, while the metal grains outside of the melt regions are recording cooling rates at much lower temperatures. It is likely the melt regions in the breccias cooled substantially prior to coming to rest against the chondritic basement, and thereafter the melt-chondrite rocks cooled more slowly.
\end{abstract}




\section{Table of Contents}

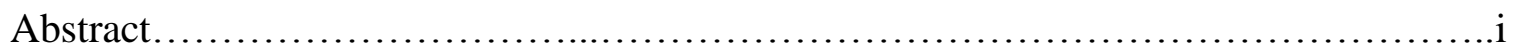

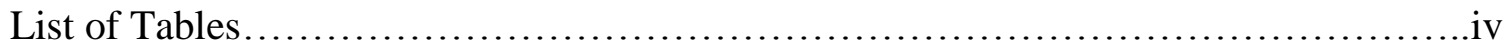

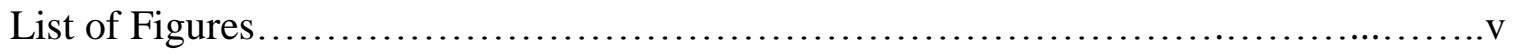

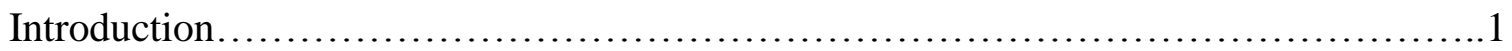

Shock processing of chondrites and the potential utility of metallic minerals.....6

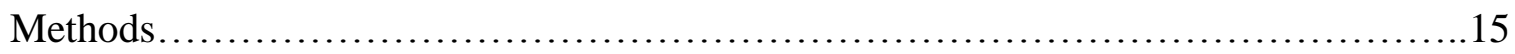





Electron Microprobe Analyses.............................................17

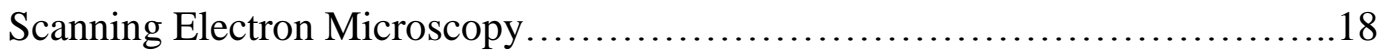

Cooling Rate Measurements: Dendrites...................................19

Closure Temperature Estimates: Zoned Kamacite-Taenite Structures.............19

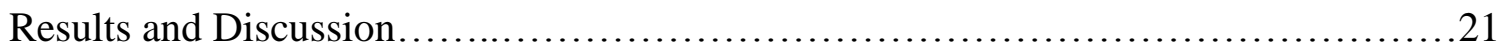



Metal Textures and Compositions............................................26

Dendritic Cooling Rates....................................................

Central Ni in Taenite Cooling Rates.........................................40

Phosphorus Enrichment in Metals........................................42

Nickel Enrichment in Troilite ...........................................49

Metal Textures and Their Significance ......................................55

Overall variation in Metal Grain Compositions..............................66 
Presence of Carbide Grains.............................................. 74

Conclusions .................................................................. 80

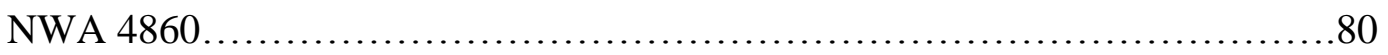

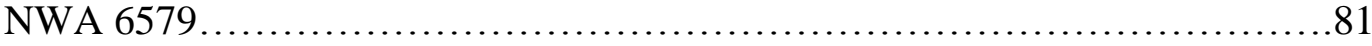





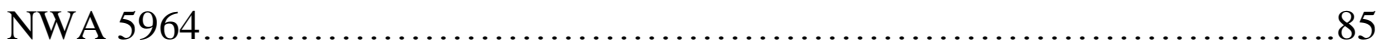

Summary ........................................................ 88






\section{List of Tables}

Table 1: Petrographic criteria for shock stages and estimated corresponding pressures and temperatures, after Stöffler et al. (1993) ${ }^{*}$ and Schmitt (2000) ${ }^{* *}$. One value was extrapolated from the Schmitt (2000) data+...........................................................4

Table 2: Official Meteoritical Bulletin names, and CML identification tags for samples used in this study.

Table 3: Starting temperatures (Ts) and final closure temperatures (Tf) for NWA 5964 grains within the chondritic host. Determined with phase diagram from SEM traverse

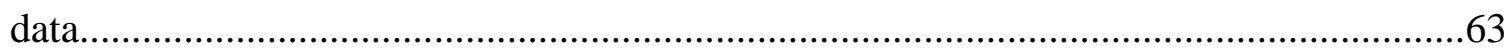

Table 4: Starting temperatures (Ts) and final closure temperatures (Tf) for NWA 6580 grains from within the chondritic host. 65

Table 5: Composition (wt\%) of carbide grains in NWA 5964 as measured with EMP analysis. *Carbon was calculated by difference from $100 \%$ total as we could not measure it directly. Average $=$ mean, stdev=standard deviation of the mean, $\min =$ minimum, $\max$



Table 6: Composition (wt\%) of carbide grains in NWA 6580 as measured with EMP analysis. *Carbon was calculated by difference from $100 \%$ total as we could not measure it directly. Average $=$ mean, $s t d e v=$ standard deviation of the mean, $\min =$ minimum, $\max$ $=$ maximum, number of analyses $=24$. .77 


\section{List of Figures}

Figure 1: Hierarchal classification scheme for meteorites (after Weisberg et al., 2006), showing the L chondrite group, which is the focus of this study.

Figure 2: FeNi phase digram after Reisener and Goldstein (2003a). Part A shows the diagram with points marked for metals experimentally heated and allowed to cool under equilibrium conditions to a closure temperature of $200{ }^{\circ} \mathrm{C}$ (Leroux et al., 2000). Part B shows in bold the Ni-rich path of transformations a $10 \% \mathrm{Ni}$ grain would undergo by cooling through equilibrium conditions (Reisener and Goldstein, 2003a), transforming from taenite of increasing $\mathrm{Ni}$ content to tetrataenite, with coexisting Ni-poor kamacite. Ms-Martensitic start temperature, only begins when kamacite nucleation in the $\mathrm{T}+\mathrm{K}$ field is not favored..

Figure 3: NWA 4860 seen in cut and polished face of hand specimen. Metal (bright) grains often are aligned into short vein segments (top right to lower left in this image), although other metal grains encircle chondrules. A vug occurs to the left of the largest metal cluster in the upper left. The U.S. Penny for scale is $1.7 \mathrm{~cm}$ in diameter

Figure 4: NWA 6579 specimen hand sample showing fine grained melt texture, and elongated metal-sulfide assemblages with scattered vesicles. The U.S. Penny shown for scale is $1.7 \mathrm{~cm}$ in diameter.

Figure 5: NWA 6454 specimen hand sample.

Figure 6: NWA 5964 specimen hand sample. Sample shows large metal grain in the center of the stone, with chondritic texture dominating to the left and melt texture dominating to the right of the large metal grain. 
Figure 7: NWA 6580 hand sample showing largely melted rock, nearly devoid of metal, and small chondritic portion (lower right corner)

Figure 8: Backscattered Electron (BSE) image showing contact between zoned olivine grains in the melt region (lower right) and unmelted chondritic host (upper left). Metal and troilite grains appear bright white, silicates are various shades of grey. Scale bar in lower left is $100 \mu \mathrm{m}$.

Figure 9: Composition (Ni wt\%) of metal grains in NWA 4860 analyzed with EMP.....28

Figure 10: Backscatter SEM micrograph of metal grains in NWA 4860. The grains are nearly uniform in composition resulting in little variance in shading in the backscatter image. Silicates appear black as the image is optimized for metal (white); sulfide is light grey.

Figure 11: Composition (Ni wt\%) of metal grains in NWA 6454 analyzed with EMP....29

Figure 12: Composition (Ni wt\%) of metal grains in NWA 6579 analyzed with EMP....30

Figure 13: Reflected light photomicrographs of typical grain textures seen in NWA 6579 (left) and NWA 6454 (right). Grains throughout both meteorites are similar globular intergrowths of metal (nearly white) and sulfide (darker gold color). Each scalebar is 100um.

Figure 14: Thin section scan of NWA 6580 as seen in transmitted light showing melt rock texture (left), accompanied by small chondritic portion (lower right). This section was cut from a larger stone showing only the melt lithology. .31 
Figure 15: Backscatter electron micrograph of largest opaque grains located in the melt region of NWA 6580. This assemblage consists of metal (bright) embedded in sulfide (grey). Individual metal grains are generally too small for reliable targeting with EMP for compositional analysis.

Figure 16: Backscatter electron micrograph of typical blocky kamacite-taenite intergrowth found in NWA 6580 unmelted region. Kamacite appears grey, taenite nearly white, troilite dark grey, silicate black 32

Figure 17: Backscatter electron micrograph of decomposed martensite grain showing the left portion decomposed forming plessite. Kamacite (grey) occurs at right; a carbide mineral (grey, with cracks) at top. This grain is located in the unmelted host region in NWA 6580.

Figure 18: Composition (wt\%) of metal grains in NWA 6580 analyzed with EMP .34

Figure 19: Backscatter electron micrograph of typical plessitic (transformed martensite) grain from chondritic portion of NWA 5964, showing a fine-grained intergrowth of Nipoor (grey) and Ni-rich (nearly white) metal.

Figure 20: Backscatter electron micrograph of typical kamacite (nearly white)-taenite (grey) blocky intergrowth grain from chondritic portion of NWA 5964. Sulfide grains (darker grey) occur nearby.

Figure 21: Backscatter electron micrograph of typical texture of metal-sulfide globules in the melted portion of NWA 5964 from thin section 4-1, showing dendritic (cellular), metal (white) that itself has fine plessite texture, amidst sulfide (grey).

Figure 22: Composition (wt \%) of unmelted metal (non dendritic, non-cellular) in the chondritic host portion of NWA 5964, analyzed with EMP .37 
Figure 23: Composition (wt\%) of metal in the melted portion of NWA 5964 thin section 4-1, as analyzed with EMP.

Figure 24: Cooling rates as determined by dendrite spacing in NWA 6579, NWA 6454, and NWA 5964.

Figure 25: Cooling rates for zoned taenite grains in NWA 6580 chondritic portion. Grains are consistent with slow cooling, generally 0.1 to $1 \mathrm{~K} / \mathrm{My}$ for small grains $(<20 \mu \mathrm{m}$ across)

Figure 26: Cooling rates for zoned taenite grains in NWA 5964, by thin section. Sections $2 \mathrm{~A}$ and $5 \mathrm{~A}$ represent grains from within the chondritic portion and are at a further distance from the shock melt than grains in chondritic clasts within thin section 4-1, which is mostly shock melt. Grains show a variety of cooling rates, but grains larger than about $8 \mu \mathrm{m}$ generally represent $10-100 \mathrm{~K} / \mathrm{My}$.

Figure 27: NWA 4860 Phosphorus and nickel content in metal grains. EMP data .44

Figure 28: NWA 6580 Phosphorus and nickel content in metal grains within the chondritic portion. EMP data. .45

Figure 29: NWA 6579 Phosphorus and nickel content in metal grains. EMP data .46

Figure 30: Reflected light photomicrograph of a metal grain in NWA 6579 showing small schreibersite grains in the metal-troilite globule.

Figure 31: NWA 6454 Phosphorus and nickel content in metal grains. EMP data. .48 
Figure 32: NWA 5964 Phosphorus and nickel content in metal grains. Metal grains within the chondritic host regions are shown in blue circles, and grains from within the melted section (4-1 thin section) are shown in red squares. EMP data

Figure 33: NWA 4860 nickel content in troilite grains. None of the grains are enriched beyond the $0.15 \mathrm{wt} \% \mathrm{Ni}$ enrichment level. EMP data.

Figure 34: NWA 6580 nickel content in troilite grains. Only one grain shows enrichment beyond the $0.15 \mathrm{wt} \% \mathrm{Ni}$ enrichment level. EMP data.

Figure 35: NWA 6454 nickel content in troilite grains. 37\% of the grains analyzed show enrichment in $\mathrm{Ni}$ beyond $0.15 \mathrm{wt} \%$. EMP data. .52

Figure 36: NWA 6579 nickel content in troilite grains. 23\% of grains show enrichment beyond $0.15 w t \%$ Ni. EMP data.

Figure 37: NWA 5964 chondritic host nickel content in troilite grains. 9\% of grains show enrichment beyond $0.15 \mathrm{wt} \% \mathrm{Ni}$. EMP data. .54

Figure 38: NWA 5964 shock melted region nickel content in troilite grains. 33\% of grains analyzed are enriched beyond $0.15 \mathrm{wt} \% \mathrm{Ni}$. EMP data...... .55

Figure 39: Backscattered electron micrograph showing kamacite (grey) taenite (white) intergrowth in metal grain. Traverse (Line Data) 36 is shown in Figure 40. Silicates appear black; troilite is dark grey....

Figure 40: Composition of grain shown in Figure 39 as Line Data 36. The Cyan line is $\mathrm{Ni}$, which shows a typical slow cooling "M" -shaped profile 
Figure 41: Backscattered electron micrograph of zoneless plessite grain from the chondritic portion of NWA 5964. The grain lacks high Ni rims, and occurs near, but not in contact with a zoned kamacite-taenite grain.

Figure 42: Chemical profile of zoneless plessite grain, SEM traverse across grain shown in Figure 41 from top to bottom as the grain is oriented in the image. The grain shows highly variable composition as it is composed of a fine grained kamacite and taenite microstructure, but lacks a general zoning pattern.

Figure 43: Backscattered electron micrograph of fine plessite grain from small melt pocket in NWA 5964 - 5A thin section. Similar to the metals in the larger melted portions the grains here show thin rims of nickel enrichments. Metals (light grey and white), troilite (darker), silicates (black)

Figure 44: Composition of Metal-Sulfide assemblage shown in Figure 43 as calculated by Aztec software across traverse marked Line Data 24. Ni shown in purple clearly outlines the sulfide to metal grain boundary with high Ni (tetrataenite) spikes showing the rimmed metal grain

Figure 45: NWA 5964 closure temperatures determined from SEM traverse compositional data from Table 3

Figure 46: NWA 6580 closure temperatures determined from SEM traverse compositional data from Table 4 . 66

Figure 47: SEM and EMP compositions of metal grain cores from NWA 6579. .68

Figure 48: SEM compositions of metal grain cores from NWA 4860. .69 
Figure 49: SEM and EMP compositions of metal grain cores from NWA $6454 \ldots \ldots \ldots \ldots . . .70$

Figure 50: SEM and EMP compositions of metal grain cores from NWA $6580 \ldots \ldots \ldots \ldots . . .72$

Figure 51: SEM and EMP compositions of metal grain cores from NWA 5964.............74

Figure 52: Reflected light photomicrograph of metal-carbide grain from NWA 5964 showing typical metal-carbide texture with carbide along the metal-silicate contact.......75

Figure 53: Diagram of a terrestrial impact crater, annotated from French, 1998, to show the relative formation locations of the samples included in this study..........................81 


\section{Introduction}

Various materials have accreted and evolved over the existence of the solar system. Meteorites provide a record of the processes that have occurred as the solar system has evolved (Wood, 1988; Hutchison, 2004). Meteorites are classified and grouped together based upon what process or stage of evolution they have experienced. Chondrites are the most primitive and generally least processed materials remaining from the early solar nebula. Chondritic material has never been incorporated in a differentiated body, thus leaving them a mixture of silicate and metal grains. Chondrites are broken into classes based upon chemical variations within the silicates, as well as metal proportions, as shown in Figure 1. The largest class currently in the known collection of chondrite samples is the ordinary chondrite. Ordinary chondrites are further subdivided by bulk iron in the sample. The $\mathrm{H}$ group is high bulk iron (metallic $\mathrm{Fe}+$ lowest $\mathrm{FeO}$ in silicates), L group is low bulk iron (less metal and higher FeO in silicates), and the LL group with the least bulk iron and metal with highest $\mathrm{FeO}$ in silicates (there is some overlap with the L group). Compositional variations within metals and other constituent minerals in ordinary chondrites indicate that it is not probable that these meteorites formed as part of one parent body. Instead they likely formed as part of multiple undifferentiated parent bodies corresponding to their chemical classification. 




Figure 1: Hierarchal classification scheme for meteorites (after Weisberg et al., 2006), showing the $L$ chondrite group, which is the focus of this study.

In small bodies, chondritic material was metamorphosed, being heated as the planetesimal grew (McSween et al., 2002). Short lived radionuclides, especially ${ }^{26} \mathrm{Al}$, played a major role in the metamorphic heating and processing of planetesimals (McSween et al., 1988, Göpel et al, 1994). Most chondrites were affected by some degree of thermal metamorphism, resulting in changes in the mineralogy and in some cases the chemical composition of the material (McSween et al., 2002). Similar to larger bodies and planets, the material was presumably heated more the deeper it was buried within the planetesimal. This model is known as the onion shell model (Dodd, 1969). The degree of thermal metamorphism is recorded as the petrographic type, with type groupings grading from type 3 , minimally altered, to type 6 , close to melting and original textures nearly destroyed (Dodd, 1981). 
As newly formed chondritic materials collided within the solar nebula planetesimals grew. The chondritic material began to be heated and processed as collisions released thermal energy. Additional alterations such as hydrothermal or shock alterations can be determined for meteorite samples based upon post metamorphic processes. Collisions were common in the solar nebula and were responsible for both creating and destroying planetesimals (Wood, 1988). Collisions that created planetesimals were partially responsible for metamorphic processes. Collisions that are larger can destroy smaller planetesimals; these were accompanied by higher pressure waves, and a large release of thermal energy resulting in deformation of the chondritic material (Stöffler et al.,1988; Sharp and DeCarli, 1988).

Shock effects resulting from impacts on the parent body are common features seen in meteorites (Stöffler et al., 1988; 1991).The degree of shock in chondrites is determined, most commonly, based on the degree of deformation of olivine and plagioclase in the sample (Stöffler et al., 1991). The shock stage classification scheme of Stöffler and colleagues ranges from unshocked S1 to very strongly shocked S6, and a class beyond for significantly shock melted meteorites (Table 1). Once a meteorite has landed on Earth chemical alteration, including the oxidation of metal and destruction and creation of various minerals, results from interaction with air and water. A weathering grade is assigned to each ordinary chondrite to account for this terrestrial alteration. The weathering grade is also determined based upon the weathering and oxidation of the metals, troilite $(\mathrm{FeS})$, and silicates. This scale ranges from W0: no oxidation of metals, to W6: massive replacement of silicates by clay minerals (Wlotzka, 1993). 
Table 1: Petrographic criteria for shock stages and estimated corresponding pressures and temperatures, after Stöffler et al. (1993) ${ }^{*}$ and Schmitt (2000) ${ }^{* *}$. One value was extrapolated from the Schmitt (2000) data ${ }^{+}$.

\begin{tabular}{|c|c|c|c|c|}
\hline $\begin{array}{l}\text { Shock } \\
\text { Stage }\end{array}$ & $\begin{array}{c}\text { Olivine and Plagioclase } \\
\text { effects }\end{array}$ & Melting Effects & $\begin{array}{c}\text { Shock } \\
\text { pressure, GPa }\end{array}$ & $\begin{array}{l}\text { Post Shock } \\
\text { T increase }{ }^{\circ} \mathrm{C}\end{array}$ \\
\hline S1 & $\begin{array}{l}\text { Sharp optical extinction (ol, } \\
\text { plag) }\end{array}$ & No melt & $<5^{*}$ & $10-20^{*}$ \\
\hline S2 & $\begin{array}{l}\text { Undulatory extinction (ol, } \\
\text { plag) }\end{array}$ & No melt & $5-10^{*}$ & $\begin{array}{l}20-50^{*}, \\
\sim 97^{* *}\end{array}$ \\
\hline S3 & $\begin{array}{l}\text { Undulatory extinction (ol, } \\
\text { plag), planar fractures }(\mathrm{ol})\end{array}$ & $\begin{array}{l}\text { Incipient melt } \\
\text { pockets and } \\
\text { shock veins }\end{array}$ & $10-20 *$ & $\begin{array}{l}100-150^{*} \\
177-247^{* *}\end{array}$ \\
\hline $\mathrm{S} 4$ & $\begin{array}{l}\text { Mosaic extinction and planar } \\
\text { fractures (ol), undulose } \\
\text { extinction and planar } \\
\text { fractures (plag) }\end{array}$ & $\begin{array}{l}\text { Melt pockets } \\
\quad \text { and } \\
\text { interconnecting } \\
\text { melt veins }\end{array}$ & $15-35^{*}$ & $\begin{array}{l}250-350^{*} \\
367-437^{* *}\end{array}$ \\
\hline S5 & $\begin{array}{l}\text { strong mosaic extinction and } \\
\text { planar fractures and } \\
\text { deformation features (ol), } \\
\text { maskelynite (plag) }\end{array}$ & $\begin{array}{l}\text { pervasive melt } \\
\text { pockets, veins, } \\
\text { dikes }\end{array}$ & $30-55^{*}$ & $\begin{array}{l}600-850^{*} \\
694-837^{* *}\end{array}$ \\
\hline S6 & $\begin{array}{l}\text { recrystallization and localized } \\
\text { ringwoodite }(\mathrm{ol}), \text { mixed melt } \\
\text { (plag) }\end{array}$ & $\begin{array}{l}\text { pervasive melt } \\
\text { pockets, veins, } \\
\text { dikes }\end{array}$ & $>45-55^{*}$ & $\begin{array}{c}1500-1750^{*} \\
1123^{* *}- \\
1338^{+}\end{array}$ \\
\hline $\begin{array}{l}\text { Impact } \\
\text { Melt }\end{array}$ & $\begin{array}{l}\text { All minerals crystallize from } \\
\text { melt to produce igneous } \\
\text { textured rock }\end{array}$ & Whole rock melt & $75-90^{*}$ & $\begin{array}{l}>1500^{*} \\
>1338^{+}\end{array}$ \\
\hline
\end{tabular}

The overall classification of a meteorite sample requires grouping based upon chemical compositions, as well as the various types of alterations. Many chondrites are breccias, some are composed of pieces of a similar lithology, and others may be composed of pieces of multiple lithologies (Wood, 1988; Hutchison, 2004; Bischoff et al., 2006). Many chondrites fall into the category of genomict breccias, containing clasts of similar composition but various petrographic types (metamorphic grades) (Dodd, 1981; Scott and Rajan, 1981; Wood, 1988; Hutchison, 2004; Bischoff et al., 2006; 
Weisberg et al, 2006). Few chondrites are polymict breccias, containing clasts of two or more unique compositions; while some are composed of shock lithified fragments from the surface of a planetesimal, either regolith breccias that show direct evidence for surface exposure in the form of implanted solar wind gases or flare tracks, or fragmental breccias that lack surface exposure evidence but that consist of a variety of debris (Wood, 1988, Housen and Wilkening 1978). Polymict, regolith, fragmental, and genomict breccias can result in complicated classifications, as the material is much less uniform that unbrecciated or monomict breccias. The mixture of materials can result in multiple metamorphic types, or shock stages to be present within a single sample. In this study we attempt to constrain the thermal histories of two complex brecciated chondrites containing both melt regions and chondritic host regions. 


\section{Shock processing of chondrites and the potential utility of metallic minerals}

Petrographic shock effects of olivine and plagioclase are the principal criteria for assigning shock stages to chondrites (Table 1), and are calibrated for pressure and temperature effects using experimental data (Stöffler et al., 1988, 1991, Schmitt, 2000). At the lowest shock stages the olivine and plagioclase show minor modification, typically resulting in undulatory extinction when viewed in cross polarized light. The silicate minerals show progressive deformation features, such as mosaic extinction and planar fractures as the pressure and temperature of the shock front increases. At shock stage S3 silicates can begin to melt in localized pockets, with larger melt veins forming as shock stage increases to S6 (Table 1).

Although silicate minerals reveal a great deal about the maximum conditions as a result of shock processing, they less obviously record information about the cooling rate or thermal histories associated with shock. Diffusion within silicates is relatively slow, diffusion rates in metals and sulfides are more rapid, and metals undergo subsolidus transformations as they cool. Metals and sulfides have been shown to contain vital information about shock processing and cooling conditions (Smith and Goldstein, 1977; Bennett and McSween, 1996). A variety of studies have been conducted in attempts to experimentally recreate the variety of compositions and textures seen in the metal and sulfide structures in ordinary chondrites (Scott, 1982; Reisener and Goldstein, 2003b; Leroux et al., 2000; Bennett and McSween, 1996; Wilkening, 1978). Onorato et al. (1978) propose that metal grains within a single chondrite may record various stages of cooling, which Stöffler et al. (1991) describe as two stages of cooling. The first stage 
beginning immediately after impact melt material is mixed with cold clasts and the second being after these two materials have equilibrated, and they cool to ambient temperatures together. Despite the rapid diffusion rate in metals and sulfides, and their unique ability to record cooling conditions after a shock event, these materials have been comparatively overlooked in studies on shocked chondrites.

Fe-Ni metal is a major constituent of most meteorites; ordinary chondrites contain between 5 and 20\% iron-nickel metal by weight (Dodd, 1981; Hutchison, 2004). In relatively unshocked or low shock stage chondrites the chondritic metal grains are distributed randomly throughout the silicate matrix as 0.01 to $1 \mathrm{~mm}$ sized particles (Reisener and Goldstein, 2003b). This metal may occur in a variety of phases, depending on the original composition and cooling history of the metal. Figure 2 shows the phase diagram for the Fe-Ni system depicting the conditions where kamacite (low $\mathrm{Ni}, \alpha$ phase), taenite (high Ni, $\gamma$ phase) and martensite ( $\alpha_{2}$ phase) are likely to form. The metal-troilite (FeS) eutectic can be used as an indication of temperatures in excess of 950 to $1000^{\circ} \mathrm{C}$ (McSween et al., 1988). Metal and sulfide grains heated beyond the eutectic will have been melted and will exhibit textures indicative of such melting. The transformations shown on the diagram in Figure 2 are subsolidus phase transformations, occurring well below the melting temperature for Fe-Ni metal, and are dominantly controlled by kinetics, diffusion, and nucleation conditions (Reisener and Goldstein, 2003b). 

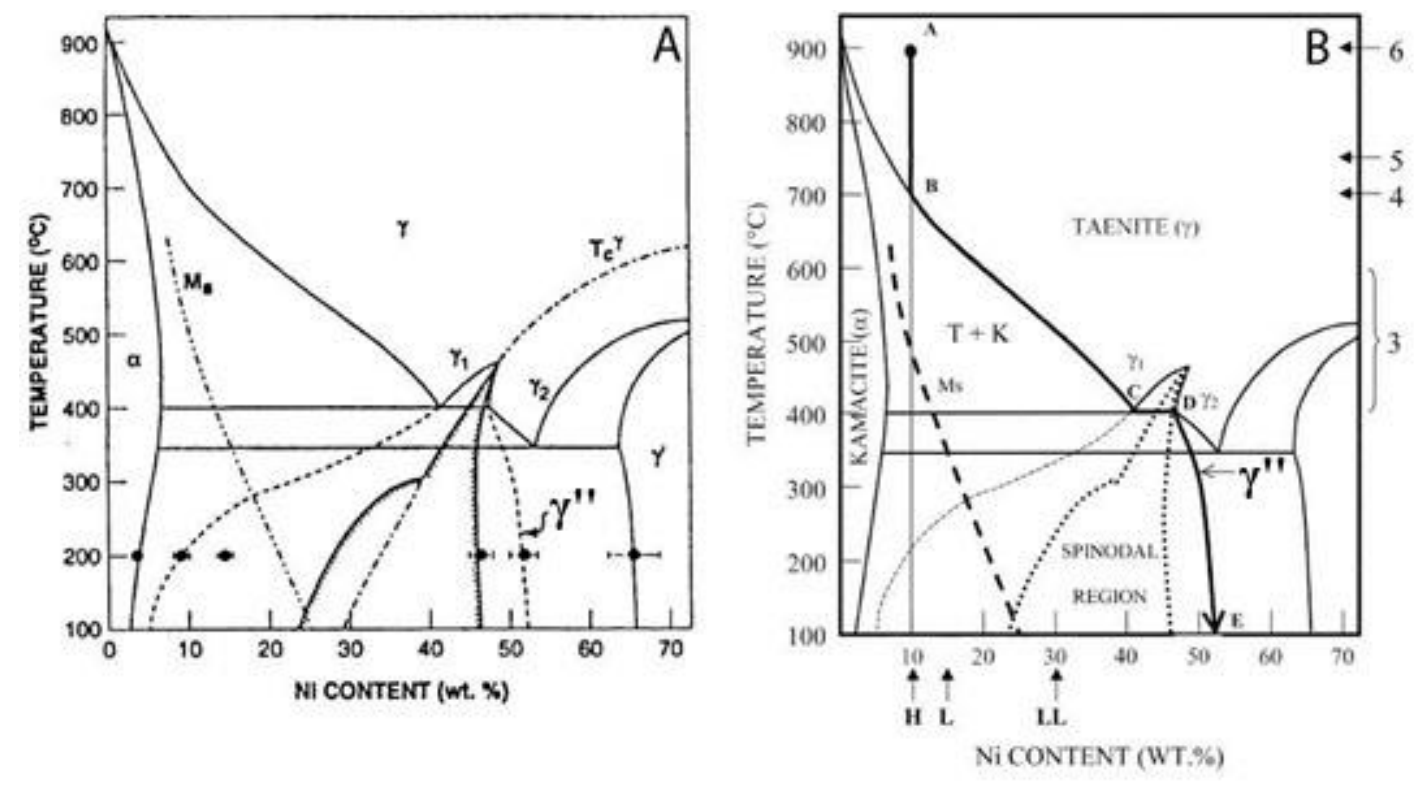

Figure 2: FeNi phase digram after Reisener and Goldstein (2003a). Part A shows the diagram with points marked for metals experimentally heated and allowed to cool under equilibrium conditions to a closure temperature of $200{ }^{\circ} \mathrm{C}$ (Leroux et al., 2000). Part B shows in bold the Ni-rich path of transformations a $10 \%$ Ni grain would undergo by cooling through equilibrium conditions (Reisener and Goldstein, 2003a), transforming from taenite of increasing Ni content to tetrataenite, with coexisting Ni-poor kamacite. Ms-Martensitic start temperature, only begins when kamacite nucleation in the $\mathbf{T}+\mathrm{K}$ field is not favored.

Low shock stage chondrites may still maintain textural and compositional indicators of the thermal metamorphism that occurred while a part of the parent body. Dodd (1969) proposed a layered asteroid model in which higher petrologic grades are from deeper within the body than lower grades, allowing higher grades to cool more slowly as they are partially thermally insulated by the overriding layers. This model, the so-called onion-shell model, is generally accepted in some form for ordinary chondrites, although there is evidence for parent body disruption and re-accretion events (e.g., Hutchison, 2004; Taylor et al., 1987). Regardless, in any metamorphic model involving endogenic heating, relatively slow cooling following peak metamorphic temperature would be expected. Under these conditions, zoned taenite and kamacite phases formed 
by diffusion controlled transformations are expected (Massalski et al., 1966; Reisener and Goldstein, 2003b). Wood (1967) showed the Ni diffusion differences between kamacite and taenite lead to an $\mathrm{M}$ shape when plotting Ni concentration across a taenite grain as the grain boundaries are enriched with $\mathrm{Ni}$, and the center is left with lower $\mathrm{Ni}$ concentrations. Wood (1967) concluded the zoned "M"- shaped profile is the result of incomplete diffusion during cooling. The central composition reflects the temperature at which diffusion began to cease in the grain (Ts), while the rim composition is indicative of the final temperature at which diffusion ceased (Tf). If the grains had been significantly reheated, it is likely this structure would be destroyed (Bennett and McSween, 1996). The size of this zoning has been shown to be a function of the cooling rate, meaning the central $\mathrm{Ni}$ content and the diameter of the taenite grain can be used together to determine a cooling rate (Wood, 1967; Willis and Goldstein, 1981; Taylor et al., 1987).

Martensite has been interpreted as a product of rapid cooling in past studies (Taylor and Heymann, 1970; Scott, 1982; Bennett and McSween, 1996). However, Reisener and Goldstein (2003b) demonstrated through experiment that nucleation effects, not just cooling, can control whether martensite forms or not. Taenite was found to only precipitate kamacite when the grain was polygranular taenite, meaning that high energy taenite-taenite grain boundaries were present. According to these authors, a lack of high energy grain boundaries resulted in undercooling until the diffusionless martensite transformation began. Upon further cooling the martensite was found to decompose to a fine-grained mixture of high- and low-Ni metal known as plessite (Massalski et al., 
1966), composed chiefly of tetrataenite $\left(\gamma^{\prime \prime}\right)$ and kamacite (Reisener and Goldstein, 2003b; Goldstein and Micheal, 2006). However, the presence of martensite or the decomposed plessite texture that forms from it can be an indirect recorder of shock effects. Heating and grain growth can annihilate taenite-taenite grain boundaries (Reisener and Goldstein, 2003b), so shock heating can produce a single taenite grain that upon cooling can produce martensite instead of kamacite and zoned taenite. Many metal grains in ordinary chondrites have compositions and textures consistent with slow cooling at depth within a parent body (Willis and Goldstein, 1981; Taylor et al., 1987), although some shock processed chondrites show evidence for faster cooling rates (Smith and Goldstein, 1977; Scott, 1982).

As Fe-Ni metal is cooled either rapidly or slowly, further subsolidus transformations occur until a closure temperature is reached. The closure temperature is the temperature in which the diffusion of $\mathrm{Ni}$ through the solid metal is stopped. The transformations that occur depend on multiple parameters: 1) initial composition of the metal (somewhat different for the H, L, and LL chondrite groups, Figure 2B), 2) nucleation sites for further transformations, and 3) cooling rate (Leroux et al., 2000; and references therein). A typical bulk nickel content in metal grains for $\mathrm{H}$ or $\mathrm{L}$ chondrites is about $10-15 \%$, so following the phase diagram in Figure 2, the typical slow cooling trend is for a metal to begin in the taenite field, then around $700^{\circ} \mathrm{C}$ kamacite will begin to exsolve forming kamacite + taenite assemblages (Reisener and Goldstein, 2003a). If nucleation of kamacite is suppressed, the martensite transformation begins at $400-500^{\circ} \mathrm{C}$ (Reisener and Goldstein, 2003a). Due to the predictable diffusion trends the distribution 
and concentration of $\mathrm{Ni}$ through the Fe-Ni metal alloy can be used to determine the closure temperature using the Fe-Ni phase diagram (Figure 2). Under slow cooling conditions that approach equilibrium, the closure temperature could be as low as $200^{\circ} \mathrm{C}$, as is the case for the example cooling profile seen in the corresponding set of metal compositions in Figure 2A.

Wilkening (1978) reported the presence of cellular dendritic metal-sulfide assemblage in the Tysnes Island H4 chondrite. Wilkening (1978) described the assemblage as eutectic-like, noting the modal proportions are not the expected proportions of a eutectic mixture, but are very close to the $\mathrm{Fe}+\mathrm{FeS}$ total for the H-group chondrites. Wilkening (1978) determined the metal-sulfide assemblage in Tysnes Island was formed through a complete melting of a portion of the H-chondrite host material. The melting was followed by rapid (but incomplete) segregation of the silicate and metallic fluids followed by rapid quenching of the chondrite. When metal-sulfide assemblages are melted and rapidly cooled they form a dendritic structure that has in the past been misidentified as a eutectic structure, and is now understood to represent disequilibrium rapid cooling (Scott, 1982). The spacing $\mathrm{d}$ between the arms or cells decreases with increasing cooling rate $\mathrm{R}$ according to equation 1.

$$
d=\alpha \mathrm{R}^{-\mathrm{n}}
$$

The coefficients were determined to be constant over a large range of cooling rates and (Smith and Goldstein, 1977; Scott, 1982). $\alpha$ and $n$ were found to be 93 $\mu \mathrm{m}^{*} \mathrm{sec} /{ }^{\circ} \mathrm{C}$ and 0.34 respectively (Scott 1982). This allows for simple analysis of 
dendritic metal-sulfide assemblages to determine the cooling rate, but can only be used if the sample was heated enough to form a metallic melt and subsequently rapidly cooled.

Phosphorus can be used as an indicator of relative cooling rates in metal grains. Rapidly cooled shock-reheated metal in chondrites contains elevated concentrations of phosphorus (Smith and Goldstein, 1977, Semenenko and Golovko, 1994). For example, Ming et al. (1995) reported elevated phosphorus content in the metals of the dendritic structure in the Yanzhuang (H6) chondrite. Elevated P in rapidly cooled, shock-reheated metal can be explained as a kinetic effect that prevents $\mathrm{P}$ from forming schreibersite $\left.\left[(\mathrm{Fe}, \mathrm{Ni})_{3} \mathrm{P}\right)\right]$ or phosphate $\left.\left[\mathrm{Ca}_{3}\left(\mathrm{PO}_{4}\right)_{2}\right)\right]$ upon cooling (Smith and Goldstein, 1977; Ming et al., 1995; Ruzicka et al., 2005).

The solubility of phosphorus in the metal system has been determined to be related to the oxygen fugacity $\left(f \mathrm{O}_{2}\right)$ or free oxygen available for chemical reactions. The oxygen fugacity of an equilibrated chondrite is too high for the reduction of phosphorus into the metal grains, leaving metal grains in typical, unshocked chondrites with phosphorus contents below $0.1 \mathrm{wt} \%$ (Williams, 1971). Shocked chondrite environments may have a low enough oxygen fugacity to allow the enrichment of phosphorus in the metal systems (Taylor and Heymann, 1971). Taylor and Heymann (1971) propose the shock conditions may release $\mathrm{C}$ or $\mathrm{CO}$, which if present could act as a reducing agent lowering the $f \mathrm{O}_{2}$. However, high temperatures alone will shift equilibria in favor of dissolving P in metal and out of phosphate (Ruzicka et al., 2005). In any case, high P contents in metal $(>0.1 \mathrm{wt} \%)$ are considered evidence of shock heating (Smith and Goldstein, 1977). In particular, elevated $P$ in metal should be indicative of both high- 
temperature reheating and relatively rapid cooling at temperatures $>750{ }^{\circ} \mathrm{C}$, provided schreibersite does not form (Ruzicka et al., 2005).

Yet another indicator of rapid cooling is the concentration of Ni in troilite. Troilite $(\mathrm{FeS})$ is an abundant mineral in ordinary chondrites, and present in all the samples included in this study. Within rapidly solidified assemblages enrichments of Ni in troilite have been reported (Fredriksson et al., 1975; Smith and Goldstein, 1977, Semenenko and Golovko, 1994). Fredriksson et al. indicate the enrichment of $\mathrm{Ni}$ is the result of rapid cooling to temperatures below $500^{\circ} \mathrm{C}$. Studies by Kullerud (1963) found that the solubility of $\mathrm{Ni}$ in troilite increases dramatically between $650{ }^{\circ} \mathrm{C}$ and $900{ }^{\circ} \mathrm{C}$. Smith and Goldstein (1977) determined (via extrapolation of Kullerud's data) the solubility of Ni in troilite for a slowly cooled ordinary chondrite would be $\sim 0.01 \mathrm{wt} \%$ at $350{ }^{\circ} \mathrm{C}$, and compositions with greater than $0.02 \mathrm{wt} \% \mathrm{Ni}$ must be an indicator of severe reheating with relatively rapid cooling. If the cooling after a shock process leading to severe reheating were slow, the Ni would simply diffuse out of the troilite and into the metal based on solubility relations.

Troilite is easily compressed and readily melted upon shock heating and compression; light shock produces twinning and moderate shock will cause recrystallization (Scott, 1982; Bennett and McSween, 1996; Schmitt, 2000). Troilite often shows signs of melting in shock stages above S3; melting begins along grain boundaries by developing a bubbly or "fizzed" texture (Bennett and McSween, 1996). More intense events, leading to S6 shock stage commonly shows metal-sulfide-silicate melt features (Bennett and McSween, 1996). Smith and Goldstein (1977) described samples heat 
treated to 1050 to $1250{ }^{\circ} \mathrm{C}$ exhibiting substantial enrichment of $\mathrm{Ni}$ in troilite $(0.15$ to 6.05 wt $\%)$ when followed by rapid cooling $\left(\sim 25^{\circ} \mathrm{C} / \mathrm{hr}\right)$. They also note samples with lower cooling rates in heat treatments exhibited lower Ni concentrations in the troilite, consistent with the Ni diffusing into the metal, when the cooling is slow.

Wood (1967) reports on several experimentally reheated chondrites and the signatures of the cooling conditions preserved in the composition, textures, and structures of the metal grains. One specific meteorite was Seres, which exhibits clear indications of metal and sulfide melting indicating temperatures in excess of $1000^{\circ} \mathrm{C}$. Wood also reports the presence of high Ni plessite within the same meteorite, which should not form if reheating is in excess of $400^{\circ} \mathrm{C}$. Wood (1967) concludes examples such as this are indications of multiple shock events, indicating the most intense heating would have happened first for multiple-shock cases; logically we can only record successive events if they are less intense, because otherwise the evidence for prior events is overwritten. These types of inconsistencies are the focus of this proposed work as they potentially reveal more about the collisions and thermal processing of asteroidal parent bodies. Using samples within the CML collection we investigate two brecciated chondrites containing a mixture of shock melt and chondritic host to reconcile available evidence regarding the shock and thermal histories experienced by these samples. 


\section{Methods}

\section{Samples}

Samples utilized in this study are all samples donated to the Cascadia Meteorite Lab (CML) collection (Table 2). The goal was to select a suite of samples to compare to two complex chondrite-melt breccias (NWA 5964, NWA 6580). The additional samples needed to exhibit indicators of intense shock effects and a single chemical affinity (L chondrite) in addition to a low weathering grade. To this end, a heavily shocked but largely unmelted chondrite (NWA 4860, shock stage S6) and two L melt rocks (NWA 6454 and 6579) were examined.

The two melt breccias were the focus of study. NWA 5964 is an L chondrite genomict breccia, incorporating type 3-6 material, and the shock indicators vary across the sample, ranging from intermediate shock S3 to regions of silicate melt. NWA 6580 is an L chondrite melt breccia that shows a small chondritic host portion consistent with lower shock stages, and just a few millimeters away the sample has been largely melted. 
Table 2: Official Meteoritical Bulletin names, and CML identification tags for samples used in this study.

\begin{tabular}{cccc}
\hline $\begin{array}{c}\text { Official } \\
\text { Name }\end{array}$ & $\begin{array}{c}\text { CML ID and thin } \\
\text { section numbers }\end{array}$ & Classification & Comments \\
\hline NWA 4860 & CML0288 & L4 S6 W1 & $\begin{array}{c}\text { Mostly unmelted, but heavily } \\
\text { shocked. }\end{array}$ \\
NWA 5964 & $\begin{array}{c}\text { CML0175 } \\
\text { Thin sections: 2A, }\end{array}$ & $\begin{array}{c}\text { L 3-6 breccia, S3-6 } \\
\text { melt breccia, W1 }\end{array}$ & $\begin{array}{c}\text { Large shock melt region, large } \\
\text { recrystallized clasts, coarse } \\
\text { grained igneous clasts. }\end{array}$ \\
NWA 6454 & CML0273 & L melt rock W1 & $\begin{array}{c}\text { Impact melt. } \\
\text { Impact melt. }\end{array}$ \\
NWA 6579 & CML0358 & L melt rock W2 & Largely melted rock, small \\
NWA 6580 & CML0371 & melt breccia W1 & portion of chondritic host. \\
\hline
\end{tabular}

In addition to the two samples that show various shock stages, three samples were chosen for comparison based upon their uniform textures and compositions. The 3 additional samples were chosen as they too are L composition chondrites representing higher levels of shock. NWA 4860 is an L4 chondrite with typical S6 features. NWA 6454 and NWA 6579 are classified as L-melt rocks and were included so as to observe the effects of melting on metal grains. Prior to incorporation in the study each sample was classified and submitted to the Nomenclature Committee of the Meteoritical Society for name and classification approval (Table 2).

Each sample had at least one polished thin section made from a representative section of the sample. NWA 5964 had three distinct textural regions (shock melted region, uniform host region, complex host region) and initially was represented by one thin section per textural region. Upon initial review, the shock melted portion contained few grains large enough for analysis, so two additional sections, cut in parallel within the melt region, were also included in the study. In total five thin sections from NWA 5964 
were included, while the other meteorites each included just one representative thin section.

\section{Optical Microscopy}

Low magnification transmitted light thin section scans were acquired with a Nikon Super Coolscan 5000 ED with the Nikon Scan 4 software. Petrographic characteristics were determined by optical analysis on the Leica DM2500P microscope utilizing the Leica Application Suite image capture software. Using reflected light, plane transmitted light, and cross polarized light, thin section maps were constructed for each thin section, and pieced together in Photoshop®. Additional optical imaging was also used to collect detail about the metal and silicate mineral textures, petrographic types, mineral assembles, mineral occurrences, shock deformations, weathering stage and mineral phase relations.

\section{Electron Microprobe Analyses}

Metals, sulfides and auxiliary opaque minerals were targeted using the Portland State University Remote Electron Microprobe (REM) facility to access the Cameca SX100 electron microprobe (EMP) housed at Oregon State University. Data was collected with $50 \mathrm{nA}, 15 \mathrm{keV}$ operating settings, generally with a $1 \mu \mathrm{m}$ beam size. Metal standards were used for calibration where applicable (Ni, Fe, FLAP, CROM, CO, PYRI standards were used to calibrate $\mathrm{Ni}, \mathrm{Fe}, \mathrm{P}, \mathrm{Cr}, \mathrm{Co}$, and $\mathrm{S}$ respectively). Count times on the peaks were 10 seconds for Fe and 20 seconds for $\mathrm{Ni}, \mathrm{P}, \mathrm{Co}$, and $\mathrm{S}$. The background dwell 
times were 5 seconds on each side of the peak for Fe, and 10 seconds on each side of the peak for Ni, $\mathrm{P}, \mathrm{Co}$, and $\mathrm{S}$. The dwell time for $\mathrm{Cr}$ was 30 seconds on the peak and 15 on each side of the peak. For some samples silicate minerals were analyzed for the purpose of classification, for each sample metals, sulfides, and carbide phases were targeted for this study. Silicon measurements were calibrated to the FO83 standard and used a dwell time of 20 seconds on the peak, and 10 seconds on each side of the peak. Single and multi-point $\sim 1 \mu \mathrm{m}$ spot analyses were collected for grains of interest, as determined by optical techniques. In some cases defocused beam analyses were collected, effectively averaging grain compositions over a larger area $(\sim 5 \mu \mathrm{m})$. Some traverse analyses were conducted (10-50 points) on select metal grains that displayed evidence of compositional zoning through optical analysis. EMP data were considered valid for inclusion in the study if the totals were $98-102 \%$ and showed no indications of being overlaps of multiple phases.

\section{Scanning Electron Microscopy}

Silicate, metal, sulfide and carbide phases were analyzed using the Portland State University Zeiss Sigma field emission, variable pressure scanning electron microscope (SEM). SEM data were collected in low pressure (high vacuum) mode, at an accelerating voltage of $15 \mathrm{kV}$. Utilizing the AZtec software package from Oxford, compositional data were calibrated for individual elements against pre-determined standards measured by Oxford Instruments and beam current was measured with pure copper. Data were collected as single point and traverse analysis across grains of interest. In some cases 
EDS maps were collected as well. The SEM was used to determine the major elemental compositions of the metal grains. Backscattered images were collected for all samples to aid in compositional and mineral assemblage comparisons. SEM data were considered valid for inclusion in the study if the totals were $98-102 \%$ and showed no indications of being overlaps of multiple phases.

\section{Cooling Rate Measurements: Dendrites}

Following the methods outlined by Scott (1982) all grains with a dendritic or cellular metal-sulfide intergrowth texture were included for analysis. Using primarily reflected light imagery, the center to center distance between adjacent dendrite arms, or distance between neighboring cells was measured for each occurrence and an average for the assemblage was used where multiple measurements were taken from a single grain.

\section{Closure Temperature Estimates: Zoned Kamacite-Taenite Structures}

The zoned kamacite taenite particles in NWA 5964 and NWA 6580 were used to determine a closure temperature, at which the diffusion in the metals stopped. Diffusion stops in the center of the grains, while continuing at the edges, so calculated closure temperature varies with location inside an individual grain. The central composition of the taenite grain is used to determine the temperature at which diffusion began to stop, hereafter referred to as the start temperature (Ts), while the rim compositions of the kamacite and taenite (where they are in contact with one another) were used to determine a final closure temperature (Tc). Using the curves on the phase diagram (Figure 2) we 
were able to determine the start temperatures and closure temperatures for many of the grains using the SEM compositional traverses.

\section{Cooling Rate Measurements: Central Ni in Taenite}

Of the meteorites in this study, only the melt breccias NWA 5964 and NWA 6580 contained measurable zoned taenite grains. The zoned taenite grains were analyzed using the SEM, where a traverse across the grain could be obtained. From each of these traverses, the central composition and distance from the grain edge were collected. The average error was determined by the step size of the traverses and the standard deviation of the composition of the central 4 points from the grain. There may also be an unknown error related to the irregularity of the grain shapes and the possibility of shorter diffusion paths not visible as we are viewing a 2 dimensional slice of a 3 dimensional system. The cooling curves shown in this thesis are based on the work of Taylor et al. (1987) and were provided courtesy of Ed Scott. 


\section{Results and Discussion}

General Petrography

NWA 4860 is a heavily shocked S6 L-chondrite with remnant chondrules, some partially surrounded by metal. Although some melt pockets and short metallic veins are present, the sample is mostly unmelted. Olivine in NWA 4860 has generally recrystallized, characteristic of an S6 chondrite. A distinctive feature in NWA 4860 uncommon in chondrites is the presence of vugs, probably produced by hot gases generated during intense shock heating. See Figure 3.

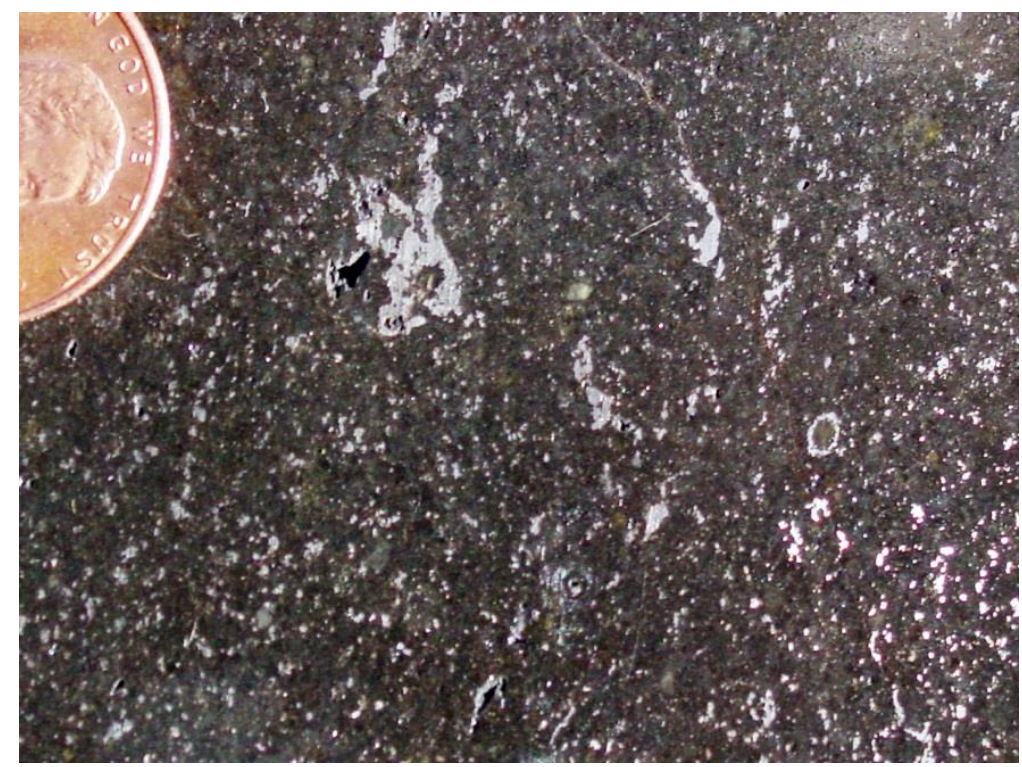

Figure 3: NWA 4860 seen in cut and polished face of hand specimen. Metal (bright) grains often are aligned into short vein segments (top right to lower left in this image), although other metal grains encircle chondrules. A vug occurs to the left of the largest metal cluster in the upper left. The U.S. Penny for scale is $1.7 \mathrm{~cm}$ in diameter.

NWA 6579 is an L melt rock sample with silicates dominated by euhedral- to subhedral small $(\sim 25 \mu \mathrm{m}$ diameter) olivine crystals set in glass. Opaque minerals are 
dominated by cellular metal-troilite assemblages. The metal-sulfide grains are elongate all in the same direction, and vesicles or vugs are present (Figure 4).

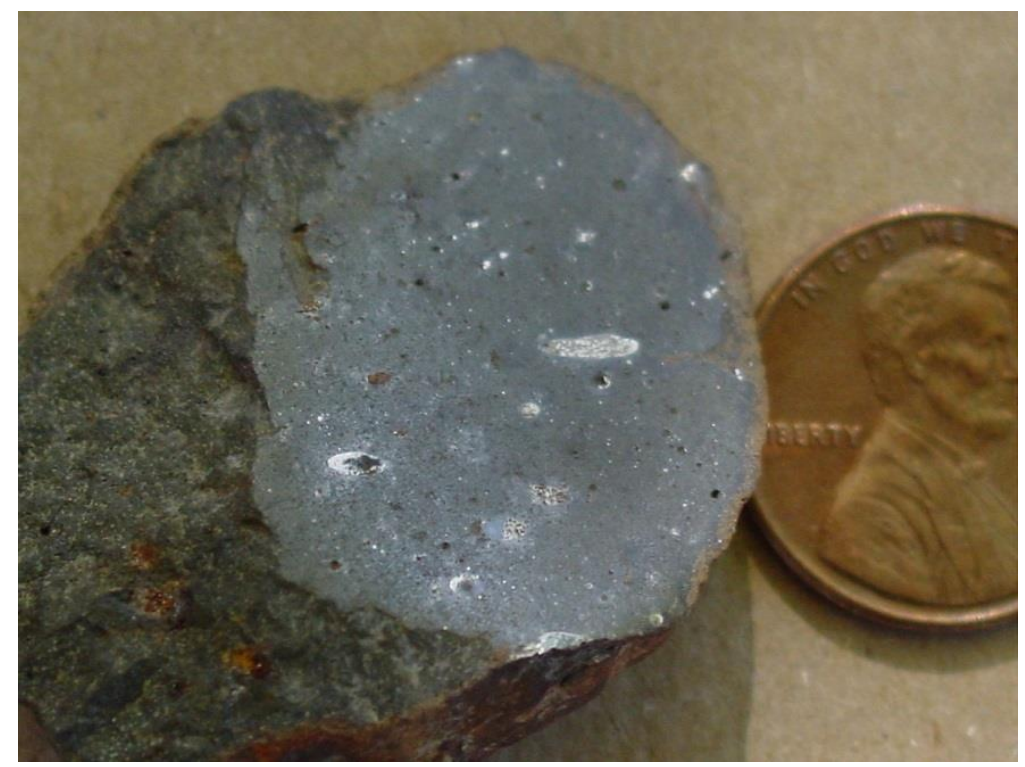

Figure 4: NWA 6579 specimen hand sample showing fine grained melt texture, and elongated metalsulfide assemblages with scattered vesicles. The U.S. Penny shown for scale is $1.7 \mathrm{~cm}$ in diameter.

NWA 6454, also an L melt rock sample, lacks chondritic texture and is dominated by small $(<20 \mu \mathrm{m})$ euhedral to subhedral olivine set in glass. Opaque minerals are also dominated by metal-troilite cellular assemblages. Silicate portions can be subdivided into coarser, clast-like portions (olivine grain size $\sim 5-15 \mu \mathrm{m}$ in diameter) and finer-grained interstitial areas (olivine grains $<3 \mu \mathrm{m}$ ). Shock veins connect some of the metal-sulfide particles and in places merge into the finer-grained silicate regions. Clasts of olivine and low-Ca pyroxene are present which show a recrystallization texture (granular subgrains meeting in triple junctions). See Figure 5. 


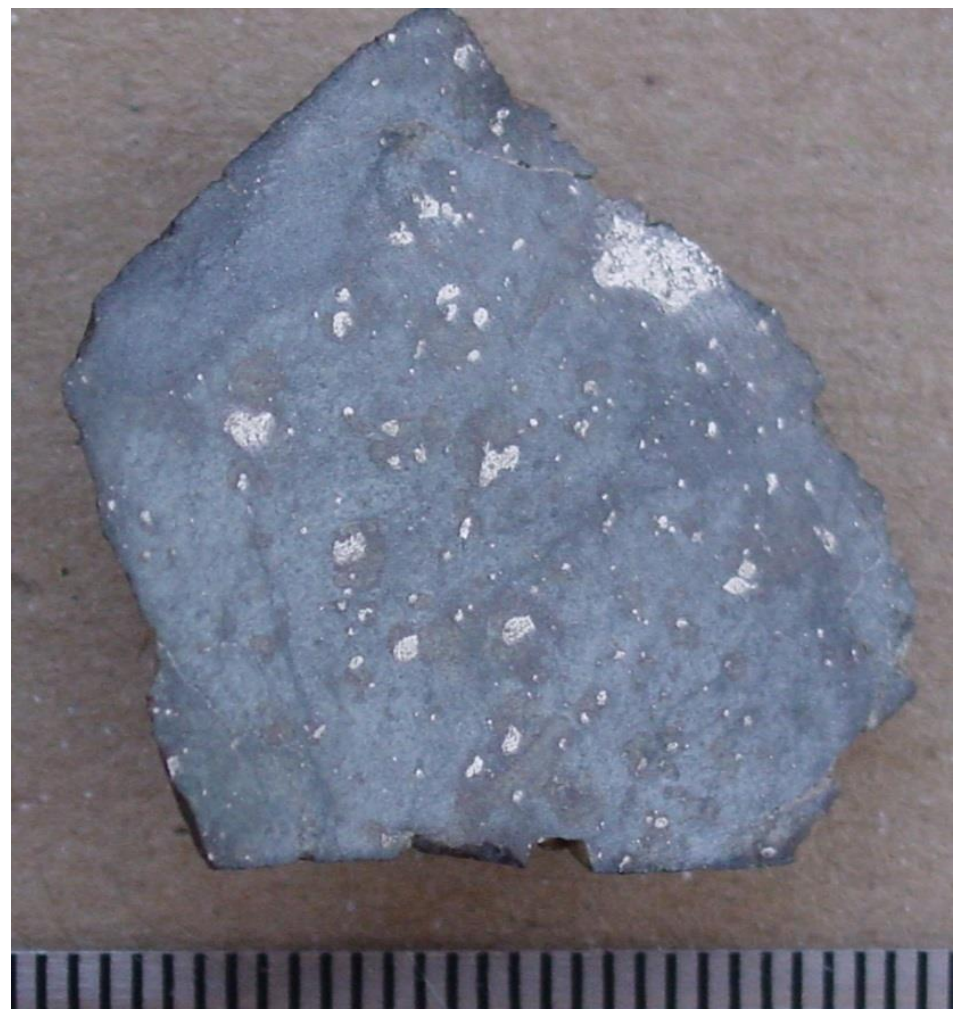

Figure 5: NWA 6454 specimen hand sample. The ruler shows $1 \mathrm{~mm}$ increments.

NWA 5964 contains a large shock melt region $(\sim 1.5 \mathrm{~cm} \mathrm{x} \sim 2 \mathrm{~cm}$ preserved area), in abrupt contact with chondrite. See Figure 6. Within the unmelted host there are several large recrystallized clasts and some coarse grained igneous clasts with poikilitic texture. In general clasts throughout the chondritic host vary in texture and petrographic type ranging from type 3 to type 6 , making this meteorite a genomict breccia. Small melt pockets and small metal-sulfide melt droplets exist in the matrix materials near some of the clasts, but the contact between the main melt and chondritic portions is sharp. 


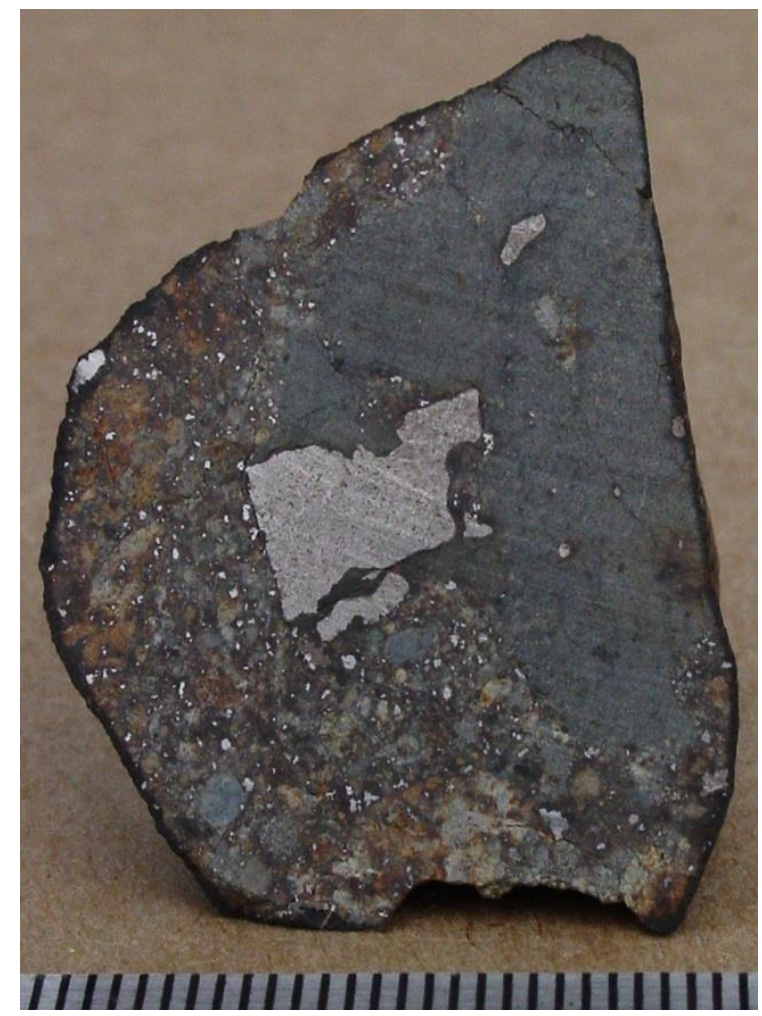

Figure 6: NWA 5964 specimen hand sample. Sample shows large metal grain in the center of the stone, with chondritic texture dominating to the left and melt texture dominating to the right of the large metal grain. The ruler has $1 \mathrm{~mm}$ increments. 
NWA 6580 is an L melt breccia dominated by melt texture, containing a small chondritic portion ( $9 \mathrm{~mm}$ wide preserved portion). See Figure 7 . The main melt lithology is nearly devoid of opaque minerals, and consists of strongly zoned olivine grains $(\sim 50 \mu \mathrm{m})$ set in glass. The melt lithology is in sharp contact with the chondritic lithology, showing no significant transition between regions (Figure 8).



Figure 7: NWA 6580 hand sample showing largely melted rock, nearly devoid of metal, and small chondritic portion (lower right corner). The U.S. Penny for scale is $1.7 \mathrm{~cm}$ in diameter. 




Figure 8: Backscattered Electron (BSE) image showing contact between zoned olivine grains in the melt region (lower right) and unmelted chondritic host (upper left). Metal and troilite grains appear bright white, silicates are various shades of grey. Scale bar in lower left is $100 \mu \mathrm{m}$.

\section{Metal Textures and Compositions}

Even though Fe-Ni metal is a major component of chondrites, and the metal grain composition in chondrites can be used to distinguish chondrite groups, there is a variety of textures the metal grains can form. Within the samples from the L group incorporated in this study, the metal textures vary widely, and generally vary in correlation with the thermal history of the sample. The major categories of metal textures we find in our samples are: 1) Nearly uniform kamacite, with small taenite or tetrataenite exsolutions, 2) ultra-fine-grained intergrowths of intermediate composition that represent martensite, 3 ) dendritic-cellular metal-sulfide intergrowths with martensitic metal, 4) blocky kamacite- 
taenite intergrowths, 5) grains that consist partly-to-wholly of plessite (a decomposed martensite resulting in a mixture of kamacite and taenite). Each of these grain types, with the exception of the dendritic/cellular structures, occurs with and without the presence of carbide grains in the NWA 5964 and NWA 6580 meteorites. Within the samples in this study, samples that have experienced whole rock melting, NWA 6454 and NWA 6579, show only the dendritic-cellular metal texture. Samples that have partially melted, NWA 5964 and NWA 6580 show the dendritic-cellular texture in the melt regions, and combinations of the other textures in unmelted areas. The S6 sample, NWA 4860, contains only martensite metal grains.

The metal grains in NWA 4860 are very uniform in composition (Figure 9) and texture (Figure 10). The grains represent a metal which has cooled through the martensite start temperature (Ms). The fluidized texture of the metal in the silicates indicates the metal was heated to or beyond the melting temperature. 


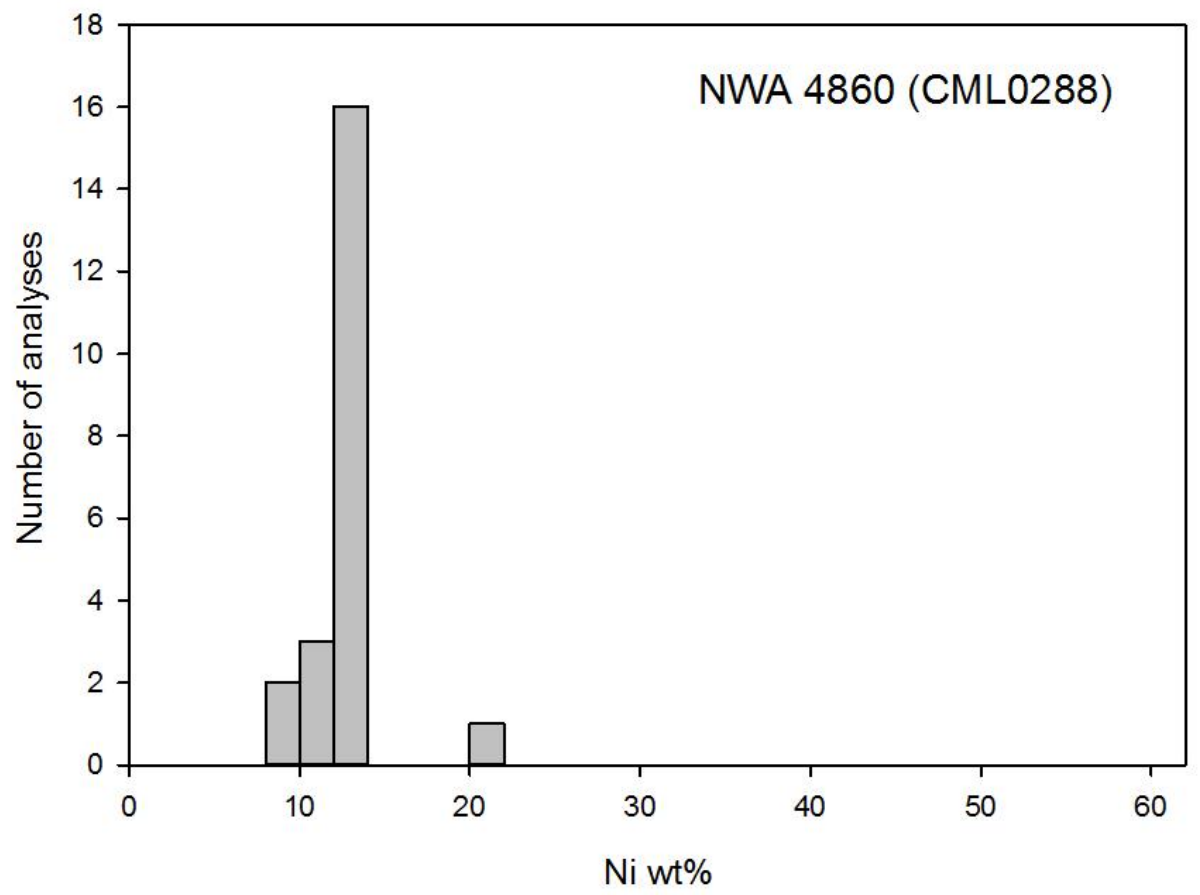

Figure 9: Composition (Ni wt\%) of metal grains in NWA 4860 analyzed with EMP.

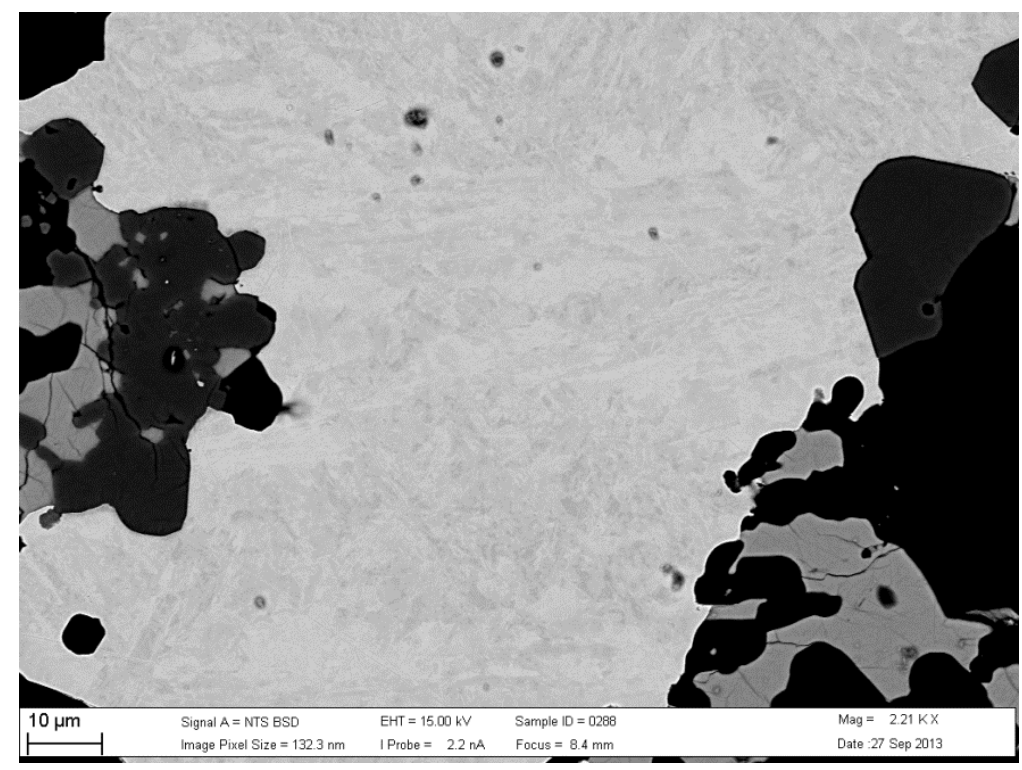

Figure 10: Backscatter SEM micrograph of metal grains in NWA 4860. The grains are nearly uniform in composition resulting in little variance in shading in the backscatter image. Silicates appear black as the image is optimized for metal (white); sulfide is light grey. Scale bar at lower left is $10 \mu \mathrm{m}$ long. 
In NWA 6454 and NWA 6579, the metals have also undergone the martensite transformation, and further decomposition to plessite leaving the metal grains as a fine grained $(<1 \mu \mathrm{m})$ intergrowth of taenite and tetrataenite in kamacite. However, in both meteorites metal and sulfide grains form dendritic or cellular assemblages, Figure 13. Both sections contain both high nickel metal (taenite and tetrataenite) and low nickel kamacite in the decomposed martensite (plessite) mixture, NWA 6454 in Figure 11 and NWA 6579 in Figure 12.



Figure 11: Composition (Ni wt\%) of metal grains in NWA 6454 analyzed with EMP. 


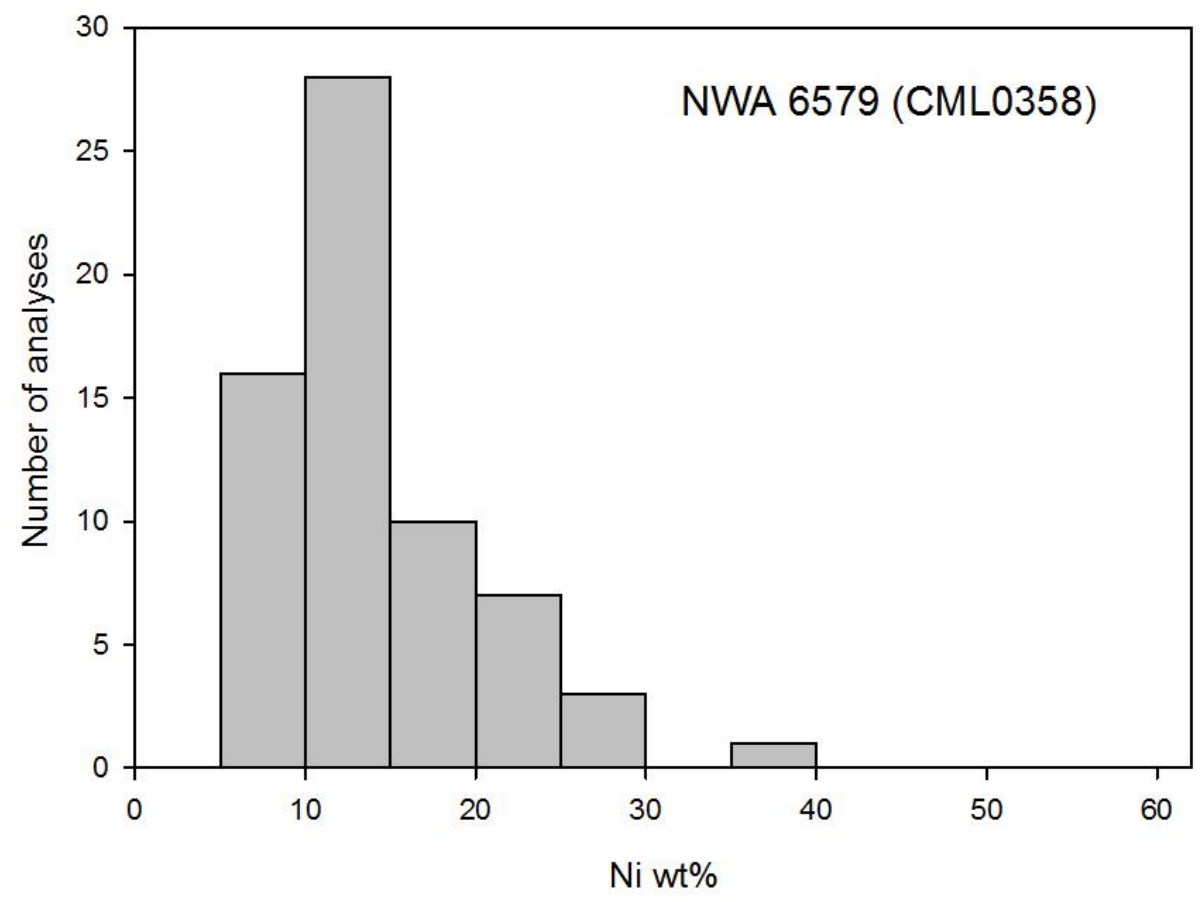

Figure 12: Composition (Ni wt\%) of metal grains in NWA 6579 analyzed with EMP.



Figure 13: Reflected light photomicrographs of typical grain textures seen in NWA 6579 (left) and NWA 6454 (right). Grains throughout both meteorites are similar globular intergrowths of metal (nearly white) and sulfide (darker gold color). Each scalebar is $100 \mathrm{um}$. 
The metal grains in NWA 6580 are almost exclusively found in the unmelted chondritic host portion of the stone, Figure 14 . The melt region contains very few opaque minerals; those which do appear in the melt portion are generally too small for microprobe or SEM analysis. The largest opaque grain found in the melt portion is shown as Figure 15. The opaque minerals in the chondritic host are generally angular grains, consisting mostly of kamacite and taenite intergrowths. The intergrowth is usually a blocky or angular assemblage of grains. See Figure 16. In some grains the martensite transformation began, but didn't affect the entire grain, as shown in Figure 17.

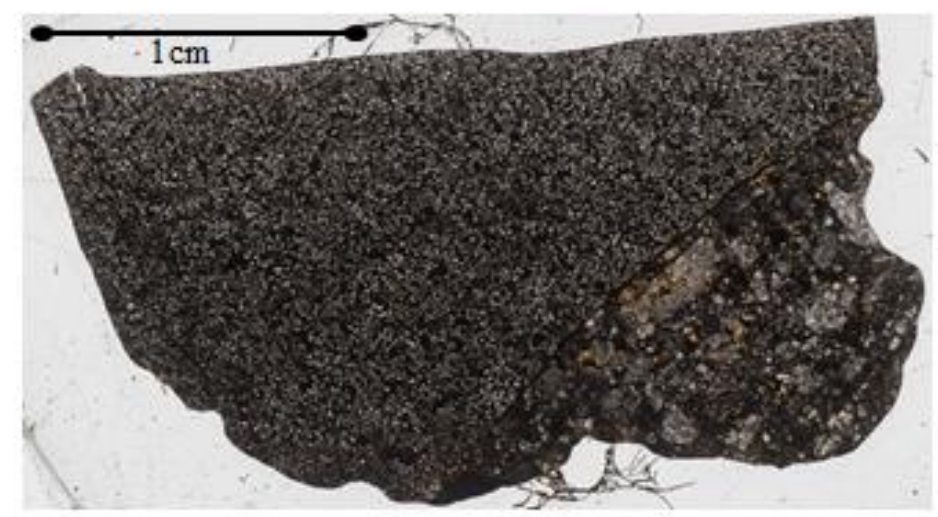

Figure 14: Thin section scan of NWA 6580 as seen in transmitted light showing melt rock texture (left), accompanied by small chondritic portion (lower right). This section was cut from a larger stone showing only the melt lithology. 


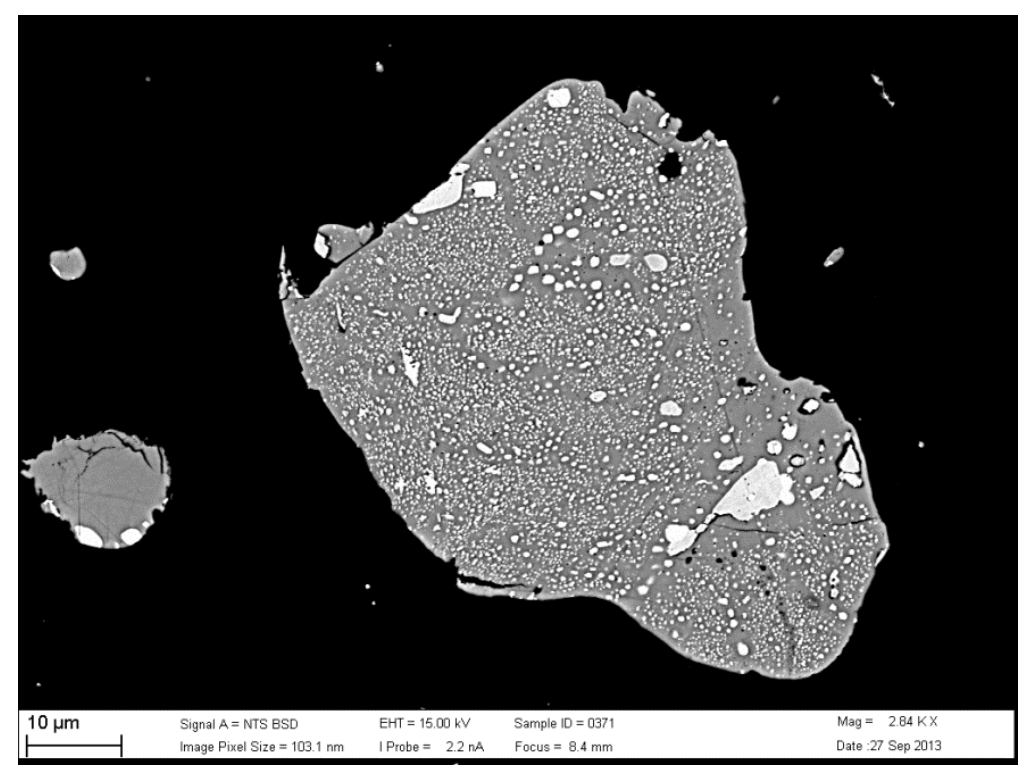

Figure 15: Backscatter electron micrograph of largest opaque grains located in the melt region of NWA 6580. This assemblage consists of metal (bright) embedded in sulfide (grey). Individual metal grains are generally too small for reliable targeting with EMP for compositional analysis. Glassy silicate surrounding the assemblage appears black.

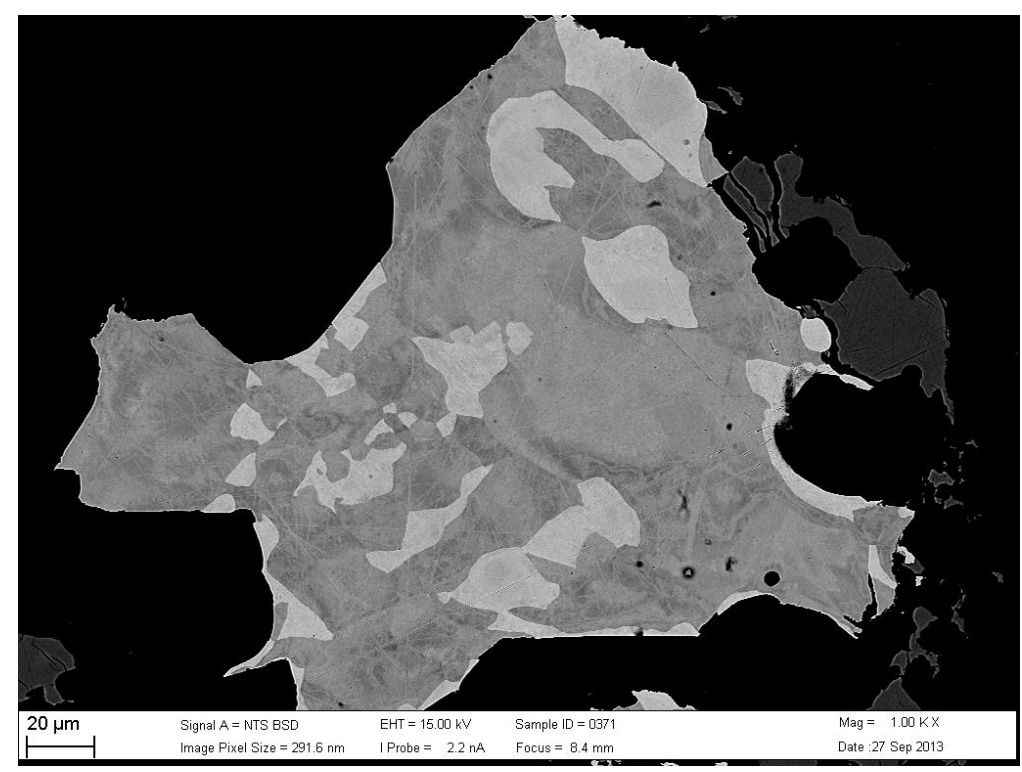

Figure 16: Backscatter electron micrograph of typical blocky kamacite-taenite intergrowth found in NWA 6580 unmelted region. Kamacite appears grey, taenite nearly white, troilite dark grey, and silicate black. 


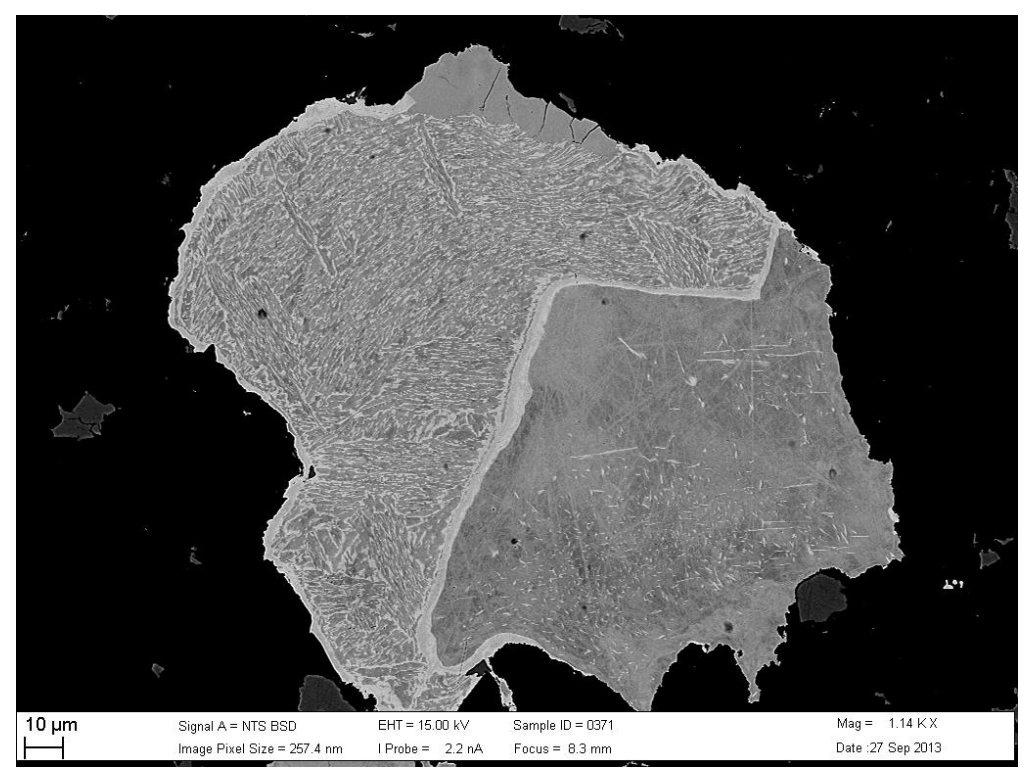

Figure 17: Backscatter electron micrograph of decomposed martensite grain showing the left portion decomposed forming plessite. Kamacite (grey) occurs at right; a carbide mineral (grey, with cracks) at top. This grain is located in the unmelted host region in NWA 6580. 




Figure 18: Composition (wt\%) of metal grains in NWA 6580 analyzed with EMP.

Metal grain textures in NWA 5964 vary between the melted and unmelted region as well as vary in texture within the chondritic host, as they do in NWA 6580. Within the melted region, metal grains are rounded dendritic intergrowths with troilite. In the chondritic portions the grains are largely angular, and include some grains that reached the martensite transformation, as in Figure 19, and others consisting of the kamacite taenite intergrowths, as in Figure 20. Many of the grains in the chondritic portions are rimmed with tetrataenite. In the melted portion most of the metal and sulfide grains appear as dendritic or cellular assemblages, the exceptions being found in small chondritic clasts within the melt. The Ni rich rims on the metal grains are much thinner within the melted region (Figure 21). Due to the complexity of the meteorite, analysis of 
NWA 5964 has been split into melted portions and unmelted host portions. The average composition for the unmelted host is shown in Figure 22, while the average grain from the melted portion, Figure 23. The compositions seen in the unmelted chondritic regions of NWA 5964 are similar to metals analyzed in NWA 6580. The metal textures seen in the chondritic portion of NWA 5964 are the same groups as in NWA 6580. Both samples tend to exhibit complex composite grains consisting of multiple textures seen in what appears as a single grain, often separated by taenite or tetrataenite boundaries (Figure 17, and Figure 19). These are likely the result of polycrystalline parent taenite grains that followed different cooling and composition paths based on local Ni concentrations and nucleation conditions. Within the melted regions of NWA 5964 the metal grains exhibit elevated P compared to the metal grains from the chondritic portions of NWA 5964 and NWA 6580. 


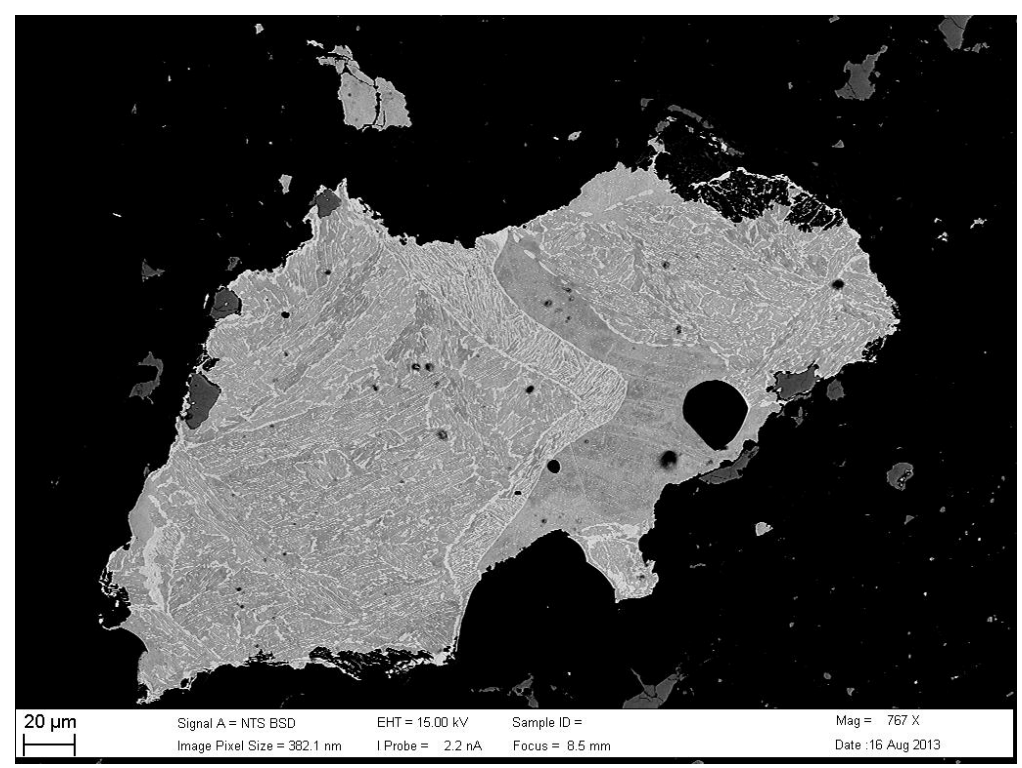

Figure 19: Backscatter electron micrograph of typical plessitic (transformed martensite) grain from chondritic portion of NWA 5964, showing a fine-grained intergrowth of Ni-poor (grey) and Ni-rich (nearly white) metal.

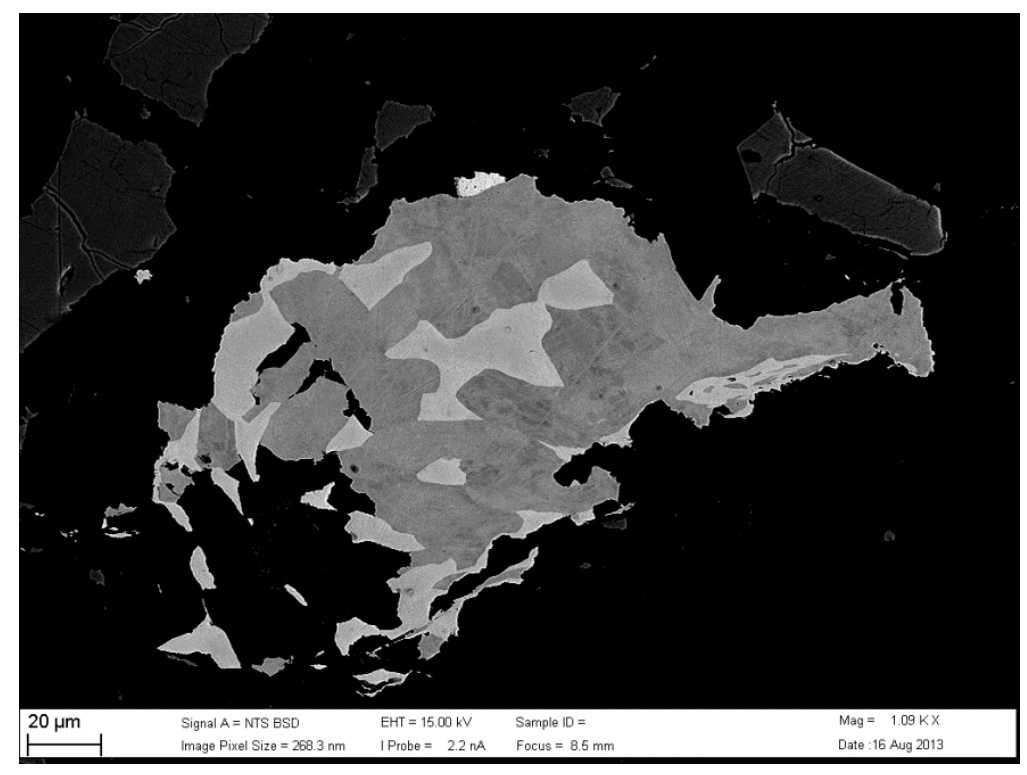

Figure 20: Backscatter electron micrograph of typical kamacite (nearly white)-taenite (grey) blocky intergrowth grain from chondritic portion of NWA 5964. Sulfide grains (darker grey) occur nearby. 


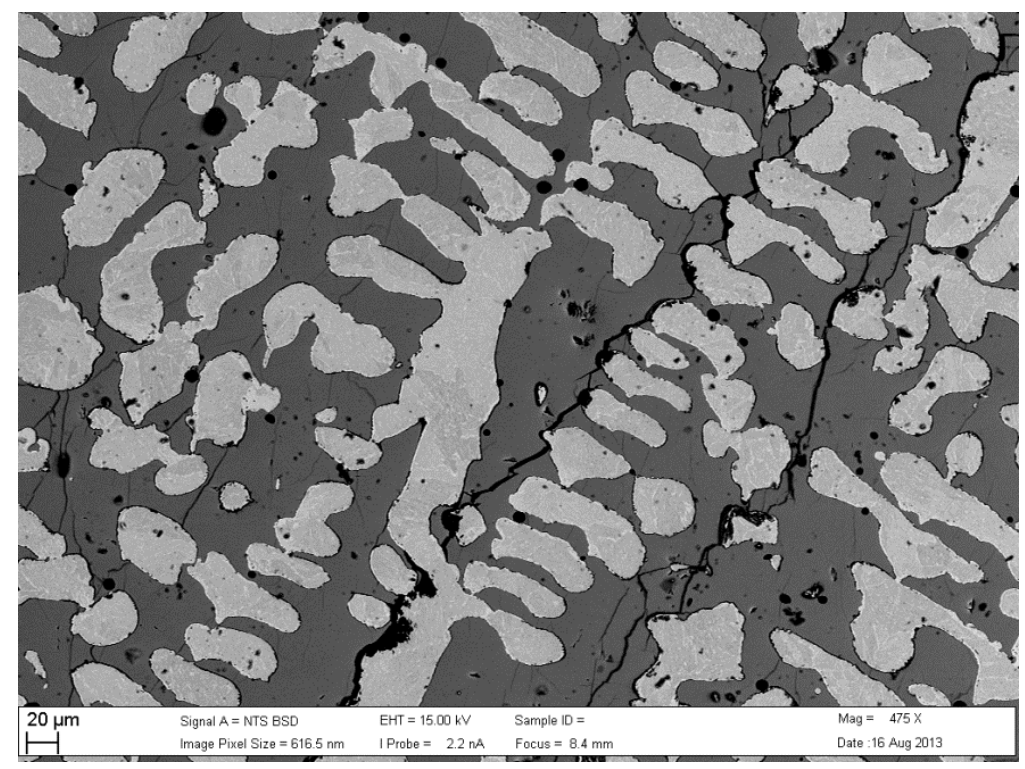

Figure 21: Backscatter electron micrograph of typical texture of metal-sulfide globules in the melted portion of NWA 5964 from thin section 4-1, showing dendritic (cellular), metal (white) that itself has fine plessite texture, amidst sulfide (grey).

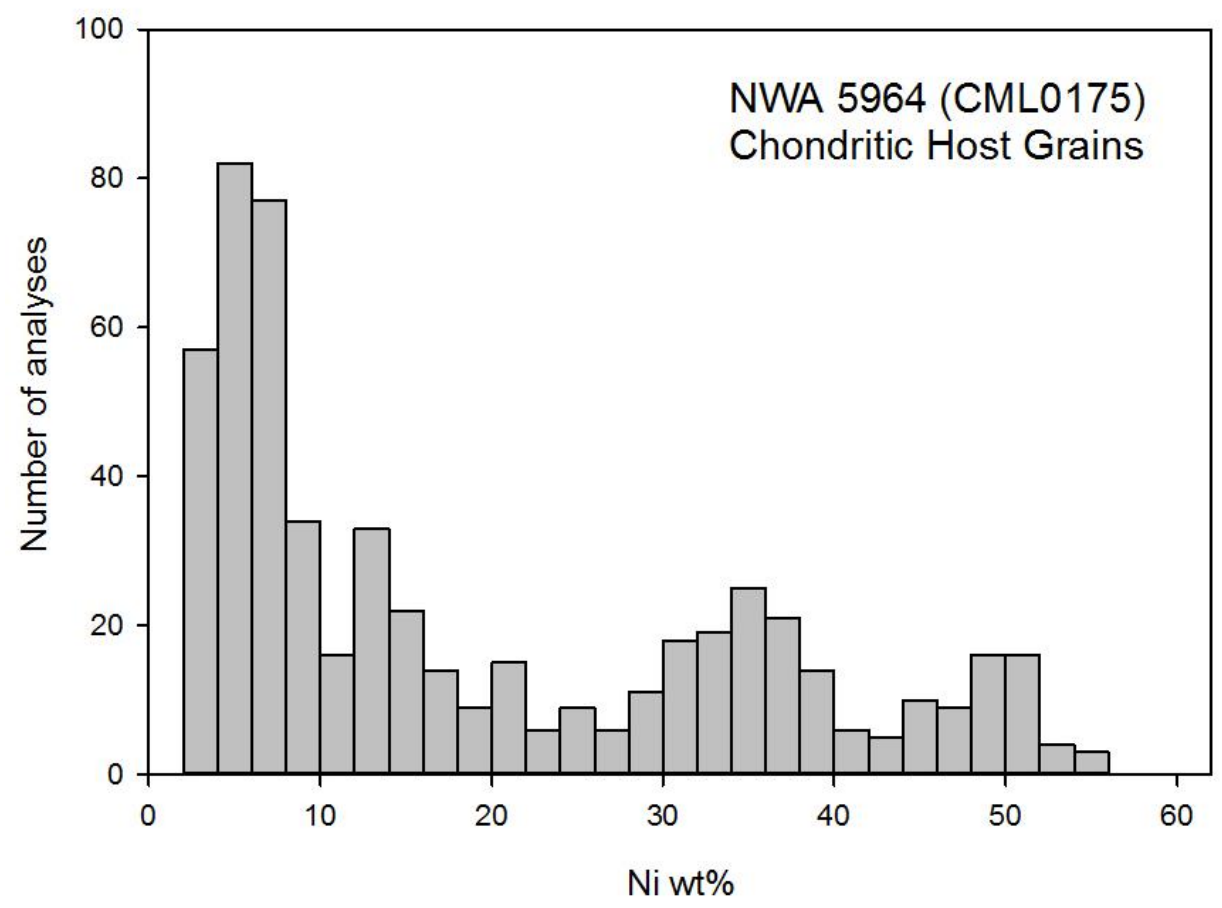

Figure 22: Composition (wt\%) of unmelted metal (non-dendritic, non-cellular) in the chondritic host portion of NWA 5964, analyzed with EMP. 




Figure 23: Composition (wt\%) of metal in the melted portion of NWA 5964 thin section 4-1, as analyzed with EMP.

\section{Dendritic Cooling Rates}

Three meteorites (NWA 5964, NWA 6454, and NWA 6579) contain dendriticcellular metal-sulfide grains, all from melted portions. Figure 24 shows arm spacing, grain diameter, and cooling rate for the three meteorites. Cooling rates of $\sim 5-200{ }^{\circ} \mathrm{C} / \mathrm{s}$ are implied, with the smallest grains cooling fastest. These cooling rates pertain to melting conditions above the metal-troilite eutectic of $\sim 950-1000{ }^{\circ} \mathrm{C}$ (McSween et al., 1988). All of the data plot above the cooling-by-radiation line as shown by Scott (1982). The radiative cooling line represents an expecting cooling rate for a metal-sulfide melt that is isolated, or ejected into space. None of our samples plot along this expected line; rather, 
they all show a cooling rate slower than radiative cooling alone, which may imply cooling in a warm melt breccia. Scott (1982) proposed that the slowest cooled meteorites in his study (Ramsdorf and Rose City, with $\sim 0.1^{\circ} \mathrm{C} / \mathrm{s}$, and Shaw $0.0001^{\circ} \mathrm{C} / \mathrm{s}$ ) were likely embedded in hot silicate material including much melt, thus reducing the thermal gradient and slowing the cooling rate. Our values generally fall between the hot silicate explanation and the radiative cooling line, possibly representing cooling in warm, but unmelted silicates.

Among the melt samples, NWA 6454 appears to have cooled somewhat slower $\left(\sim 5-10{ }^{\circ} \mathrm{C} / \mathrm{s}\right)$, compared to $\sim 10-100{ }^{\circ} \mathrm{C} / \mathrm{s}$ for NWA 6579 and the melt of NWA 5964 (Figure 18). This could indicate that the melt body that produced NWA 6454 was larger than in the other meteorites, or they had different burial depths during cooling.

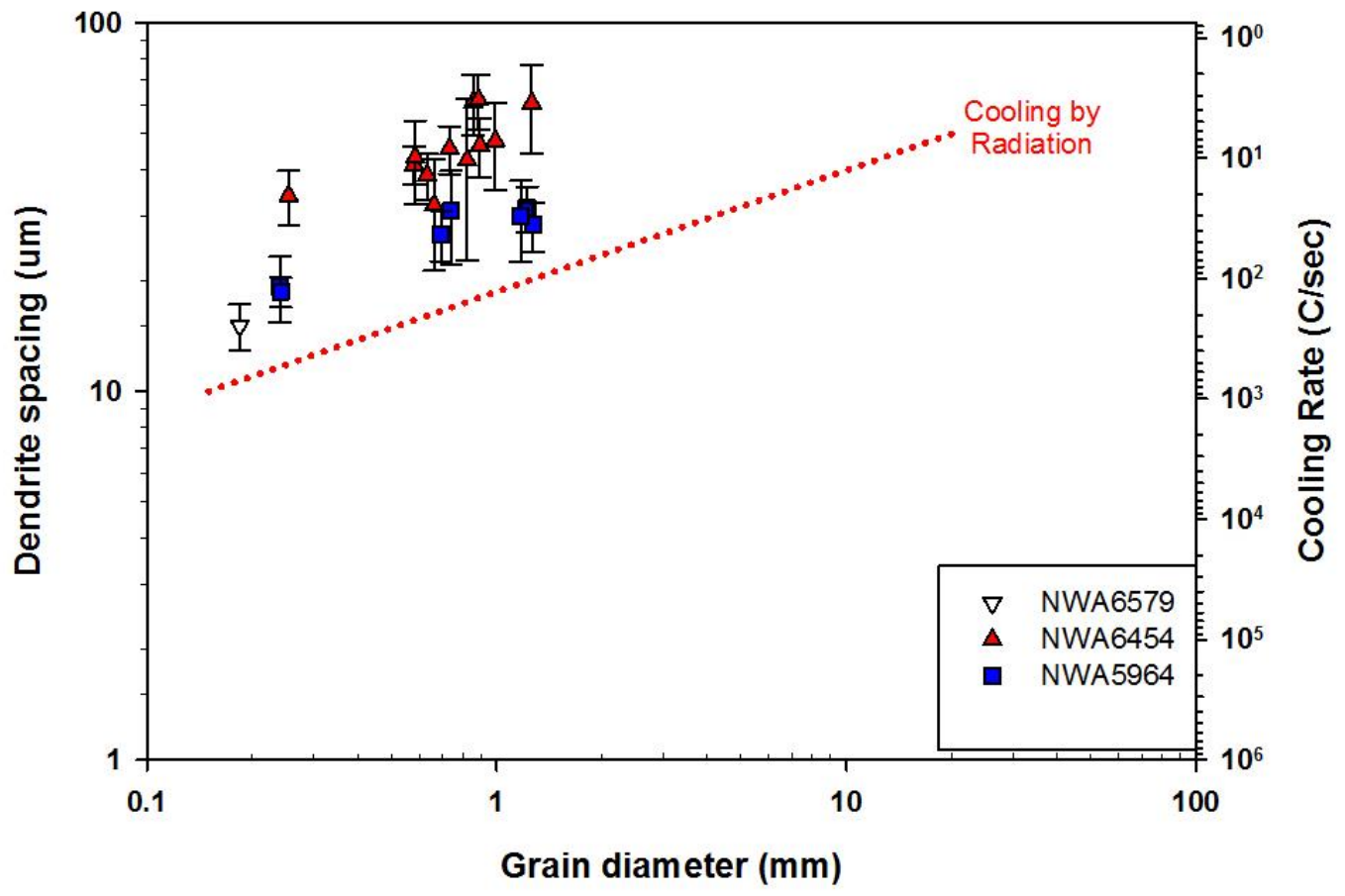

Figure 24: Cooling rates as determined by dendrite spacing in NWA 6579, NWA 6454, and NWA 5964. 


\section{Central Ni in Taenite Cooling Rates}

The zoned taenite data for NWA 6580 are shown in Figure 25. All the grains sampled were smaller than about 20 microns in diameter, and show some scatter across the curves, but are mostly giving cooling rates of $0.1-1 \mathrm{~K} / \mathrm{My}$. All of the grains were analyzed in the small chondritic portion adjacent to the large shock melt. The slow cooling rates can be explained by burial of the chondrite portion at depth at the time that the shock melt was introduced. All of the metal grains could have cooled at the same slow rate.



Figure 25: Cooling rates for zoned taenite grains in NWA 6580 chondritic portion. Grains are consistent with slow cooling, generally 0.1 to $1 \mathrm{~K} / \mathrm{My}$ for small grains ( $<20 \mu \mathrm{m}$ across $)$. 
The zoned taenite grain central composition is plotted against the distance to the nearest grain boundary in Figure 26 for NWA 5964. This sample shows consistent cooling rates for larger grains $(>8 \mu \mathrm{m})$ on the order of 10-100 K/My within the unmelted portion. Most likely this cooling rate corresponds to the event that introduced the large shock melt. The smaller grains show much more scatter, but in general are consistent with cooling rates of $\sim 100 \mathrm{~K} / \mathrm{My}$ or less. There is no obvious difference in cooling rates for metal close to the melt zone or farther from it. Only some of the smaller grains display apparently slower cooling.



Figure 26: Cooling rates for zoned taenite grains in NWA 5964, by thin section. Sections 2A and 5A represent grains from within the chondritic portion and are at a further distance from the shock melt than grains in chondritic clasts within thin section 4-1, which is mostly shock melt. Grains show a variety of cooling rates, but grains larger than about $8 \mu \mathrm{m}$ generally represent $10-100 \mathrm{~K} / \mathrm{My}$. 
The larger scatter in small grains within the chondritic portion of NWA5964 could be due to impact mixing, possibly the same process that produced the range of petrographic types (L3-6). The grains may be recording slightly different chondritic cooling rates, having originated in different areas that later became impact mixed. Specifically, some of the smaller metal grains may have been introduced into the breccia from a region that cooled more slowly. This situation is analogous to that found by Scott and Rajan (1981) in some genomict ordinary chondrite breccias.

It is also possible the smaller grains inherently have errors associated with this technique as we were averaging across the core, which would have a larger effect on distance to the rim in smaller grains than larger ones. However, this explanation does not seem valid as we see significantly less scatter using the same techniques for the same sized grains in NWA 6580.

Regardless, the slow cooling rates for the melt breccias must be indicative of low closure temperatures, in order to explain the Ni-rich composition of the taenite grains. As discussed later, the rim compositions of the taenite grains indicate cooling below $\sim 450$ $400{ }^{\circ} \mathrm{C}$, so the inferred slow cooling rates are for these temperatures and below.

Phosphorus Enrichment in Metals

Two of the meteorites, NWA 4860 (Figure 27) and the chondritic portion of melt breccia NWA 6580 (Figure 28), show no phosphorus enrichment in the metals. With 
NWA 6580 we were unable to target the metal grains in the melt portion due to their small size, so the results are only representative of the chondritic portion of the sample. These data for NWA 4860 and NWA 6580 imply either minimal sustained temperature increase during shock, or slow cooling following shock, or both. Given the high temperatures involved in shock stage S6 and in large-scale melting (Table 1), slow cooling following shock in NWA 4860 and NWA 6580 seems likely.

All three of the other samples include some grains that are not enriched with respect to phosphorus. One sample, melt rock NWA 6579 (Figure 29), contains schreibersite $\left[(\mathrm{Fe}, \mathrm{Ni})_{3} \mathrm{P}\right]$ grains associated with metal (Figure 30$)$. This indicates that the metals were saturated with respect to phosphorus, allowing this phase to form as the system cooled. Still, even with the schreibersite present, the metal grains show some enrichment of phosphorus, although the enrichment is less than seen in melt rock NWA 6454 (Figure 31) and melt breccia NWA 5964 (Figure 32). Locally high P contents, up to $\sim 0.3-1 \mathrm{wt} \%$ (Figure 29, Figure 30, Figure 31) in the metal of these three meteorites suggest extensive shock heating of P-rich materials and relatively rapid cooling following shock. The highest P contents in NWA 6454 and NWA 5964 (up to 1 wt\%) occur in metal grains with intermediate $\mathrm{Ni}$ content $(\sim 5-25 \mathrm{wt} \%)$ and mainly are located in melted lithologies (Figure 31, Figure 32). These grains include mostly martensite or plessite that could have formed by melting of P-bearing materials and subsequent rapid cooling. As previously noted, cooling rates at melting temperatures for these meteorites as inferred from metal-sulfide textures are $\sim 5-200{ }^{\circ} \mathrm{C} / \mathrm{sec}$. Such fast cooling rates appear to be needed to result in metal P contents up to $1 \mathrm{wt} \%$. Lower P contents in other grains from 
NWA 6454 (Figure 31) and NWA 5964 (Figure 32) could indicate these grains formed from precursor materials that were less P-enriched or less heated. The lower P content of metal grains in NWA 6579 ( 0.3 wt\% maximum) compared to the other two meteorites (up to $1 \mathrm{wt} \%$ maximum) can be explained by the transfer of some $\mathrm{P}$ from metal into the schreibersite in NWA 6579.

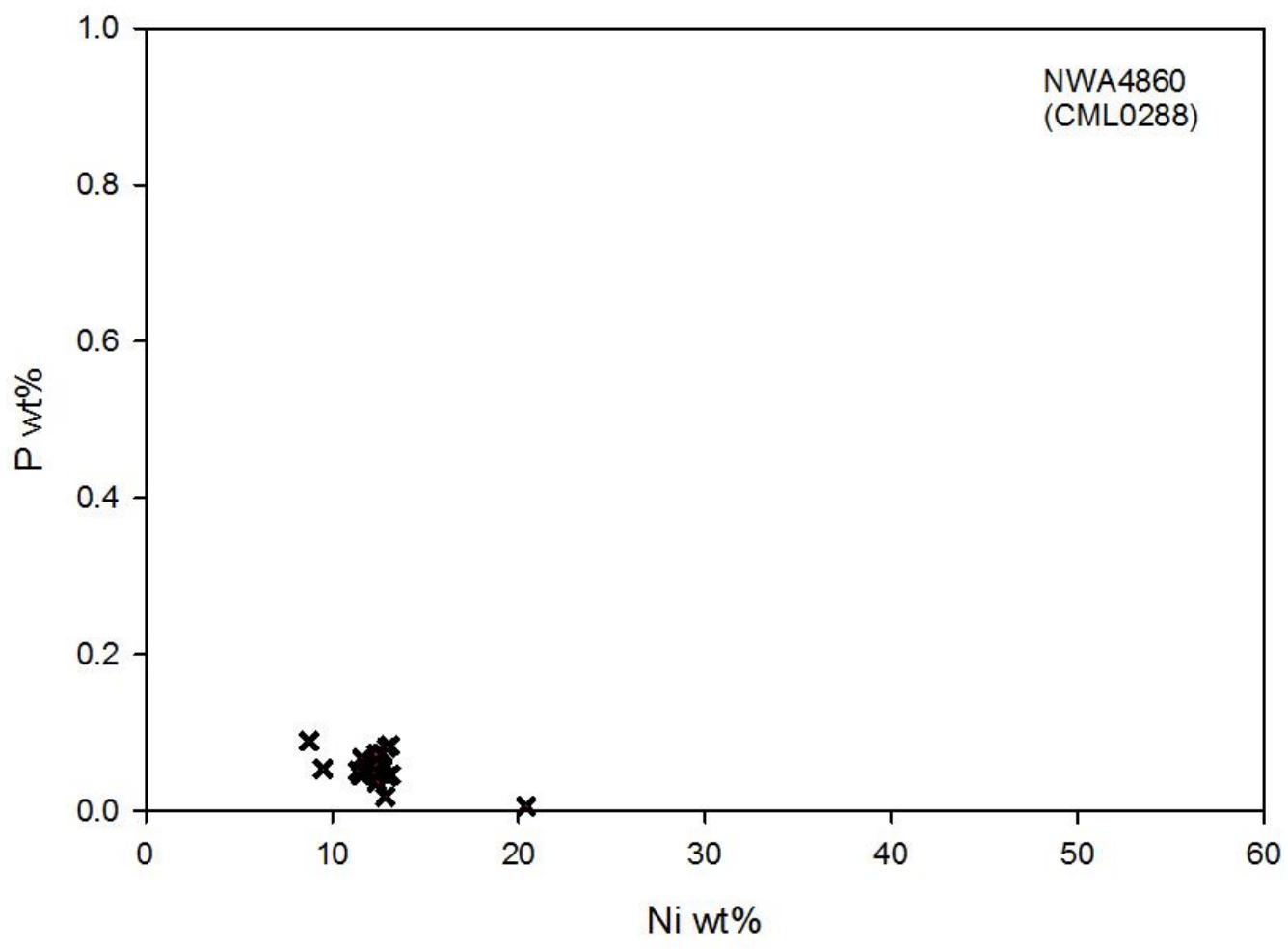

Figure 27: NWA 4860 Phosphorus and nickel content in metal grains. EMP data. 


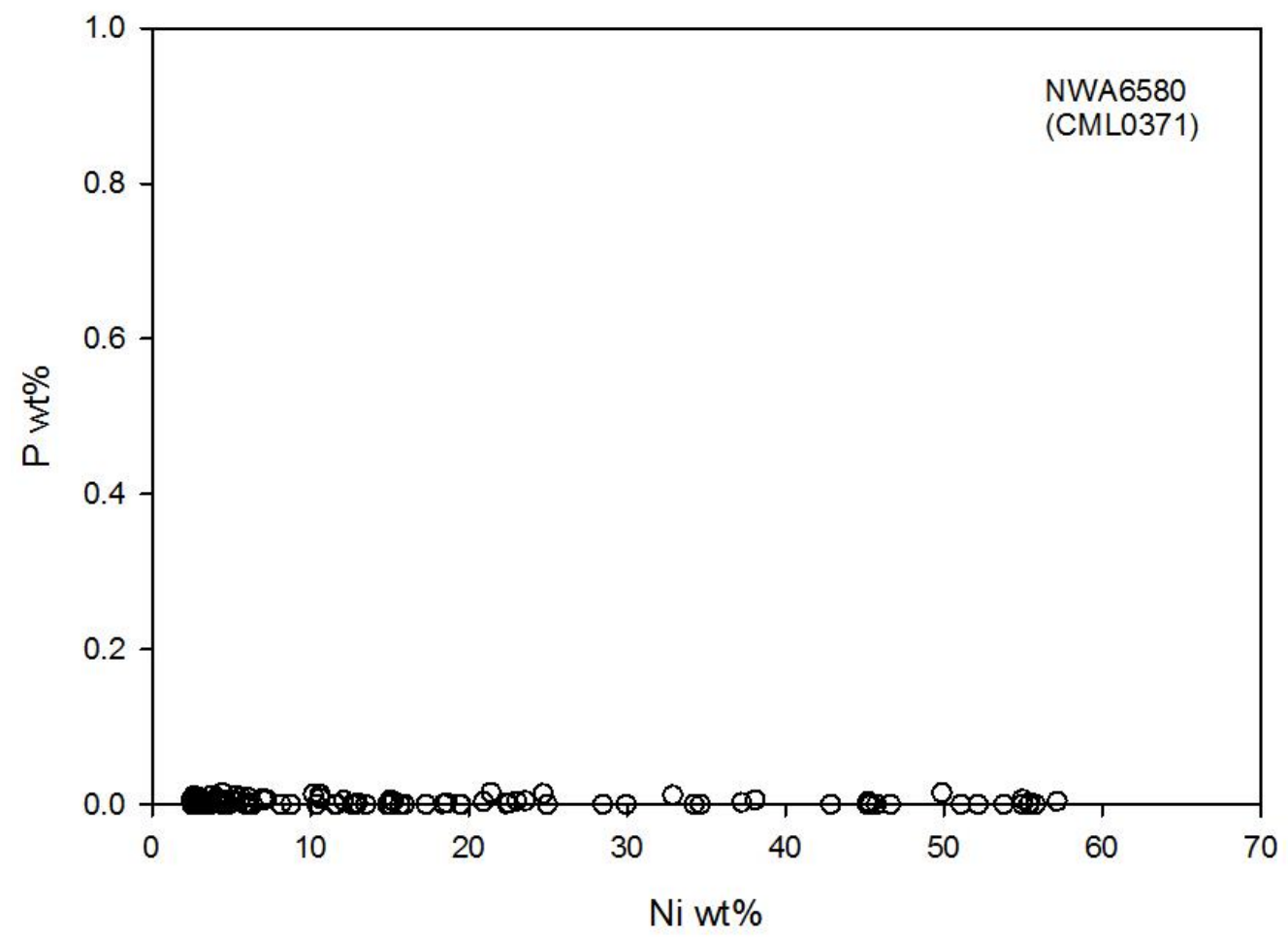

Figure 28: NWA 6580 Phosphorus and nickel content in metal grains within the chondritic portion. EMP data. 


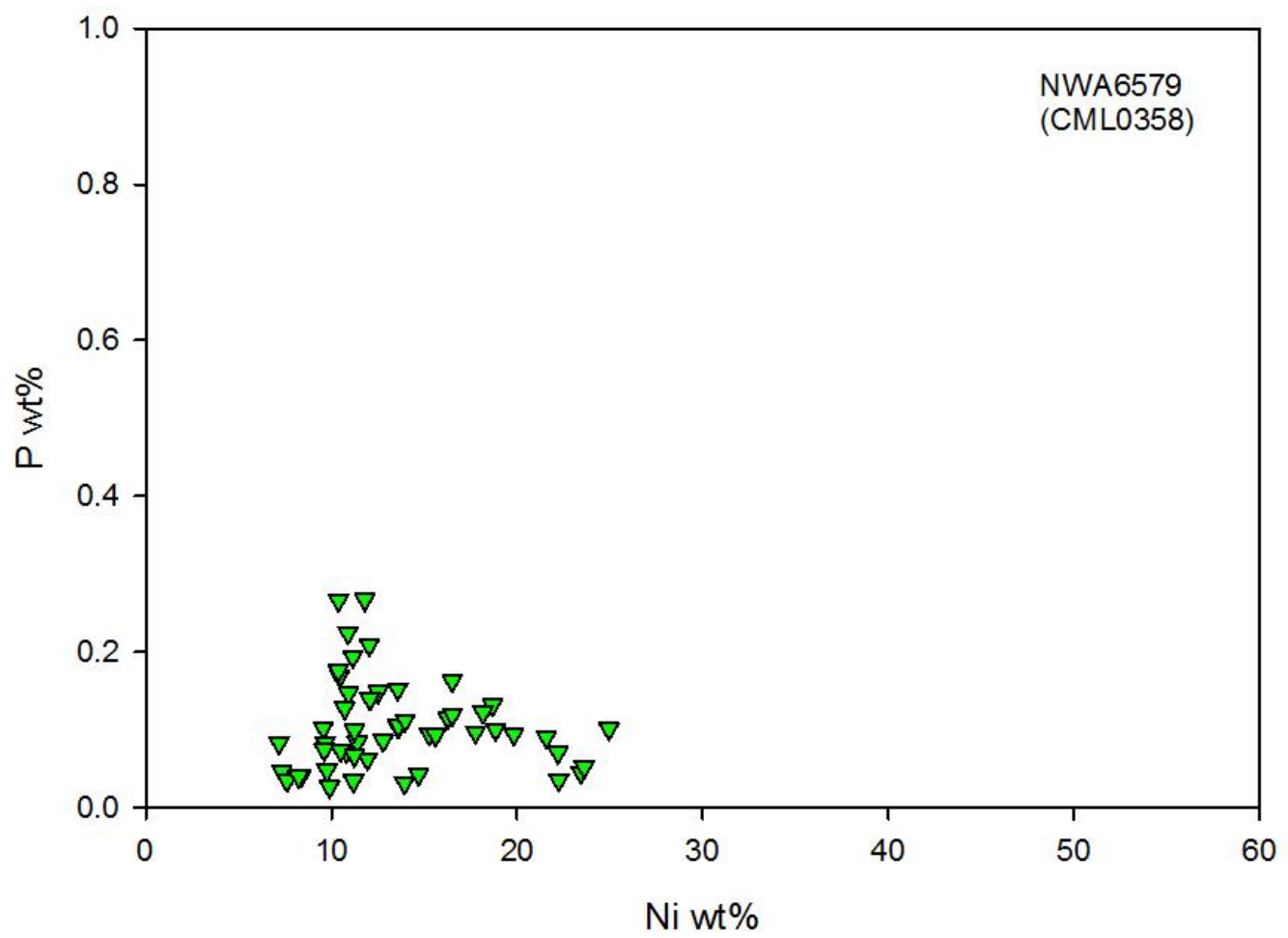

Figure 29: NWA 6579 Phosphorus and nickel content in metal grains. EMP data. 


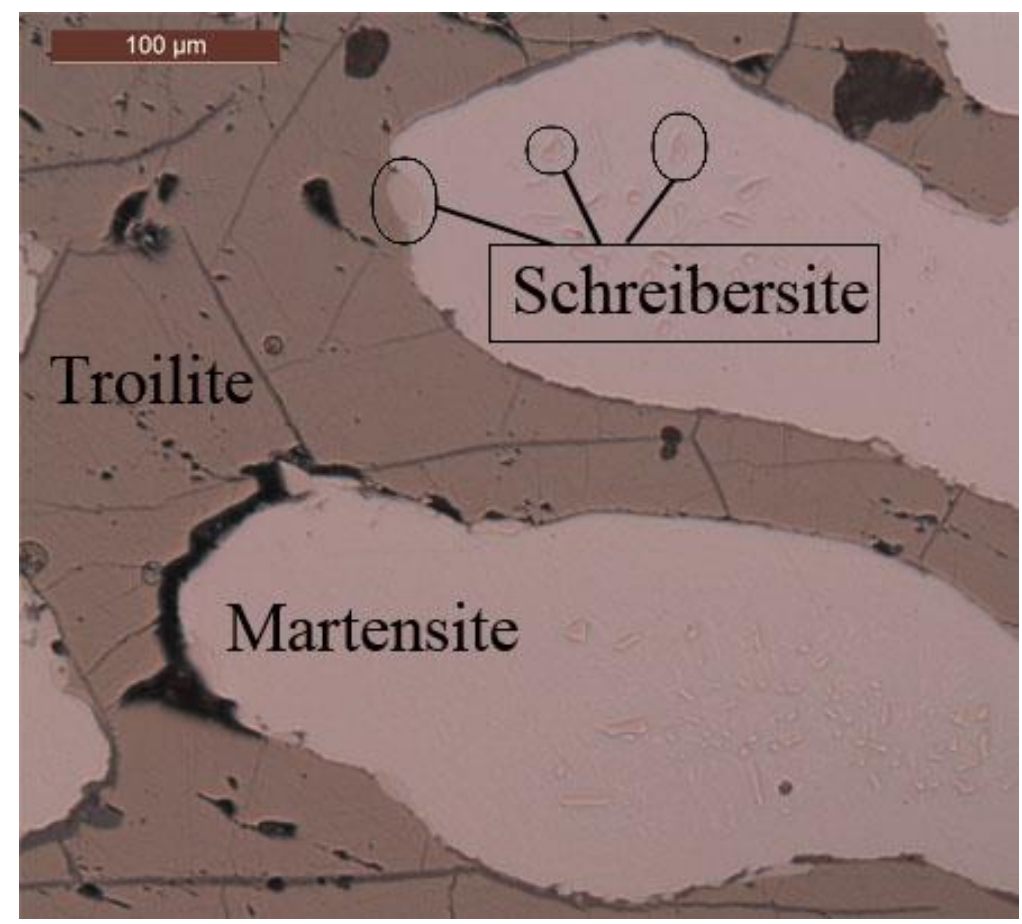

Figure 30: Reflected light photomicrograph of a metal grain in NWA 6579 showing small schreibersite grains in the metal-troilite globule. 




Figure 31: NWA 6454 Phosphorus and nickel content in metal grains. EMP data. 


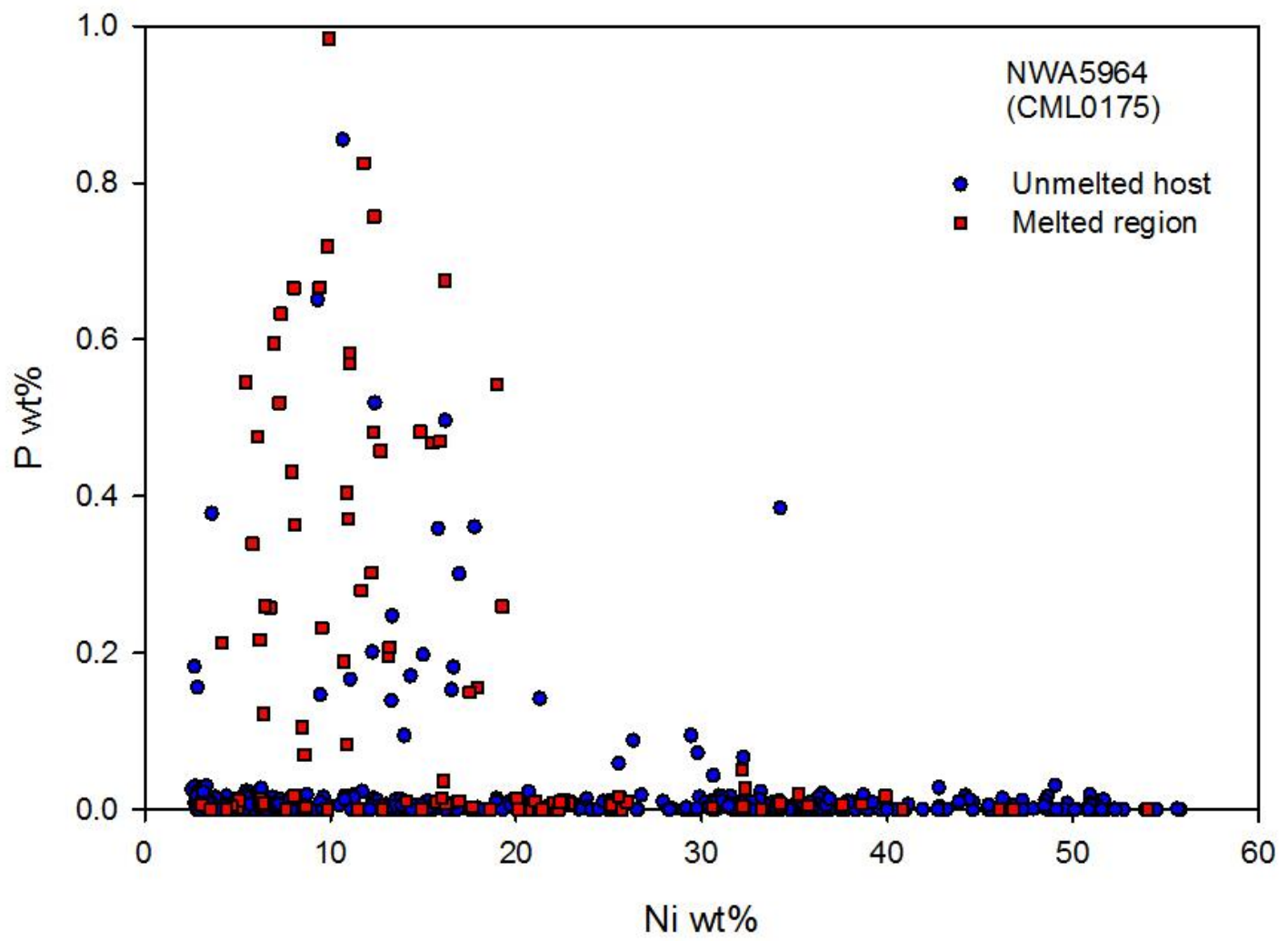

Figure 32: NWA 5964 Phosphorus and nickel content in metal grains. Metal grains within the chondritic host regions are shown in blue circles, and grains from within the melted section (4-1 thin section) are shown in red squares. EMP data.

\section{Nickel Enrichment in Troilite}

All of our samples except NWA 4860 (Figure 33) and NWA 6580 (Figure 34)

show some grains are enriched beyond $0.15 \mathrm{wt} \% \mathrm{Ni}$. NWA 4860 is the only sample which doesn't contain large regions of (or whole rock) silicate melt. We were only able to sample metal and sulfide grains within the chondritic host of NWA 6580 (Figure 34), despite the majority of the sample being melted. The sulfide grains in the melt portion were generally too small to reliably target with the EMP. 




Figure 33: NWA 4860 nickel content in troilite grains. None of the grains are enriched beyond the $0.15 \mathrm{wt} \%$ Ni enrichment level. EMP data. 


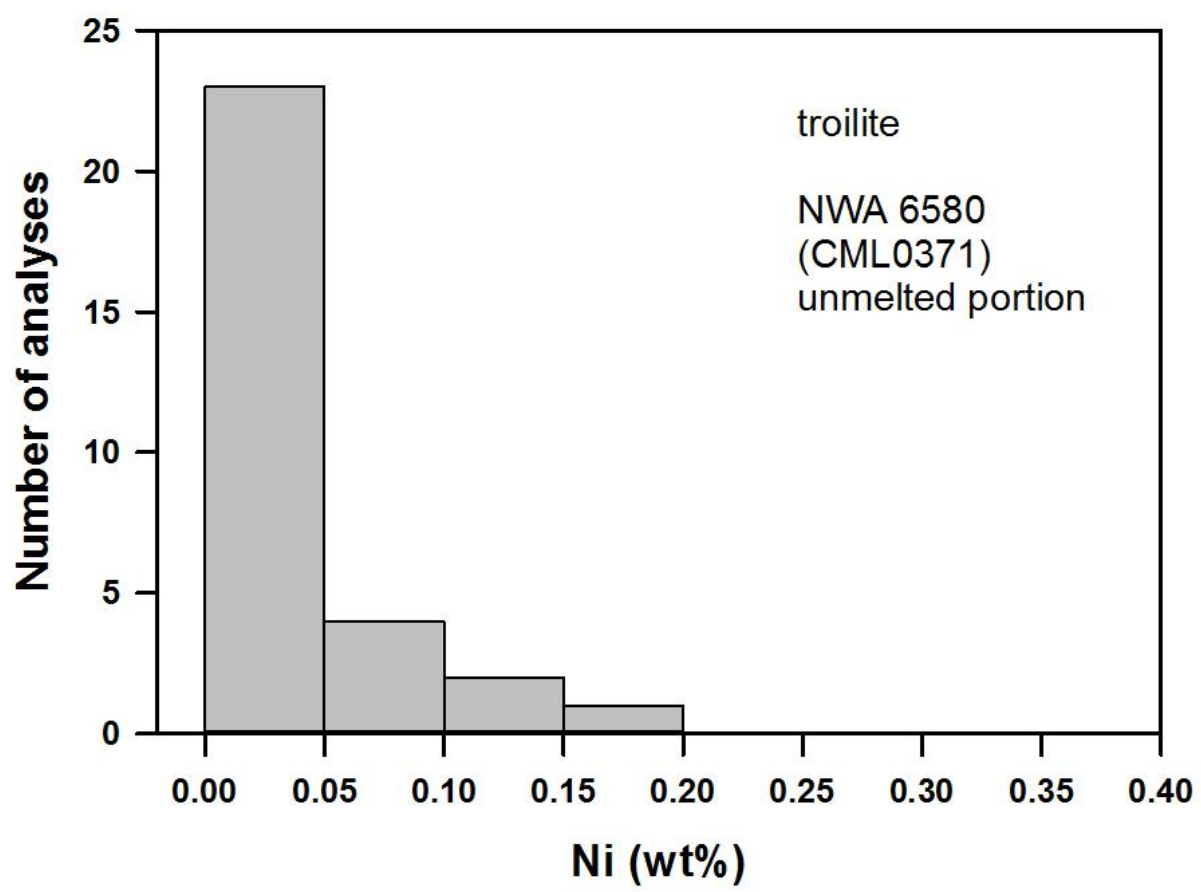

Figure 34: NWA 6580 nickel content in troilite grains. Only one grain shows enrichment beyond the 0.15 wt \% Ni enrichment level. EMP data.

NWA 6454 (Figure 35) and NWA 6579 (Figure 36) both show enrichments and a large spread in Ni wt\% seen in troilite, as expected for shock melted rocks. Both show concentrations mostly $>0.1 \mathrm{wt} \% \mathrm{Ni}$ in NWA 6579 and $>0.2 \mathrm{wt} \% \mathrm{Ni}$ in NWA 6454 with both samples having some grains nearing $0.4 \mathrm{wt} \% \mathrm{Ni}$. NWA 6464 shows $37 \%$ of analyzed grains are enriched, while NWA 6579 shows $23 \%$ of grains analyzed are enriched, however to have grains enriched the temperature needed to be raised substantially, followed by rapid cooling. The overall variation can be explained by overall heating to high temperatures followed by rapid cooling, with some grains resetting via continued diffusion to lower $\mathrm{Ni}$ contents and some not. The somewhat larger proportion of low-Ni troilite in NWA 6579 could indicate diffusion persisted longer than 
in NWA 6454. It is also likely there is spatial variation across the grains, and the $\mathrm{Ni}$ content may vary with location within the grain. We did not test for a spatial variation in the grains.



Figure 35: NWA 6454 nickel content in troilite grains. 37\% of the grains analyzed show enrichment in Ni beyond 0.15 wt\%. EMP data. 




Figure 36: NWA 6579 nickel content in troilite grains. $23 \%$ of grains show enrichment beyond $0.15 w t \%$ Ni. EMP data.

The NWA 5964 sulfide data, displayed as grains from within the chondritic host (Figure 37) and grains within the melted portion (Figure 38) both show some Ni-enriched grains, $9 \%$ of analyzed grains in the host are enriched and $33 \%$ of the grains from the melted region are enriched. Within the melt region the composition of the troilite grains is generally comparable to the two melt rocks, NWA 6454 and NWA 6579, but is most similar to NWA 6454. The unmelted chondritic region of NWA 5964 contains Ni enriched troilite grains, but the distribution is more similar to the less shocked materials in NWA 4860 and the chondritic portion of NWA 6580. The grains from the unmelted chondritic regions of NWA 5964 may represent a mixture of the expected distribution for melted and unmelted regions. 


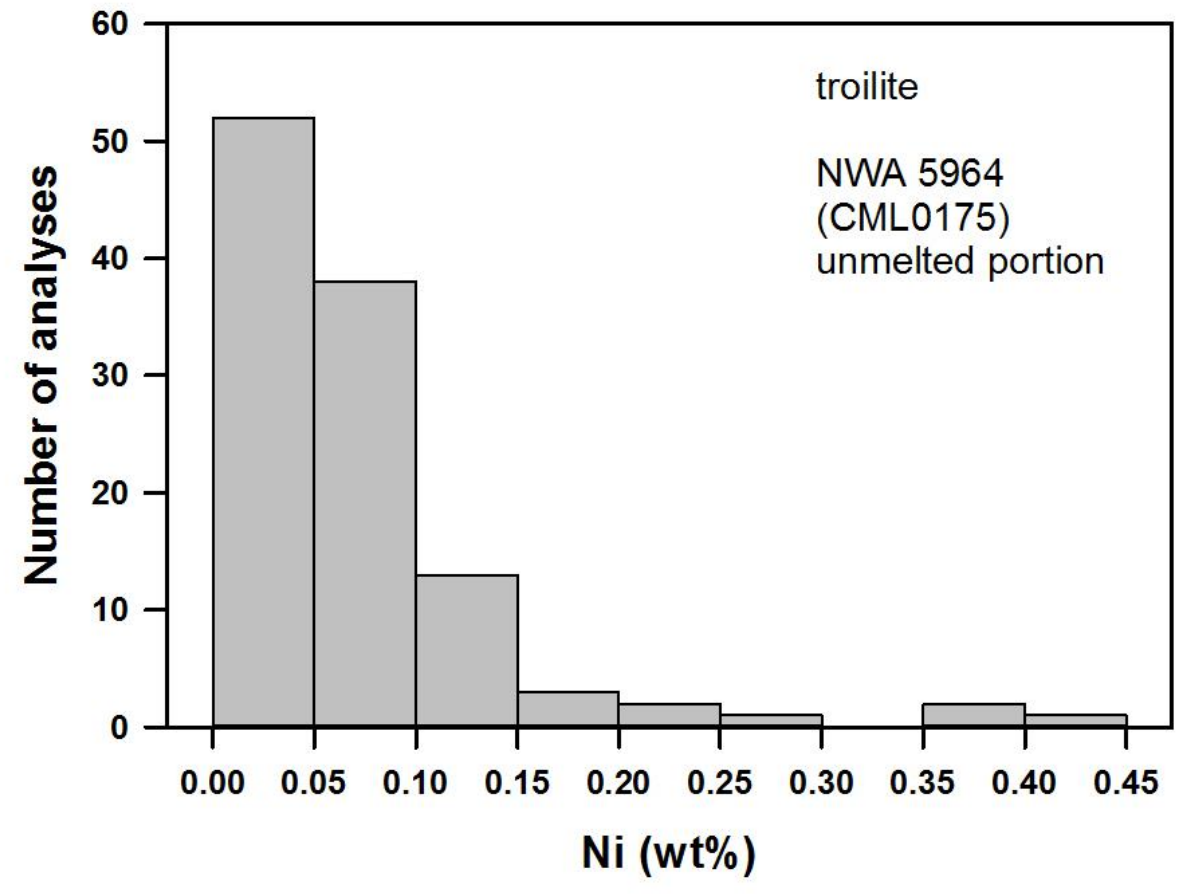

Figure 37: NWA 5964 chondritic host nickel content in troilite grains. 9\% of grains show enrichment beyond $0.15 \mathrm{wt} \%$ Ni. EMP data. 


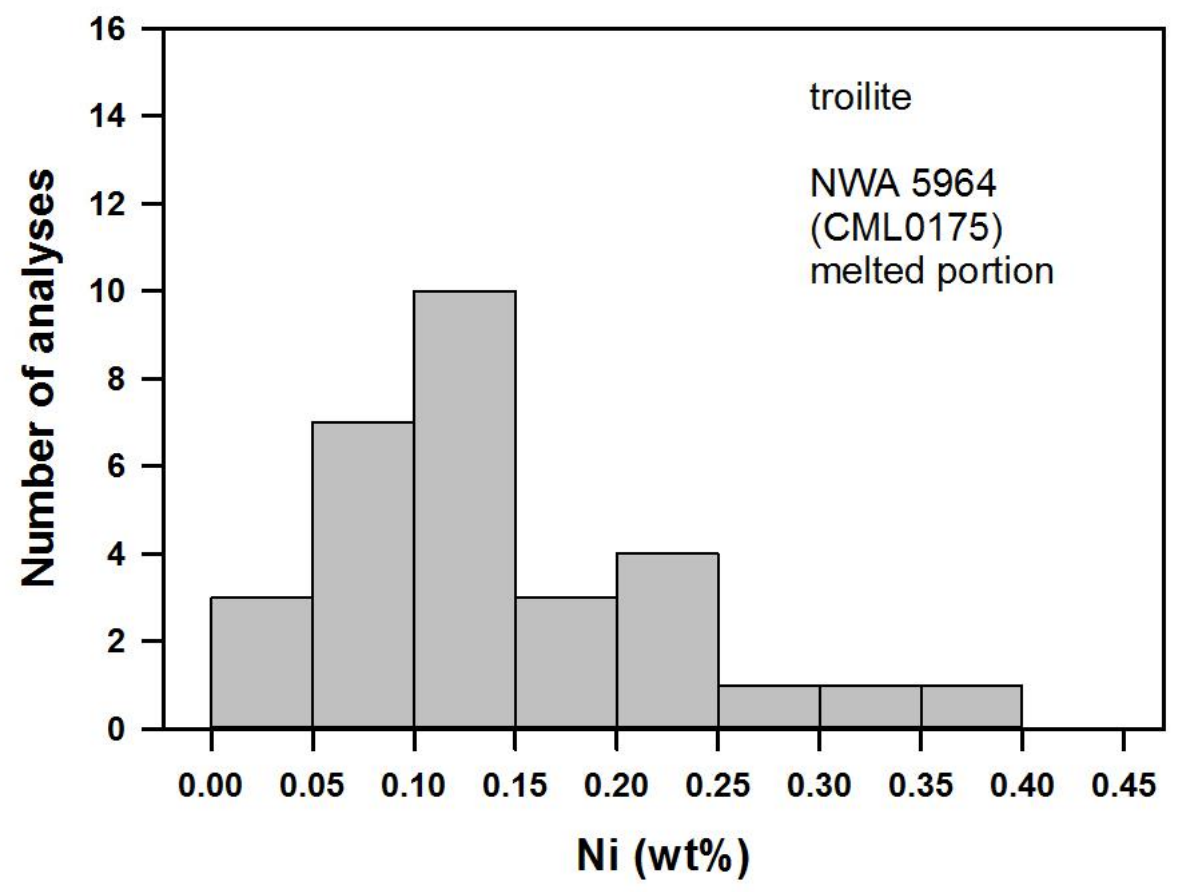

Figure 38: NWA 5964 shock melted region nickel content in troilite grains. 33\% of grains analyzed are enriched beyond $0.15 \mathrm{wt} \% \mathrm{Ni}$. EMP data.

\section{Metal Textures and Their Significance}

In most metal grains in the chondritic host regions of our samples, kamacitetaenite intergrowths are present, as in Figure 39, which when traversed will show a chemically zoned profile. See Figure 40. In kamacite-taenite grains, taenite grains typically consist of central compositions of $25-35 \mathrm{wt} \% \mathrm{Ni}$, and $45-55 \mathrm{wt} \% \mathrm{Ni}$ along the edges. Kamacite typically show a 6-7 wt $\% \mathrm{Ni}$ in cores and 5-6 wt $\% \mathrm{Ni}$ along the edges. The existence of such grains in the chondritic portions of NWA 5964 and NWA 6580 suggest only limited heating for these chondrite portions despite proximity to large amounts of melt. 


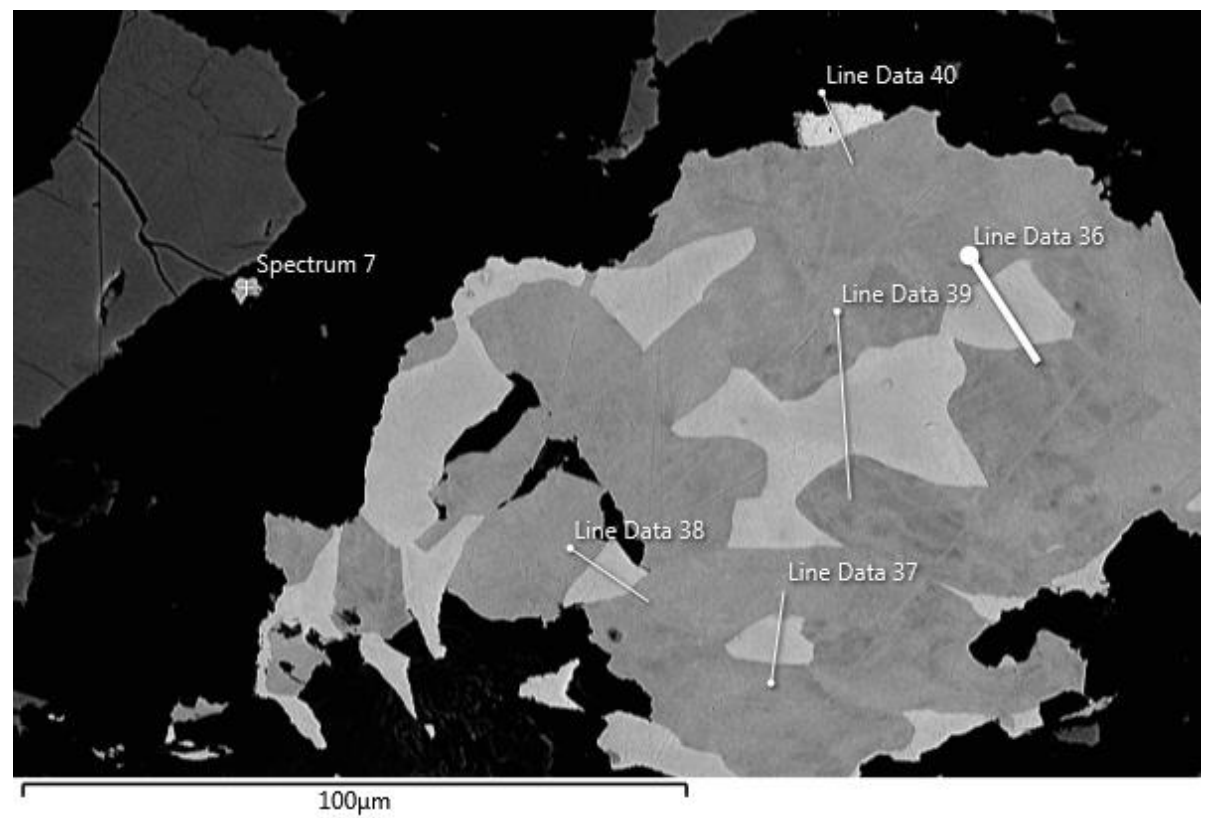

Figure 39: Backscattered electron micrograph showing kamacite (grey) taenite (white) intergrowth in metal grain. Traverse (Line Data) 36 is shown in Figure 40. Silicates appear black; troilite is dark grey.

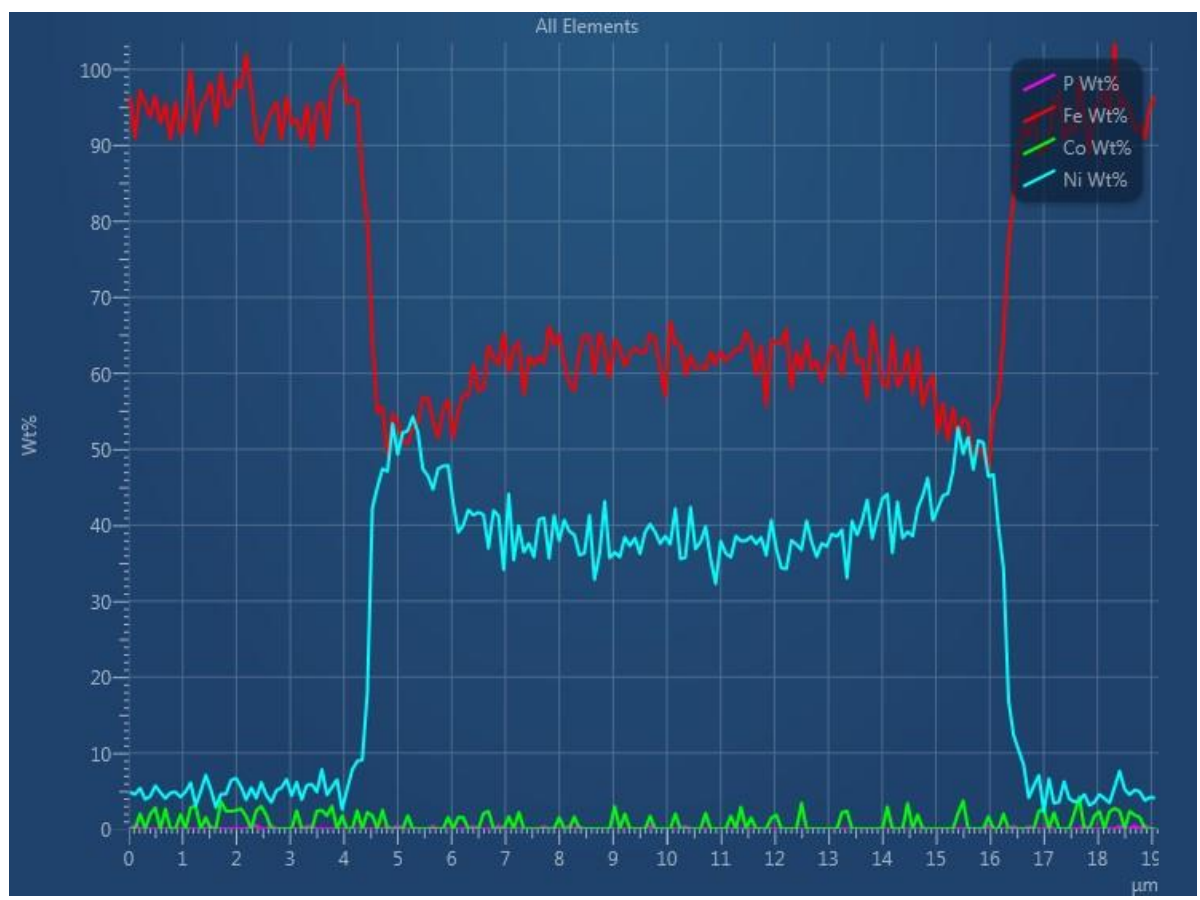

Figure 40: Composition of grain shown in Figure 39 as Line Data 36. The Cyan line is Ni, which shows a typical slow cooling "M" -shaped profile. 
In addition to the kamacite-taenite intergrowths, many slow cooled chondrites, including the NWA 5964 and NWA 6580 samples in this study, contain plessite structures that lack rim to rim zoning, Figure 41. These grains have previously been termed "zoneless plessite" and have been found to represent grains near, but not in contact with kamacite-taenite structures (Willis and Goldstein, 1983; Reisener and Goldstein, 2003b). The chemical profile of these grains, as seen in Figure 42, shows they lack both the "M" -shaped profile seen in zoned taenite grains, as well as a general lack of enrichment in Ni near the rims of the grains. Reisener and Goldstein (2003b) demonstrated experimentally that the zoneless plessite grain microstructure can be produced by slow cooling $\left(<5^{\circ} \mathrm{C} / \mathrm{min}\right)$ of an originally monocrystalline taenite grain. This will result in two dominant textures of metal grains (kamacite + taenite, and zoneless plessite) in slow cooled ordinary chondrites, often occurring within the same sample. The final microstructure of the grain will be determined by the original structure of the taenite (monocrystalline, or polycrystalline) and the variation is not easily related to compositional or thermal history variations (Reisener and Goldstein, 2003b). 


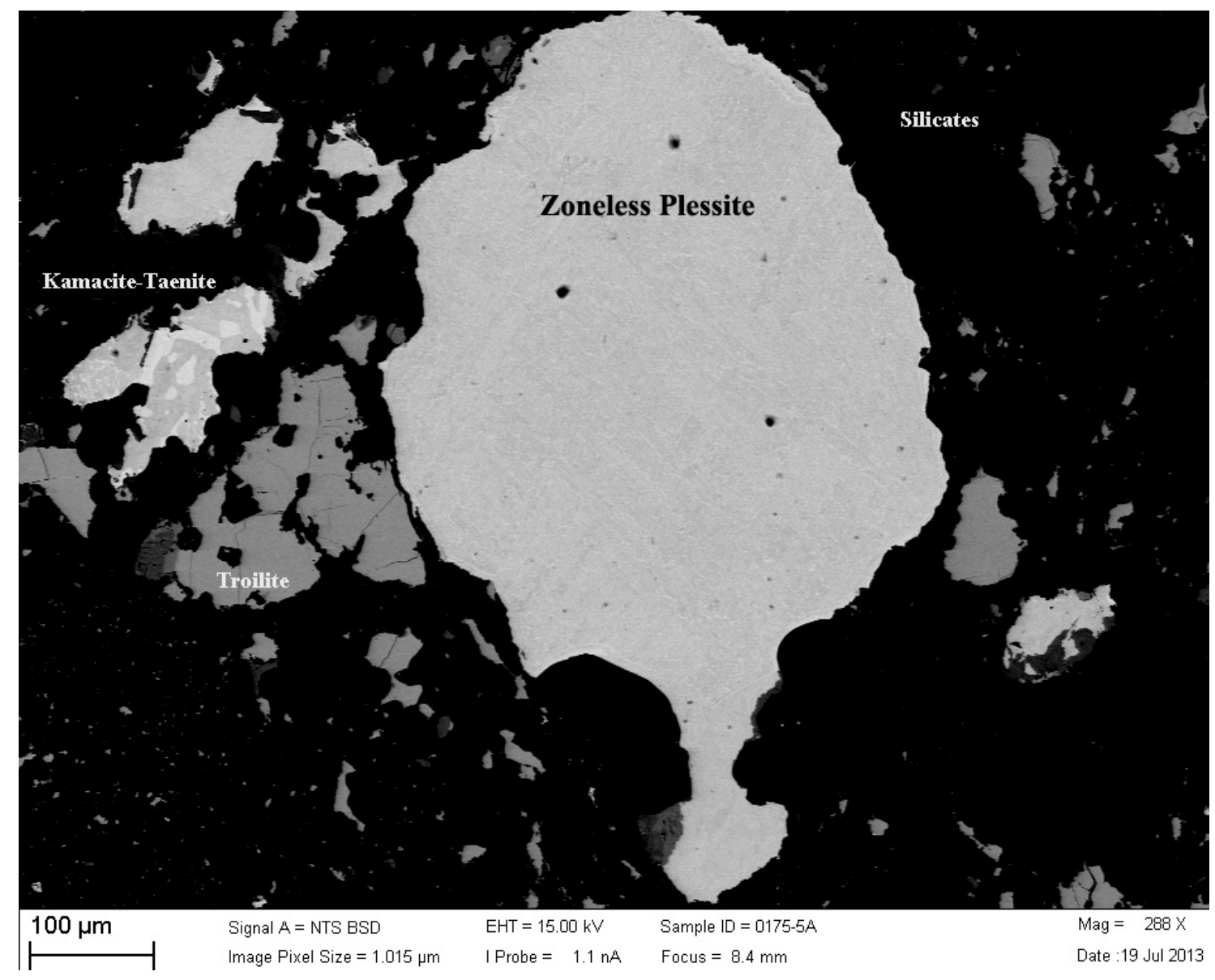

Figure 41: Backscattered electron micrograph of zoneless plessite grain from the chondritic portion of NWA 5964. The grain lacks high Ni rims, and occurs near, but not in contact with a zoned kamacite-taenite grain. 


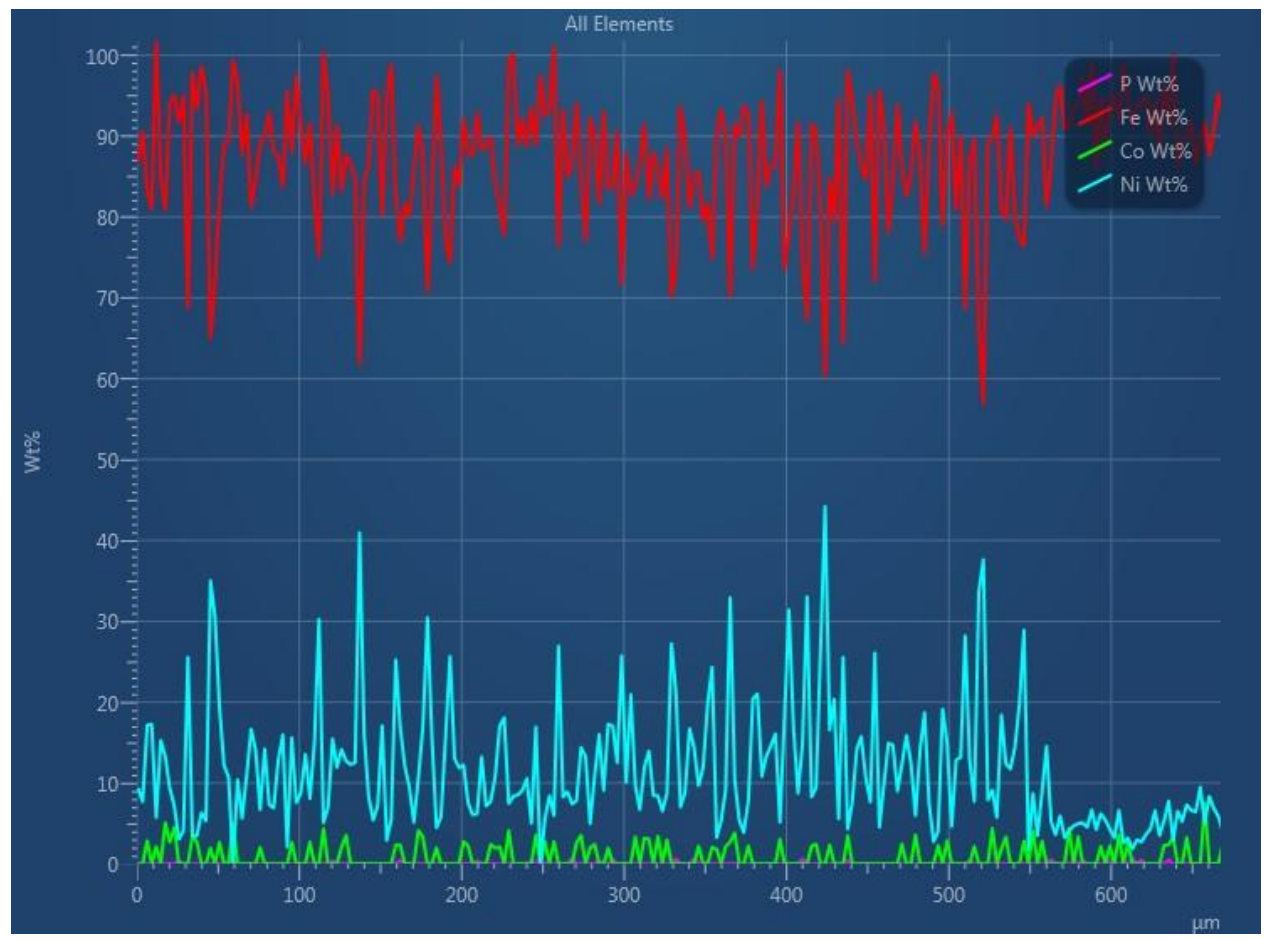

Figure 42: Chemical profile of zoneless plessite grain, SEM traverse across grain shown in Figure 41 from top to bottom as the grain is oriented in the image. The grain shows highly variable composition as it is composed of a fine grained kamacite and taenite microstructure, but lacks a general zoning pattern.

Within our shock melted samples (NWA 6454, NWA 6579, and melted regions in NWA 5964), the decomposed martensitic or plessitic microstructures are usually zoned, with rims of nickel enrichment along the grain boundaries (Figure 43, Figure 44). Such Ni-rich rims on plessite grains in melted regions can be explained by solidification zoning of the parent taenite crystals from metallic melt not destroyed by subsequent reheating. The plessite in this case could have formed by inversion of a taenite parent monocrystal following extensive heating to the point of melting. Thus zoned plessite (or plessite with Ni rich rims) in the melt rocks and the melted portion of NWA 5964 is indicative of melt solidification. In contrast, within our highly shocked, but unmelted 
sample, NWA 4860, the metal is remarkably uniform (Figure 10), but lacks the microstructure of plessite and evidence for Ni-rich rims (Figure 17). In this case, the plessite shows less evidence for crystallization from a melt, but it could have been heated extensively to below the point of melting to form a monocrystal, resulting in unzoned plessite. Therefore, unzoned plessite in NWA 4860 is indicative of strong heating but not to the point of melting.



Figure 43: Backscattered electron micrograph of fine plessite grain from small melt pocket in NWA 5964 - 5A thin section. Similar to the metals in the larger melted portions the grains here show thin rims of nickel enrichments. Metals (light grey and white), troilite (darker), silicates (black). Line Data 24 is shown in Figure 44. 


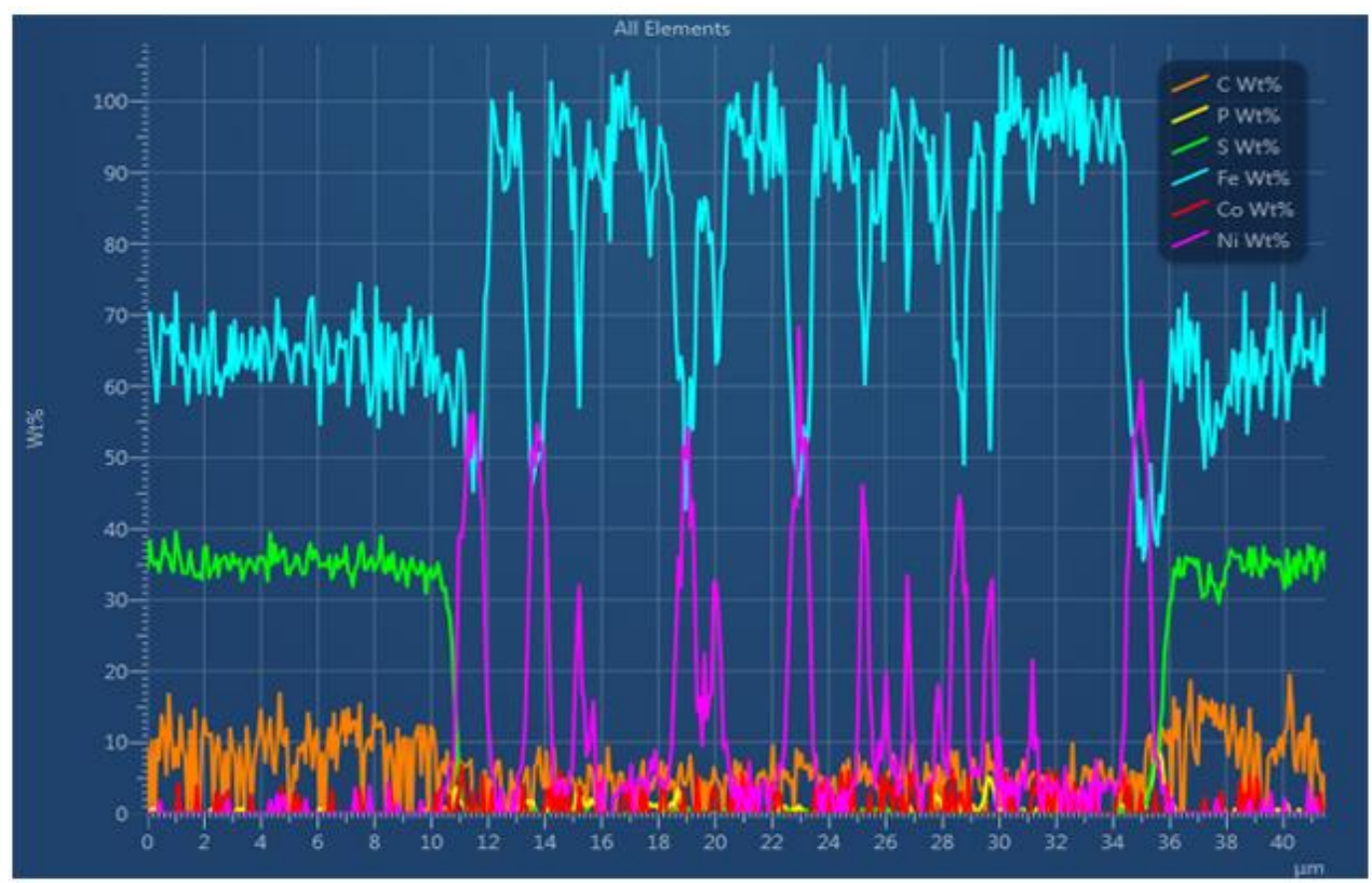

Figure 44: Composition of Metal-Sulfide assemblage shown in Figure 43 as calculated by Aztec software across traverse marked Line Data 24 . Ni shown in purple clearly outlines the sulfide to metal grain boundary with high $\mathrm{Ni}$ (tetrataenite) spikes showing the rimmed metal grain.

\section{Determining Closure Temperatures}

The closure temperatures determined for the chondritic portions of the L melt breccia meteorites are also consistent with slow cooling. If the cooling rate was fast, diffusion would be halted sooner, leaving lower concentrations of nickel in the rims of the taenite grains, or more uniform compositions across the entire grain. Many of our grains have compositions with over $45 \mathrm{wt} \% \mathrm{Ni}$. This correlates to a tetrataenite $(\gamma$ ') phase (Figure 2), and is only stable when the metal is slow cooled to temperatures below $400{ }^{\circ} \mathrm{C}$. Using profiles like the one shown in Figure 40, we calculated a start temperature (Ts) from the core composition, and a final closure temperature (Tf) from the 
composition along the grain edge. Where two phases were in contact each phase was used for an independent temperature calculation. Table 3 shows the starting temperatures, and final closure temperatures determined from grains within the chondritic portions of NWA 5964. Table 4 shows the starting and final closure temperatures for the grains within the chondritic portion of NWA 6580. The corresponding plots to these tables are shown as Figure 45 and Figure 46 respectively. Both of these samples contain the tetrataenite phase indicating in areas the sample was cooled slowly enough to allow diffusion below $\sim 400{ }^{\circ} \mathrm{C}$ to form this phase. Based on all available data for NWA 5964 and 6580, the Fe-Ni compositions of the various types of metal grains (kamacite-taenite, plessite) in these meteorites were established at temperatures of $\sim 550-100{ }^{\circ} \mathrm{C}$ (Figure 45 , Figure 46). 
Table 3: Starting temperatures (Ts) and final closure temperatures (Tf) for NWA 5964 grains within the chondritic host. Determined with phase diagram from SEM traverse data. Texture: $K=$ kamacite, $T=$ taenite, and $M=$ martensite. For Tf, some grains were rimmed with higher Ni tetrataenite (TT).

\begin{tabular}{|c|c|c|c|c|c|c|}
\hline $\begin{array}{c}\text { Grain } \\
\text { number }\end{array}$ & Traverse & Texture & Ts from $\mathrm{K}$ & $\begin{array}{c}\text { Ts from } \mathrm{T} \text { or } \\
\mathrm{M}^{+}\end{array}$ & $\mathrm{Tf}$ from $\mathrm{K}$ & $\begin{array}{c}\mathrm{Tf} \text { from } \mathrm{T} \text { or } \\
\mathrm{TT}^{*}\end{array}$ \\
\hline Grain 043 & LS1 & $\mathrm{K}+\mathrm{T}$ & & $<400$ & $244+161 /-120$ & $96+280 /-96$ \\
\hline Grain 043 & LS2 & $\mathrm{K}+\mathrm{T}$ & & $470+2 /-2$ & $202+118 /-91$ & $65+335 /-65$ \\
\hline Grain 043 & LS3 & $\mathrm{K}+\mathrm{T}$ & $471+2 /-2$ & $<335$ & $223+188 /-131$ & $<315$ \\
\hline Grain 043 & LS4 & $\mathrm{K}+\mathrm{T}$ & $471+3 /-3$ & $397+6 /-6$ & $179+85 /-69$ & $253+148 /-253$ \\
\hline Grain 034 & LS56 & $\mathrm{K}+\mathrm{T}$ & $470+3 /-3$ & $411+34 /-39$ & $178+108 /-83$ & $<340$ \\
\hline Grain 034 & LS57 & $\mathrm{K}+\mathrm{T}$ & & & $211+147 /-108$ & $<365$ \\
\hline Grain 034 & LS58 & $\mathrm{K}+\mathrm{T}$ & $472+2 /-2$ & $405+45 /-53$ & $194+67 /-57$ & $277+124 /-277$ \\
\hline Grain 034 & LS59 & $\mathrm{K}+\mathrm{T}$ & $472+2 /-2$ & $356+52 /-63$ & $162+68 /-56$ & $333+70 /-315$ \\
\hline Grain 034 & LS60 & $\mathrm{K}+\mathrm{T}$ & $472+2 /-2$ & $411+5 /-5$ & $148+64 /-53$ & $248+121 /-221$ \\
\hline Grain017 & LS36 & $\mathrm{K}+\mathrm{T}$ & $470+2 /-2$ & $366+46 /-56$ & $257+85 /-73$ & $102+246 /-102$ \\
\hline Grain017 & LS37 & $\mathrm{K}+\mathrm{T}$ & $471+3 /-3$ & $411+6 /-6$ & $170+72 /-60$ & $208+193 /-208$ \\
\hline Grain017 & LS38 & $\mathrm{K}+\mathrm{T}$ & $470+2 /-2$ & $412+5 /-5$ & $173+86 /-69$ & $275+125 /-275$ \\
\hline Grain017 & LS39 & $\mathrm{K}+\mathrm{T}$ & $469+3 /-3$ & $381+40 /-47$ & $246+162 /-121$ & $129+275 /-129$ \\
\hline Grain040 & LS23 & $\mathrm{K}+\mathrm{T}$ & $473+2 /-2$ & $411+7 /-7$ & $122+41 /-35$ & $402+7 /-98^{*}$ \\
\hline Grain033 & LS20 & $\mathrm{K}+\mathrm{T}$ & $473+2 /-2$ & $454+35 /-38$ & $161+101 /-77$ & $406+18 /-78^{*}$ \\
\hline Grain033 & LS21 & $\mathrm{K}+\mathrm{T}$ & $473+2 /-2$ & $396+48 /-58$ & $154+73 /-59$ & $126+273 /-126$ \\
\hline Grain 031 & LS14 & $K+M$ & $471+3 /-3$ & $413+5 /-5^{+}$ & $172+93 /-73$ & $292+112 /-292$ \\
\hline Grain 031 & LS16 & $K+M$ & $472+2 /-2$ & $365+53 /-66^{+}$ & $161+68 /-56$ & $403+9 /-136^{*}$ \\
\hline Grain 030 & LS12 & $\mathrm{K}+\mathrm{M}$ & $469+3 /-3$ & $552+27 /-25^{+}$ & $203+88 /-72$ & $370+22 /-24^{*}$ \\
\hline Grain 030 & LS13 & $K+M$ & & $417+44 /-52^{+}$ & $146+84 /-65$ & $325+76 /-250$ \\
\hline Grain039 & average & M & & $440+369 /-269^{+}$ & $192+92 /-74$ & \\
\hline Grain 020 & average & M & & $411+449 /-302^{+}$ & $238+96 /-80$ & \\
\hline
\end{tabular}




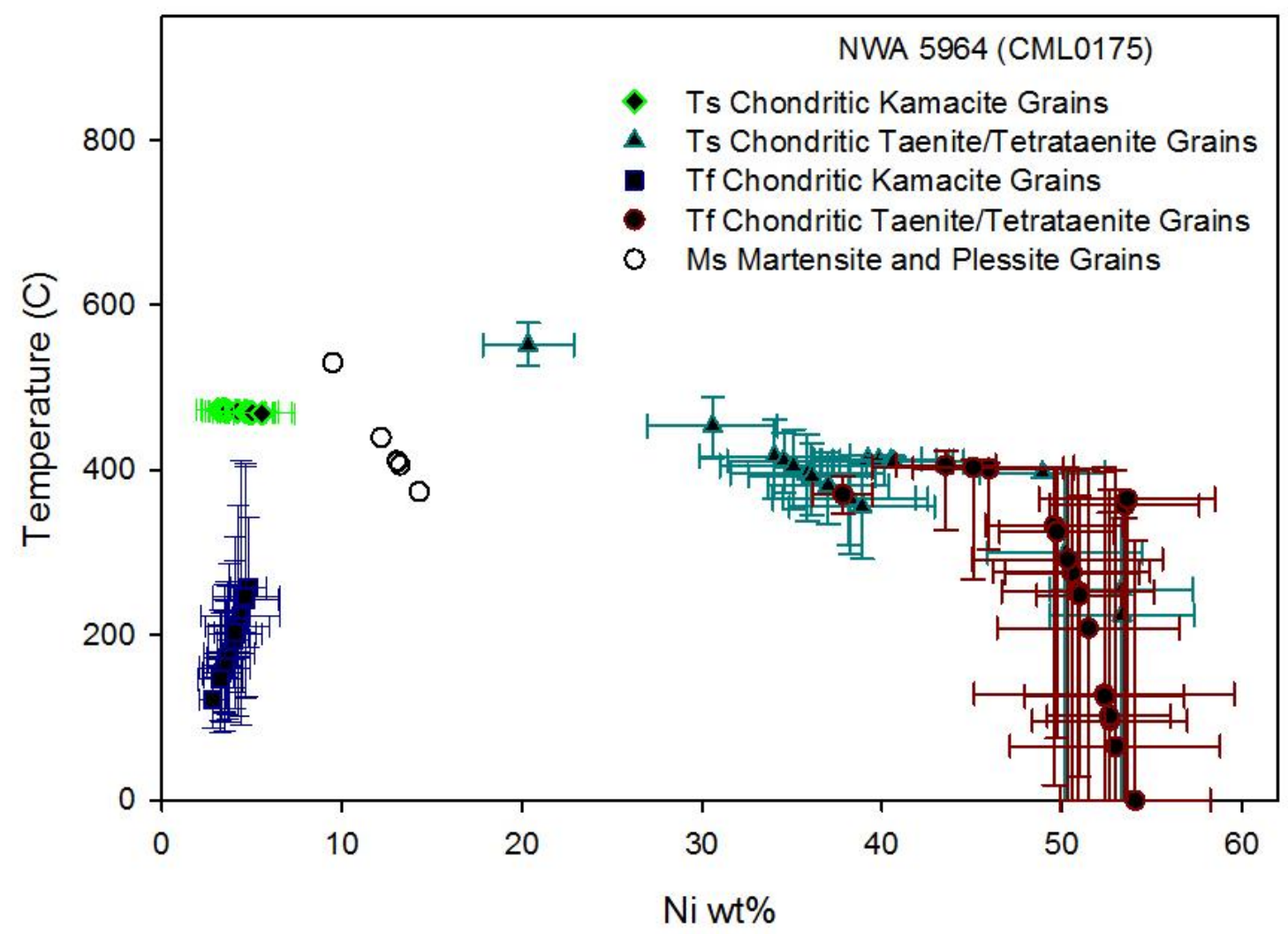

Figure 45: NWA 5964 closure temperatures determined from SEM traverse compositional data from Table 3. The Ni-rich grains $(>40 \mathrm{wt} \%)$ are tetrataenite grains while those with compositions of 20-40 wt\% Ni are taenite grains. 
Table 4: Starting temperatures (Ts) and final closure temperatures (Tf) for NWA 6580 grains from within the chondritic host. Determined with phase diagram from SEM traverse data. Texture: $\mathrm{K}=$ kamacite, $\mathrm{T}=$ =taenite, and $\mathrm{M}=$ martensite. For $\mathrm{Tf}$, some grains were rimmed with higher $\mathrm{Ni}$ tetrataenite (TT).

\begin{tabular}{|c|c|c|c|c|c|c|}
\hline $\begin{array}{l}\text { Grain } \\
\text { number }\end{array}$ & Traverse & Texture & Ts from $\mathrm{K}$ & Ts from $\mathrm{T}$ or $\mathrm{M}^{+}$ & $\mathrm{Tf}$ from $\mathrm{K}$ & $\begin{array}{c}\text { Tf from } \mathrm{T} \text { or } \\
\mathrm{TT}^{*}\end{array}$ \\
\hline $\begin{array}{c}\text { Grain } \\
034\end{array}$ & LS14 & $\mathrm{K}+\mathrm{T}$ & & & $190+65 /-55$ & $335+66 /-232$ \\
\hline $\begin{array}{c}\text { Grain } \\
035\end{array}$ & LS15 & $\mathrm{K}+\mathrm{T}$ & & $372+21 /-23$ & $143+100 /-74$ & $332+67 /-128$ \\
\hline $\begin{array}{c}\text { Grain } \\
070\end{array}$ & LS21 & $\mathrm{K}+\mathrm{T}$ & & $413+3 /-3$ & $\begin{array}{c}217 \\
+167 /-120\end{array}$ & $356+44 /-114$ \\
\hline $\begin{array}{c}\text { Grain } \\
070\end{array}$ & LS22 & $\mathrm{K}+\mathrm{T}$ & & $413+3 /-3$ & $164+83 /-66$ & $393+10 /-64$ \\
\hline $\begin{array}{c}\text { Grain } \\
070\end{array}$ & LS23 & $\mathrm{K}+\mathrm{T}$ & $474+1 /-1$ & $407+3 /-3$ & $161+79 /-64$ & $366+35 /-154$ \\
\hline $\begin{array}{c}\text { Grain } \\
073\end{array}$ & LS25 & $\mathrm{K}+\mathrm{T}$ & & $370+22 /-24$ & $269+78 /-68$ & $<420^{*}$ \\
\hline $\begin{array}{c}\text { Grain } \\
036\end{array}$ & LS18 & $\mathrm{K}+\mathrm{T}$ & & & $\begin{array}{c}393 \\
+169 /-139\end{array}$ & $\begin{array}{c}271 \\
+127 /-253\end{array}$ \\
\hline $\begin{array}{c}\text { Grain } \\
036\end{array}$ & LS16 & $\mathrm{K}+\mathrm{M}$ & $471+1 /-1$ & $448+13 /-14^{+}$ & $237+110 /-89$ & $382+23 /-250$ \\
\hline $\begin{array}{c}\text { Grain } \\
036\end{array}$ & LS17 & M & & & $\begin{array}{c}309 \\
+105 /-89^{+}\end{array}$ & $\begin{array}{c}250 \\
+148 /-250\end{array}$ \\
\hline $\begin{array}{c}\text { Grain } \\
023\end{array}$ & LS9 & $\mathrm{K}+\mathrm{T}$ & & & $275+101 /-86$ & $94+190 /-94$ \\
\hline
\end{tabular}




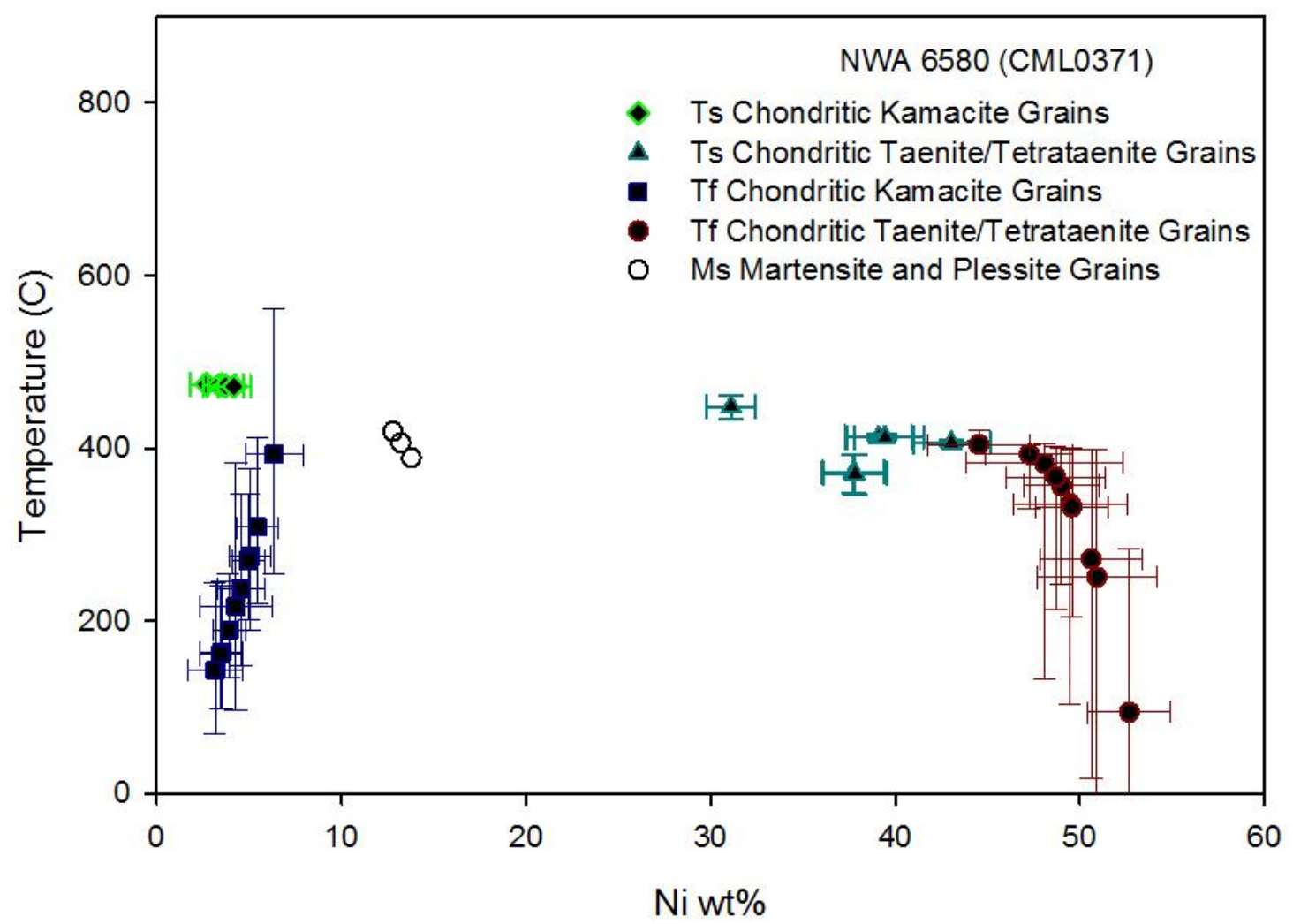

Figure 46: NWA 6580 closure temperatures determined from SEM traverse compositional data from Table 4. The Ni-rich grains (>40 wt\%) are tetrataenite grains while those with compositions of 20-40 wt\% Ni are taenite grains.

\section{Overall variation in Metal Grain Compositions}

Previous studies have shown the metal composition in severely reheated chondrites is more homogeneous than less altered chondrites (Smith and Goldstein, 1977; Heymann, 1967; Taylor and Heymann, 1971; Begemann and Wlotzka, 1969). Begemann and Wlotza (1969) proposed the homogeneity of the grain composition after severe shock reheating is due to mixing, melting, and redistribution of the metal. Smith and Goldstein 
(1977) confirmed this proposal by showing in a separate suite of samples the compositional similarity of the grains increased with increasing shock stage. Within this study, SEM and EMPA data from grain cores were used to show the homogeneity or spread in grain compositions for each meteorite. The melted NWA 6579 sample was found to contain very homogeneous grain compositions. As shown in Figure 47 the grains examined plot very similarly in composition, and all show a relatively low standard deviation. This is indicating a fine martensite or plessite composition, of a fairly uniform composition within the grains themselves and among the grains across the sample. The low spread in average Ni content of the metal in NWA 6579 suggests extensive heating, consistent with what one would expect for a melt rock. The low spread in the intragrain Ni variations suggests relatively rapid cooling following this melting. 




Figure 47: SEM and EMP compositions of metal grain cores from NWA 6579.

Similar to the melt rock NWA 6579 strongly shocked but largely unmelted NWA 4860 also exhibits a fairly uniform composition in the grains and homogeneity in grain composition across the sample (Figure 48). The grain samples in Figure 48 were all sampled with the SEM. Additional EMP data were collected, however traverses were not conducted on NWA 4860 as the grains were previously determined to be very uniform in composition. Individual grains were analyzed with the EMP, and the range of compositions found is shown in Figure 9. Consistent with the SEM, the single point EMP analyses show a very uniform composition in the metal grains in NWA 4860, suggestive 
of intense heating followed by relatively rapid cooling in the formation of this shock stage S6 meteorite.



Figure 48: SEM compositions of metal grain cores from NWA 4860.

Our other melted sample, NWA 6454, also shows a relatively homogeneous grain core composition. The SEM and EMP data from NWA 6454 are shown in Figure 49. From this we can see there is more scatter in the average central composition in NWA 6454 than we saw in NWA 6579 or NWA 4860. We also find a larger standard deviation in the central composition, indicative of a coarser texture within the plessite structure. When the plessite is coarse, the EMP and SEM are able to resolve the individual high and 
low nickel components as they become larger than the interaction volume of the electron beam. This better resolution then appears as a higher standard deviation associated with averaging the core data points from the traverse. The coarser structure could be the result of a slower cooling, which would allow for more diffusion of the metals, thus resulting in larger spread in the composition. As previously noted, metal-sulfide textures imply slower cooling during melt solidification in NWA 6454 than NWA 6579 and NWA 5964 (Figure 24). This implies the plessite in NWA 6454 metal experienced a slower cooling rate from melt temperatures.

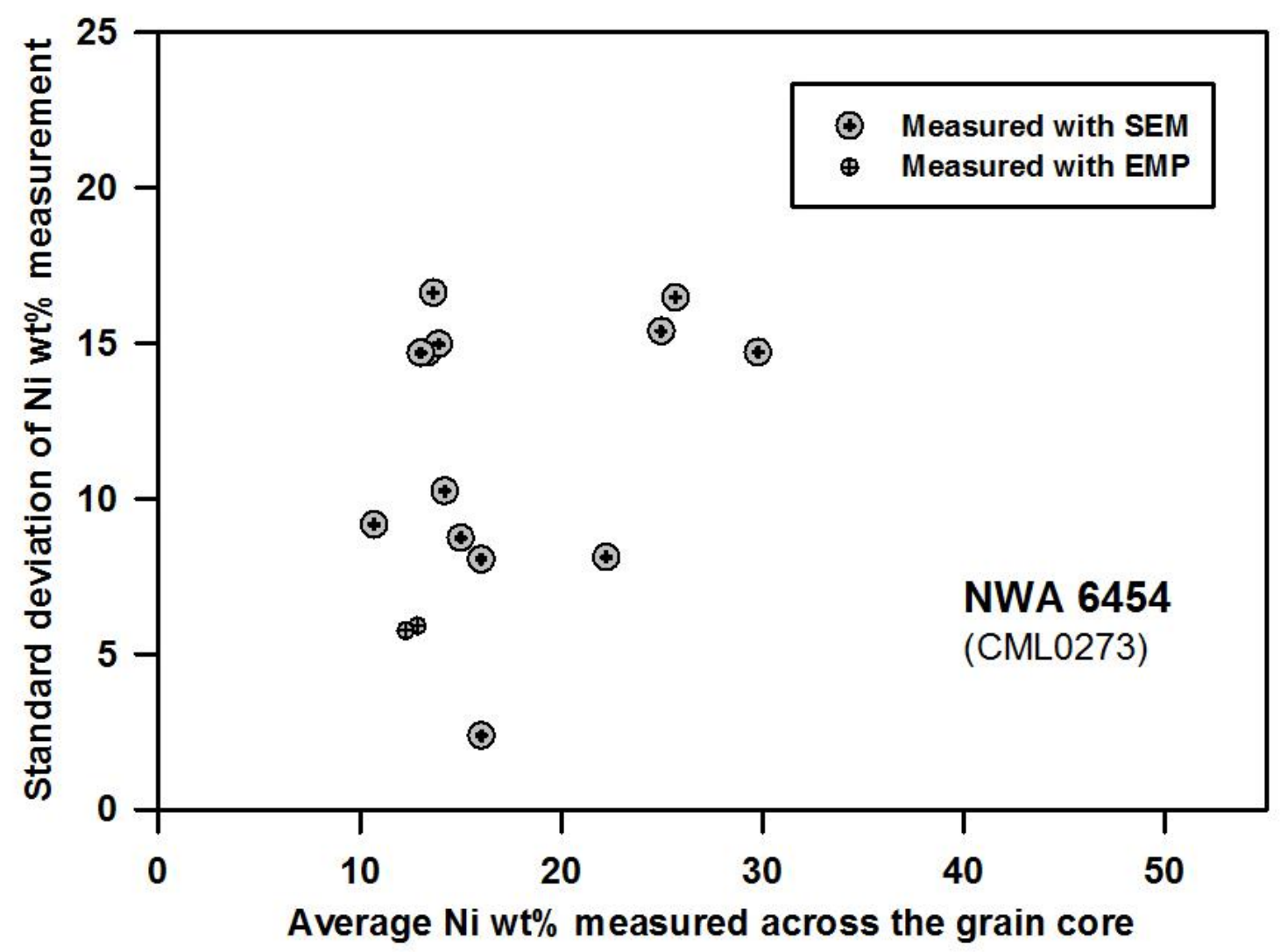

Figure 49: SEM and EMP compositions of metal grain cores from NWA 6454. 
When we examine the two breccias under the same techniques we find much more scatter in the grain compositions than in the highly shocked samples. Many of the metal grains in the chondritic portion of NWA 6580 are composed of blocky, coarse intergrowths of kamacite and taenite. These are reflected in the SEM and EMP traverse data, Figure 50, as grains with $<=5 \mathrm{wt} \%$ nickel (kamacite) and 30-40 wt \% nickel (taenite). Also present in the NWA 6580 chondritic region are grains composed of a coarse plessite structure with kamacite and taenite intergrowths nearly resolvable considering the interaction volume of the analytical techniques. In most cases the individual phases in the structure are greater than $1 \mu \mathrm{m}$. These appear in Figure 50 as the intermediate compositions, $10-20 \mathrm{wt} \% \mathrm{Ni}$, with high standard deviations as we are sampling both kamacite and taenite in the structure of the core. Despite being in such close contact to the melted region of the sample, the metal grains in the chondritic portion of NWA 6580 have a large range in Ni contents and textures consistent with mild heating and a relatively low shock stage. 


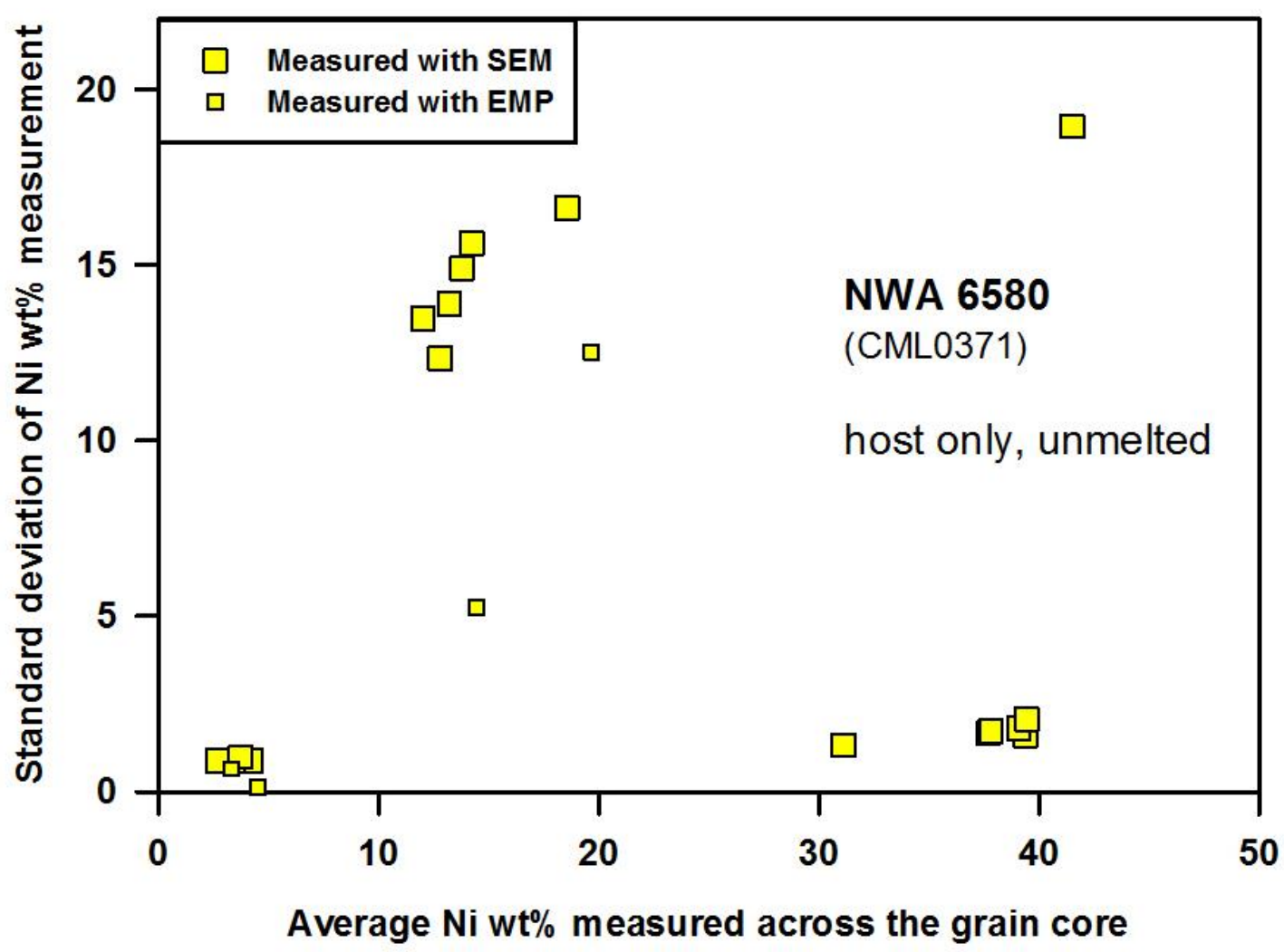

Figure 50: SEM and EMP compositions of metal grain cores from NWA 6580.

The grains within the chondritic portions of the NWA 5964 sample are strikingly similar to the NWA 6580 sample. The NWA 5964 sample contains both coarse, blocky intergrowths of kamacite and taenite, as well as coarse plessite structures in some of the chondritic grains sampled. The most apparent difference seen in the NWA 5964 sample comes from the presence of large dendritic metal-sulfide assemblages available for analysis. These appear in Figure 51 as the gray circles, contrasting the chondritic analyses shown as yellow squares. The dendritic grains in general show a martensitic composition ranging generally from 8 to $20 \mathrm{wt} \%$ nickel. The standard deviation is relatively high as 
we are sampling across the intergrowth of kamacite and taenite (or tetrataenite)

composing the martensitic structure. Some of martensitic grains in the dendritic structure appear to be polycrystalline, resulting in some high nickel regions appearing in the metal grain, likely representing a metal-metal grain boundary, and resulting in the few analyses that show compositions near $30 \mathrm{wt} \%$ nickel. The general variation in grain compositions is consistent with chondritic portions seeing relatively low shock reheating, while the grains in the melted region appear more similar to what we observed in melt rock NWA 6454. Taking all available information about the Fe-Ni distributions into account for NWA 5964, it appears that the chondritic portions were not heated much and that the melt zone was heated and transformed at lower temperature to plessite of varying coarseness as in melt rock NWA 6454. The plessite in NWA 5964 is somewhat less coarse than in NWA 6454, which can be attributed to somewhat faster cooling on average for the melt portion in NWA 5964 than for the melt rock. 




Figure 51: SEM and EMP compositions of metal grain cores from NWA 5964.

\section{Presence of Carbide Grains}

Within the chondritic portions of our two melt breccias, NWA 5964 and NWA 6580 , many of the metal grains contain a carbide phase. This carbide phase was initially thought to be cohenite $\left.\left[(\mathrm{Fe}, \mathrm{Ni})_{3} \mathrm{C}\right)\right]$ (Hauver and Ruzicka, 2011), however after further investigation with SEM and electron backscatter diffraction (EBSD) techniques it is now believed to be a haxonite $\left.\left[(\mathrm{Fe}, \mathrm{Ni})_{23} \mathrm{C}_{6}\right)\right]$ structure rather than cohenite. The exact composition is difficult to determine by chemical analysis as this typically requires carbon coating of the sample, thus eliminating the ability for a straightforward analysis of carbon content in the sample. The EBSD result is likely a more valid determination. 
Currently it has not been possible to directly measure the composition of the phase with the available instrumentation.

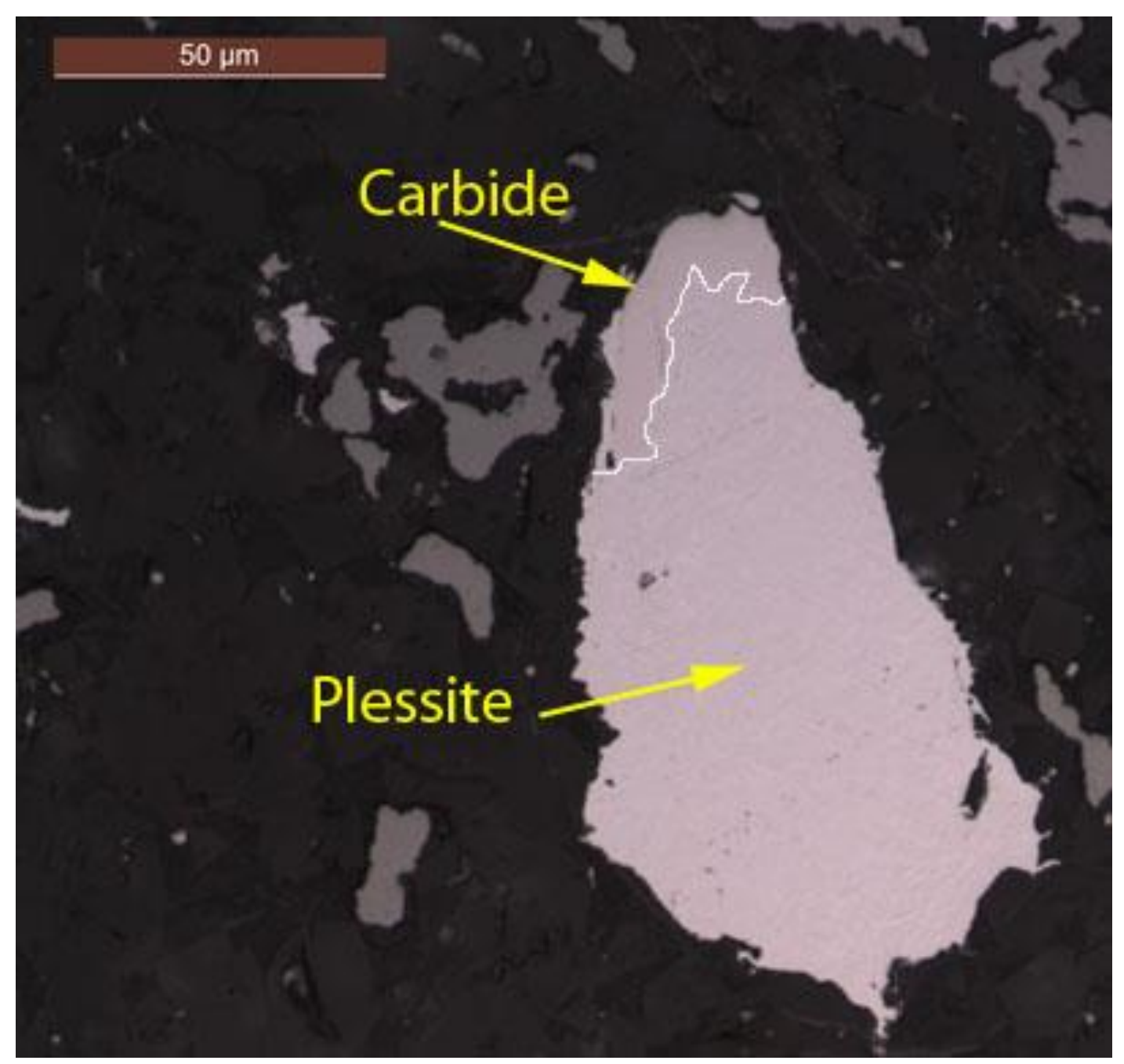

Figure 52: Reflected light photomicrograph of metal-carbide grain from NWA 5964 showing typical metal-carbide texture with carbide along the metal-silicate contact.

The carbide phase was only found in the melt breccia samples, NWA 5964 and NWA 6580. Extensive searching revealed no indications of carbides present in the melt rocks (NWA 6454 or NWA 6579) or the S6 (NWA 4860) samples. The majority of the 
carbide grains in both breccias occur along grain boundaries, either silicate-metal or metal-troilite contacts, Figure 52. The distribution of the carbides in the melt breccias show they form in metal grains that are near, but not in, melted silicates. Within one thin section of NWA 5964 (4-1) the majority of the section exhibits a melt texture, though some small clasts with chondritic textures are embedded in the melted region. The carbides found in this 4-1 thin section are limited to regions exhibiting this chondritic texture, and are never found in metal grains from the regions in which the silicates were melted.

Carbides are rare in stony meteorites, and have previously been associated with hydrothermal alteration in type 3 ordinary chondrites (Krot et al., 1997) indicating that cohenite and haxonite may form as the result of metals interacting with carbon bearing fluids. The samples in our study lack indications of hydrothermal alteration, as well as the magnetite Krot et al. (1977) found in association with the carbon rich alteration product. Krot et al. (1977) determined the most feasible way the carbides could form is through the carbidization of Fe-Ni metal by CO gas. Romig and Goldstein (1978) concluded that cohenite is only produced by relatively slow cooling from higher temperatures. Romig and Goldstein found that cooling rates of $25^{\circ} \mathrm{C} / \mathrm{hr}$ allowed cohenite to form in C-bearing systems, while more rapid cooling rates resulted in graphite forming instead.

Krot et al. (1997) found carbides to have similar Co wt\% to kamacite, and found kamacite in association with carbides are often enriched with Co (up to 18 wt\%). Our analysis found no kamacite grains overly enriched with Co, as the most enriched grain contained only $1.8 \mathrm{wt} \%$. Additionally our carbide grains in NWA 5964 show no Co 
enrichment (Table 5), and were easily identified as a separate phase from kamacite by the lack of Co. The carbide grains in NWA 6580 and NWA 5964 were consistently depleted in Co relative to kamacite. Although the exact cause of this depletion is not obvious, it may be indicative of a different origin as Krot et al. (1997) investigated the formation of carbides via hydrothermal alteration. The carbide grains in NWA 6580 (Table 6) are similar to the range of compositions seen in NWA 5964, also distinctly lacking the Co enrichment seen in other studies.

Table 5: Composition (wt\%) of carbide grains in NWA 5964 as measured with EMP analysis. * Carbon was calculated by difference from $100 \%$ total as we could not measure it directly. Average $=$ mean, stdev $=$ standard deviation of the mean, $\min =$ minimum, $\max =$ maximum, number of analyses $=40$.

\begin{tabular}{cccccc}
\hline \hline & $* \mathrm{C}$ & $\mathrm{P}$ & $\mathrm{Fe}$ & $\mathrm{Ni}$ & $\mathrm{Co}$ \\
\hline average & 6.9 & $<0.01$ & 88.2 & 5.17 & 0.02 \\
stdev & 1.2 & $<0.01$ & 2.02 & 1.08 & 0.04 \\
min & 5.0 & $<0.01$ & 81.5 & 4.42 & $<0.01$ \\
$\max$ & 9.2 & 0.02 & 90.4 & 9.00 & 0.19 \\
\hline
\end{tabular}

Table 6: Composition (wt\%) of carbide grains in NWA 6580 as measured with EMP analysis. * Carbon was calculated by difference from $100 \%$ total as we could not measure it directly. Average $=$ mean, $\mathbf{s t d e v}=$ standard deviation of the mean, $\min =$ minimum, $\max =$ maximum, number of analyses $=\mathbf{2 4}$.

\begin{tabular}{cccccc}
\hline \hline & $* \mathrm{C}$ & $\mathrm{P}$ & $\mathrm{Fe}$ & $\mathrm{Ni}$ & $\mathrm{Co}$ \\
\hline average & 8.2 & $<0.01$ & 87.0 & 4.85 & 0.02 \\
stdev & 0.78 & $<0.01$ & 1.05 & 1.10 & 0.05 \\
$\min$ & 6.1 & $<0.01$ & 84.1 & 4.40 & $<0.01$ \\
$\max$ & 9.3 & 0.02 & 89.6 & 9.81 & 0.22 \\
\hline
\end{tabular}

Based on the average composition of the metals in the carbide phase, and the calculated carbon content (determined as difference from 100\% total) the NWA 5964 carbide phase would have a composition of approximately $\left[\mathrm{Fe}, \mathrm{Ni}, \mathrm{Co}{ }_{3} \mathrm{C}\right.$, with a carbon to 
metal atomic ratio of 0.346 . The same calculation for the NWA6580 carbide results in a composition of approximately $[\mathrm{Fe}, \mathrm{Ni}, \mathrm{Co}]_{2.4} \mathrm{C}$, with a carbon to metal atomic ratio of 0.415. The ideal formula for cohenite is $[\mathrm{Fe}, \mathrm{Ni}, \mathrm{Co}]_{3} \mathrm{C}($ carbon $/ \mathrm{metal}=0.33$ ) while the ideal formula for haxonite is $(\mathrm{Fe}, \mathrm{Ni}){ }_{23} \mathrm{C}_{6}($ carbon/metal $=0.26)$. Thus based on EMPA data, the carbide in NWA 5964 more closely chemically resembles cohenite than haxonite, and haxonite does not chemically match either carbide in NWA 5964 or NWA 6580. Clearly additional work will need to be done to fully determine the precise composition and structure of these phases.

The grains containing carbides are included in the calculations that produced the closure temperature data shown in Figure 45 and Figure 46, indicating the metal grains recorded diffusion over temperatures significantly lower (mainly $<400{ }^{\circ} \mathrm{C}$ ) than the expected temperatures where carbides are expected to form. This suggests that the carbides formed at low temperatures $\left(<400{ }^{\circ} \mathrm{C}\right)$ also. Previously it was proposed the carbide was likely the result of contact metamorphism triggered by shock heating (Hauver and Ruzicka, 2011). Semenenko and Golovko (1994) suggested that carbon was mobile during shock effects, but proposed a concentration in localized melt veins. However in the case of the melt breccias it is evident that the carbides are forming in areas that saw reduced shock effects, but were in close spatial relation to the melted silicates. The residual heat from nearby shock melt could have been enough to allow the carbidization of the preexisting Fe-Ni grains, forming carbides along grain boundaries.

The source of the carbon is not directly apparent, as carbon is not a major component of ordinary chondrites; however we believe the carbon is being released from 
the melted chondrite portions. Schaefer and Fegley (2006) found that the outgassing of L and LL chondrite material produced small amounts of $\mathrm{CO}_{2}$ and $\mathrm{CO}$ at temperatures above $600^{\circ} \mathrm{C}$, while $\mathrm{H}$ chondrites require temperatures above $700^{\circ} \mathrm{C}$. Given the large regions of melted silicates in both breccia samples it is apparent that temperatures were high enough to produce $\mathrm{C}$ rich vapors. If the melting of silicate material is required to mobilize $\mathrm{C}$ rich vapor, it is then logical the vapors would interact with the surrounding solid material, and not the molten material that liberated it. This results in the unmelted regions surrounding the melt to be dusted with carbides. CO could have been present in our melt rock NWA 6454 , resulting in lower $f \mathrm{O}_{2}$, allowing for the precipitation of schreibersite in the metals (Heymann, 1971), indicating the presence of CO in melted chondritic material is not unexpected or unusual. 


\section{Conclusions}

Within the samples from the L group incorporated in this study, the metal textures and compositions vary widely, and generally vary in correlation with the thermal history of the sample. Based on the textural and compositional data collected we can constrain the thermal histories of these samples. This is most easily done sample by sample.

NWA 4860

The texture of the silicates and metal grains in NWA 4860 are consistent with the S6 descriptions from Stöffler et al. (1991), Table 1. The sample as a whole shows some melt pockets, but is largely unmelted, and contains relic chondrules. There are also vugs present, indicating there was some hot gas mobilized as a result of the reheating.

The chemical trends in the metal and sulfides indicate the sample experienced less heating and slower cooling than our melt rock samples, NWA 6454 and NWA 6579. The lack of Ni enrichments in troilite (Figure 33), as well as the lack of P in the metal (Figure 27 ), is consistent with slow cooling after a strong heating event. In both cases the lack of enrichment is attributed to slow enough cooling to allow diffusion out of the grains. The uniform composition of all the martensite grains, and the lack of high Ni rims on them, is consistent with extensive heating but not to the point of melting. The S6 material composing NWA 4860 is likely to form in the fallout material that surrounds an impact crater, as shown in Figure 53. The crater model shown in Figure 53 was developed by 
French, 1998, based on terrestrial impact craters, however the dynamics are expected to be similar regardless of the body being impacted.

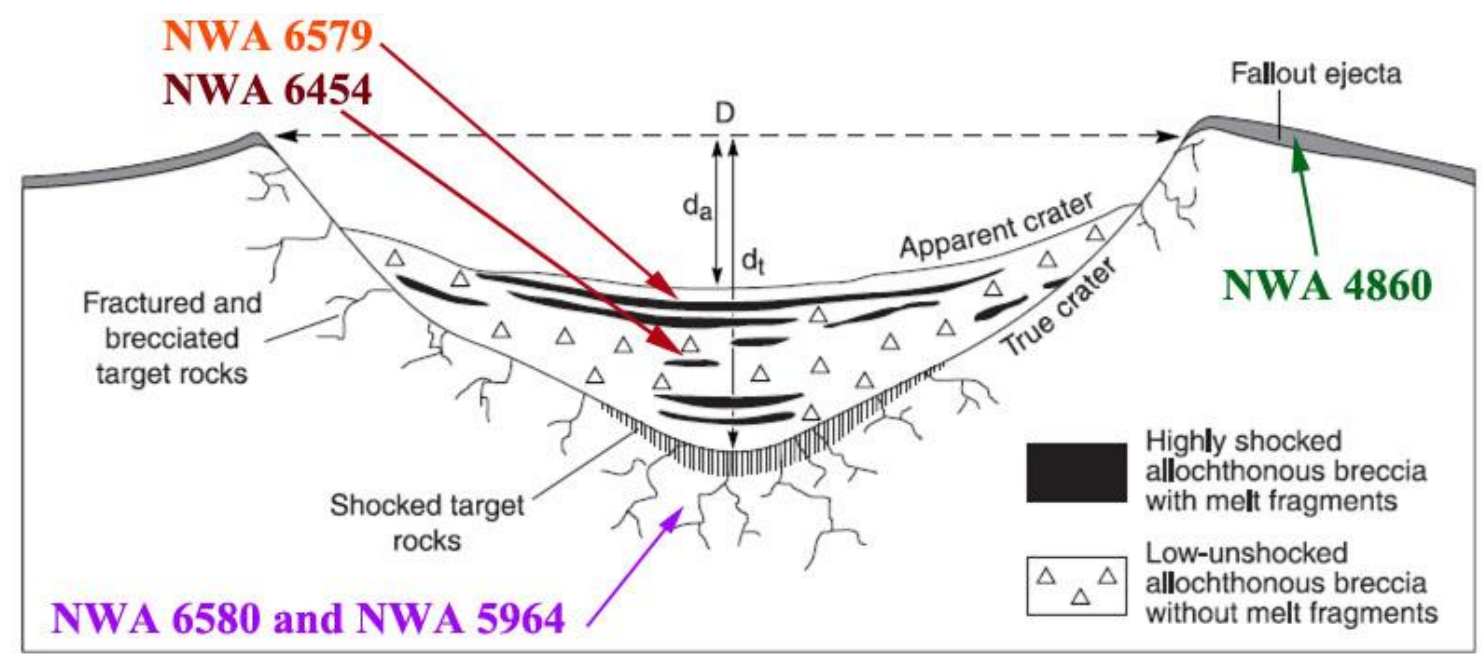

Figure 53: Diagram of a terrestrial impact crater, annotated from French, 1998, to show the relative formation locations of the samples included in this study.

NWA 6579

The silicate and metal-sulfide textures indicated that NWA 6579 experienced significant shock heating to the point of melting. Most of the metal-sulfide grains were not cellular or dendritic (Figure 13), however one grain did exhibit a dendritic structure and yielded a cooling rate of $\sim 1-100{ }^{\circ} \mathrm{C} / \mathrm{sec}$ for cooling conditions above the metaltroilite eutectic $\left(\sim 950-1000{ }^{\circ} \mathrm{C}\right)$.

The metal compositions showed some enrichment in P (Figure 29), and the metal grains also contain the phosphide mineral schreibersite (Figure 30). It is likely the 
elevated $\mathrm{P}$ in the metal is the result of rapid cooling, while the schreibersite indicates the system cooled slowly enough to partially form the phosphide as a result of oversaturation with respect to $\mathrm{P}$ as the system cooled. The elevated Ni in the troilite of NWA 6579 (Figure 36) indicates a rapid cooling rate consistent with metal-troilite textures.

Based upon the melting textures it is apparent NWA 6579 experienced more heating than NWA 4860. The additional chemical data is suggestive of a more rapid cooling rate in NWA 6579 also. Based on all available data, NWA 6579 probably formed from a near-surface impact melt on the parent body that was embedded in warm materials (Figure 53).

NWA 6454

Similar to the NWA 6579, NWA 6454 exhibits silicate and metal textures consistent with whole rock melt. The metal-sulfide grains regularly exhibit cellular or dendritic assemblages (Figure 13), and resulted in more data points collected for cooling data. These data indicate the metal-sulfide system cooled to crystallization at a rate of $\sim 1$ $10{ }^{\circ} \mathrm{C} / \mathrm{sec}$ (Figure 24), somewhat more slowly than NWA 6579.

The metal grains are enriched in $\mathrm{P}$ (Figure 31). While not all of the grains show a large enrichment, many show more enrichment than seen in NWA 6579 (Figure 29). This higher enrichment level can be explained by a less P-saturated melt composition that did not favor the formation of schreibersite, and which thereby allowed more $\mathrm{P}$ to be retained in metal despite somewhat slower cooling during metal-sulfide solidification. However 
cooling must still have been relatively rapid as troilite grains are enriched in Ni (Figure $35)$.

The overall metal compositions and the variation in metal grain composition show the metal grains from NWA 6579 are more uniform than NWA 6454. This can be explained by the plessite structure of NWA 6454 being somewhat coarse, thus resulting in more apparent spread in the analyzed compositions. This coarser plessite would indicate a slightly slower cooling rate than seen in NWA 6579, consistent with the dendritic cooling rate data. Altogether, the data suggest that the NWA 6454 impact melt formed either a greater depth below more insulating material than NWA 6579 (Figure 53 ), or that it formed in a larger mass of heated rock, or both. A greater cooling depth with more overburden pressure and slower cooling overall is consistent with the lack of vesicles in this meteorite. Either vesicles did not form because of the higher pressure, or perhaps more likely, they rose up toward the surface and were removed from the NWA 6454 source area.

NWA 6580

There is a large portion of NWA 6580 that has clearly melted. The silicates in this region are zoned olivine crystals set in glass, indicative of melting and likely fairly rapid cooling. The melt region of NWA 6580 was nearly devoid of metals and sulfides, and those that were present were too small for reliable chemical analysis, but resemble the quench cooled textures used for dendritic cooling rate measurements (Figure 15). For the 
sample to be significantly melted it is likely the thermal history involves localized heating nearly as intense if not mostly similar to that seen in NWA 6579 and NWA 6454.

In contrast, the chondritic portion of NWA 6580 lacks the characteristics of a severely reheated system. There is no enrichment of $\mathrm{P}$ in any of the metal grains analyzed (Figure 28). This is typical for slow cooled chondritic textures. Likewise, the troilite grains in general show no enrichment in $\mathrm{Ni}$, and no analysis recorded more than $0.2 \mathrm{wt} \%$ Ni in the troilite (Figure 34).

The metal grains within the chondritic portion contain some grains that are composite zoned taenite and kamacite grains. These grains yielded a cooling rate of $\sim 0.1$ to $1 \mathrm{~K} / \mathrm{My}$ (Figure 25), which is significantly slower than the apparent cooling rates determined in the melt samples NWA 6579 and NWA 6454. In addition, all of the grains in the chondritic portion could have been subjected to the same, slow cooling rate. The closure temperature data for NWA 6580 indicates the zoned grains are recording cooling data at temperatures of $\sim 370$ to $470{ }^{\circ} \mathrm{C}$ at the grain cores (Table 4) and down to temperatures below $300{ }^{\circ} \mathrm{C}$ along most of the grain rims (Figure 46). The presence of tetrataenite is also indicative of slow cooling, and diffusion continuing to low temperatures.

There are two possibilities to explain the data for NWA 6580, depending on whether the shock melt and chondritic portion cooled in separate locations or together in the same location. If not cooling together, slow-cooling material from depth in the parent body (the chondritic portion) could have been brought up closer to the surface where it 
came in contact with the shock melt. This implies substantial disruption of the parent body with large-scale impact reworking. In this scenario, the contact between melt and chondrite could be a purely tectonic contact that formed as a result of shock processes.

If the melt and chondrite portion did cool together, cooling would have had to have been rapid at high temperature during solidification of the impact melt and much slower at lower subsolidus temperatures. This could occur if a smaller portion of shock melt was injected into a much larger portion of chondritic rock at depth below the surface of the parent body. In this case, the contact between melt and chondrite would be an intrusive contact, although one that must have involved a strong mechanical, impactinduced component, judging from the sharp nature of the contact. Injection of melt would have had to occur at depth to explain the slow cooling of the chondritic portion. This type of setting could have arisen below a large impact crater that fractured basement rocks and injected shock melt into the underlying chondrite as shown in Figure 53.

NWA 5964

This sample is the most complex of the samples included in the study. The large melt region sits in direct and sharp contact with the complex chondritic region. Within the chondritic region the texture varies from type 3 to type 6 across various clasts, and the shock stage varies from S3-S6. The extent of the melting must have been less than experienced by NWA 6579 and NWA 6454 as NWA 5964 is not a whole rock melt. 
The structure of the metal-sulfide assemblages is generally cellular or dendritic, and resulted in a measured cooling rate of $\sim 10-100{ }^{\circ} \mathrm{C}$ (Figure 24). This cooling rate is slightly slower than what was determined for NWA 6454, however the metal within the dendrites consistently contains high Ni rims, and the overall variation in metal composition is slightly greater in NWA 5964 (Figure 23) than in NWA 6454 (Figure 11). This implies a two phase cooling, with a rapid cooling to crystallization of the metalsulfide structure, followed by slower cooling through temperatures allowing subsolidus diffusion of Ni. The troilite in the melt portion of NWA 5964 shows enrichments in Ni, similar to those seen in NWA 6454, also consistent with rapid cooling.

Within the chondritic portion the taenite grains that exhibit zoning reflect a cooling rate $>10 \mathrm{~K} / \mathrm{My}$ for grains larger than $8 \mu \mathrm{m}$ (Figure 26). The smaller grains showed more scatter, but generally reflect slower cooling rates. The closure temperatures for these types of grains range from a start temperature in the core of the grains of $\sim 550$ to $350{ }^{\circ} \mathrm{C}$, to final closing temperatures $<300{ }^{\circ} \mathrm{C}$ as determined from the grain edge compositions (Table 3). The presence of tetrataenite in the metal grains is consistent with the slow cooling data (Figure 45).

The troilite grains within the chondritic portion of NWA 5964 show a complex scatter, and may represent a combination of observed distributions for melted and unmelted regions. The enrichment pattern showed no obvious correlation to distance from the shock melt, and may represent other processes, or irregular distances to the melt portion in the unobserved third dimension. 
As with the other melt breccia, two overall scenarios are possible for NWA 5964. Either the chondritic portion cooled at depth and was later impact-mixed with alreadysolidified shock melt closer to the surface, or impact melt became intrusively mixed with chondritic material at depth while the melt was still hot. As with NWA 6580, intrusion of melt into chondrite at depth below the surface, as shown in Figure 53, seems more likely. The presence of carbide in the chondritic portion favors the idea of heating by a shock melt. In addition, the irregular and in places convolute contact between melt and chondrite in NWA 5964 (Figure 6) is much better explained as an intrusive contact than a purely mechanical or tectonic boundary that formed cold.

NWA 5964 also suggests significant impact-reworking of parent body materials. The large variety of petrographic types and shock stages in the chondritic host implies transport of parent body materials over a range of depths and under different shock conditions. This impact-mixing could have largely occurred before the injection of the shock melt, which then mostly reset taenite cooling rates to one common value $(\sim 10-100$ ${ }^{\circ} \mathrm{C} / \mathrm{My}$ ). However, not all of the smaller taenite grains were reset to this common value, and the presence of some apparently more slowly-cooled grains $\left(\sim 1-10{ }^{\circ} \mathrm{C} / \mathrm{My}\right)$ seems to indicate impact mixing even after the injection of the large shock melt. Thus, an extended history of impact reworking is implied for NWA 5964 and the parent body from which it was derived. 


\section{Summary}

The textures and compositions of metal and troilite grains can provide important constraints on the histories of shock-reheated samples. Dendritic metal-sulfide assemblages give high-T cooling rates (to the metal-sulfide eutectic) in impact-melted portions. Below the eutectic, metal grains are able to diffuse and continue with subsolidus transformations until the closure temperature is reached. The diffusion of Ni through metal grains is indicative of slow cooling, and typically results in kamacite and taenite grains forming when cooled slowly enough. The lack of this compositional variation is attributed to more rapid cooling and a faster closing of the diffusion system. A similar effect is seen with $\mathrm{P}$ enrichments after shock reheating, leaving rapidly cooled metal grains enriched compared to more slowly cooled metal grains. Within troilite, the $\mathrm{Ni}$ content is indicative of the cooling rate, again with an enrichment indicating rapid cooling, while the lack of enrichment indicates system cooled slow enough to allow the Ni to diffuse out of the troilite and into metal phases, or the troilite precursor could have been a monosulfide solid solution (mss). Metals maintaining their original chondritic textures after shock reheating are indicative of lower levels of shock heating and lack of melting. The chondritic metal grains record much slower cooling rates, and this often results in compositional zoning of kamacite and taenite grains. The overall Ni variations detected between and within grains from the reheated samples give information about maximum heating and cooling rates. The carbides found to be present in the shock melt breccia samples (NWA 5964 and NWA 6580) probably formed as a result of shock heating and mobilization of carbon bearing gases. 
None of the dendritic samples plot along the radiative cooling line, indicating they all cooled more slowly than would be expected for radiative cooling alone, suggesting all the melt samples with dendrite structures (NWA 5964, NWA 6454, and NWA 6579) likely cooled in warm but unmelted silicate material. The textural setting seen in NWA 5964 is the prime example of this explanation, with large melt portion surrounded by chondritic material. Among the melt samples, NWA 6454 appears to have cooled somewhat slower $\left(\sim 5-10{ }^{\circ} \mathrm{C} / \mathrm{s}\right)$, compared to $\sim 10-100{ }^{\circ} \mathrm{C} / \mathrm{s}$ for NWA 6579 and the melt of NWA 5964 (Figure 24). This could indicate that the melt body that produced NWA 6454 was larger than in the other meteorites.

The metals in the chondritic portions represent much slower cooling rates, likely representing the cooling after the large shock event that introduced the melt. Only two of our samples contained chondritic portions to be examined by these methods. The NWA 6580 showed a slower cooling rate of 0.1-1 K/My, while the NWA 5964 sample reflects faster cooling rates of 10-100 K/My. The slower cooling rates in NWA 6580 and NWA 5964 can be explained by burial of the chondrite portion at depth as the shock melt was introduced. Based on all available data for NWA 5964 and 6580, the Fe-Ni compositions of the various types of metal grains (kamacite-taenite, martensite) in these meteorites were established at temperatures of $\sim 550-100{ }^{\circ} \mathrm{C}$ (Figure 39, Figure 40 ). All of the metal grains could have cooled at the same, slow rate through the temperatures below $\sim 550{ }^{\circ} \mathrm{C}$. In general the metal and troilite compositions within the chondritic portions of NWA 5694 and NWA 6580 suggest only limited heating, despite their close proximity to large melt regions in each sample. 
The presence of carbides in NWA 5964 and NWA 6580 indicate the metals were likely still reacting and diffusing to temperatures $<400{ }^{\circ} \mathrm{C}$. The stability of carbides in the system is dependent upon mobile carbon, and slow cooling to relatively low temperatures. The lack of carbide grains in the melt regions may indicate the carbon was mobilized and moved away from the melt region, this mobility would allow the hot gas to react with warm metal grains in the chondritic portion, leaving carbides preferentially along metal grain boundaries. The residual heat from the nearby shock melt may have been enough to allow the carbidization of the preexisting Fe-Ni metal grains in a contact metamorphism setting. 


\section{References}

Begemann, F., and Wlotzka, F., 1969, Shock induced thermal metamorphism and mechanical deformations in the Ramsdorf chondrite: Geochimica et Cosmochimica Acta, 33, 1351-1370.

Bennett, M.B. and McSween, H.Y. Jr., 1996, Shock features in iron-nickel metal and troilite of L-group ordinary chondrites: Meteoritics and Planetary Science, 31, 255-264.

Bischoff A., Scott E.R.D., Metzler K., and Goodrich C.A., 2006, Nature and origins of meteoritic breccias. Meteorites and the Early Solar System II, Tucson, Arizona, University of Arizona Press, 679-712 p.

Boctor, N.Z., Bell, P.M. and Mao, H.K., 1982, Petrology and shock metamorphism of Pampa del Infierno chondrite: Geochimica et Cosmochimica Acta, 46, 1903-1911.

Brett, R., 1967, Cohenite: its occurrence and proposed origin: Geochimica et Cosmochimica Acta, 31, 143-159.

Brett, R., 2009, Cohenite in Meteorites: A proposed Origin: Science, 153, 60-62.

Bunch T.E. and Rajan R.S., 1988, Meteorite regolithic breccias. Meteorites and the Early Solar System, Tucson, Arizona, University of Arizona Press, 144-164 p.

Dodd, R. T., 1969, Metamorphism of the ordinary chondrites: A review. Geochimica et Cosmochimica Acta, 33, 161-203.

Dodd, R. T. Jf., 1981. Meteorites. Cambridge Univ. Press, Cambridge, United Kingdom, $368 \mathrm{p}$.

Flemings, M.C., 1974, Solidification Processing, McGraw-Hill, New York, New York, $364 \mathrm{p}$.

Fredriksson, K., Jarosewich, E., Nelen, J.A., Noonan, A.F. and Dube, A., 1975, The Pulsora anomaly: A case against metamorphic equilibration in chondrites: Smithsonian Contributions to the Earth Sciences, 14, 41-53.

French, B.M., 1998, Traces of Catastrophe: A Handbook of Shock-Metamorphic Effects in Terrestrial Meteorite Impact Structures, LPI Contribution No. 954, Lunar and Planetary Institute, Huston, 120 pp.

Goldstein J.I. and Michael J.R., 2006, The formation of plessite in meteoritic metal: Meteoritics and Planetary Science, 41, 553-570. 
Hauver, K., Ruzicka, A., 2011, Cohenite in NWA 5964 (L3-6 Melt Breccia): A Possible Product of Shock-Induced Contact Metamorphism: Lunar and Planetary Science Conference, $42^{\text {nd }}$ Annual Meeting, Houston, Texas, Abstracts, no. 1608, p. 2627.

Herndon, J.M. and Rudee, M.L., 1978, Thermal history of the Abee enstatite chondrite: Earth and Planetary Science Letters, 41, 101-106.

Heymann, D., 1967, On the origin of hypersthene chondrites: ages and shock effects of black chondrites: Icarus, 6, 189-221.

Housen, K.R. and Wilkening, L.L., 1982, Regoliths on small bodies in the solar system: Annual Review of Earth and Planetary Science, 10, 355-376.

Hutchison R., 2004. Meteorites: A petrologic, chemical and isotopic synthesis: Cambridge, United Kingdom, Cambridge Planetary Science, 506 p.

Kullerud, G., 1963, The Fe-Ni-S system: Carnegie Institute Yearbook, 62, 175-189.

Leroux, H., Doukhan, J.C. and Perron, C., 2000, Microstructures of metal grains in ordinary chondrites: Implications for their thermal histories: Meteoritics and Planetary Science, 35, 569-580.

Massalski T.B., Park F.R., and Vassamillet L.F., 1966, Speculations about plessite: Geochimica et Cosmochimica Acta, 30, 649-662.

McSween, H.Y. Jr., Ghosh, A., Grimm, R.E., Wilson, L. and Young, E.D., 2002, Thermal evolution models of asteroids, Asteroids III, Tucson, Arizona, University of Arizona Press, 559-571 p.

McSween, H.Y. Jr., Sears, D.W.G. and Dodd, R.T. 1988, Thermal Metamorphism, Meteorites and the Early Solar System, Tucson, Arizona, University of Arizona Press, 102-113 p.

Ming, C., Xiande, X. and Goresy, 1995, Nonequilibrium solidification and microstructures of metal phases in the shock induced melt of the Yanzhuang (H6) chondrite: Meteoritics, 30, 28-32.

Onorato, P. I. K., Uhlmann, D. R., and Simonds, C. H., 1978, The thermal history of the Manicouagan impact melt sheet: Journal of Geophysical Research, 83, 27892798.

Reisener, R.J. and Goldstein, J.I., 2003a, Ordinary chondrite metallography: Part 1. Fe-Ni taenite cooling experiments: Meteoritics and Planetary Science, 11, 1669-1678. 
Reisener, R.J. and Goldstein, J.I., 2003b, Ordinary chondrite metallography: Part 2. Formation of zoned and unzoned metal particles in relatively unshocked $\mathrm{H}, \mathrm{L}$, and LL chondrites: Meteorics and Planetary Science, 11, 1679-1696.

Romig, A., Goldstein, J., 1978, Determination of the Fe-Ni-C phase diagram: Metallurgical Transactions. A Physical Metallurgy and Materials Science, 9, 11, 1599.

Ruzicka A., Killgore M., Mittlefehldt D.W., and Fries M.D., 2005, Portales Valley: Petrology of a metallic-melt meteorite breccia: Meteoritics and Planetary Science, 40, 261-296.

Schmitt, R.T., 2000, Shock experiments with the H6 chondrite Kernouve: Pressure calibration of microscopic shock effects: Meteoritics and Planetary Science, 35, $545-560$

Scott, E.R.D., 1982, Origin of rapidly solidified metal-troilite grains in chondrites and iron meteorites: Geochimica et Cosmochimica Acta, 46, 813-823.

Scott, E.R.D., 2007 Chondrites and the Protoplanetary Disk, Annual Review of Earth and Planetary Sciences, v. 35, 577-620.

Scott, E. R.D., and Rajan, R.S., 1981, Metallic minerals, thermal histories and parent bodies of some xenolithic, ordinary chondrite meteorites: Geochimica et Cosmochimica Acta, 45, 53-67.

Semenenko, V.P., and Golovko, N. V., 1994, Shock-induced black veins and organic compounds in ordinary chondrites: Geochimica et Cosmochimica Acta, 58, 5, 1525-1535.

Sharp T.G. and DeCarli P.S., 2006, Shock effects in meteorites. Meteorites and the Early Solar System II, Tucson, Arizona, University of Arizona Press, 653-677 p.

Sears, D.W.G. and Dodd, R.T., 1988, Overview and classification of meteorites, Meteorites and the Early Solar System, Tucson, Arizona, University of Arizona Press, 3-31 p.

Smith B.A. and Goldstein, J.I., 1977, The metallic microstructures and thermal histories of severely reheated chondrites: Geochimica et Cosmochimica Acta, 41, 10611072 . 
Stöffler D., Bischoff A., Buchwald V., Rubin A.E., 1988, Shock effects in meteorites, Meteorites and the Early Solar System, Tucson, Arizona, University of Arizona Press, 165-202 p.

Stöffler, D., Keil, K. and Scott, E.R.D., 1991, Shock metamorphism of ordinary chondrites: Geochimica et Cosmochimica Acta, 55, 3845-3867.

Taylor, J. and Heymann, D., 1971, Postshock thermal histories of reheated chondrites: Journal of Geophysical Research, 76, 8, 1879-1893.

Taylor G.J., Maggiore P., Scott E.R.D., Rubin A.E., and Keil K., 1987, Original structures, and fragmentation and reassembly histories of asteroids: Evidence from meteorites. Icarus, 69, 1-13.

Weisberg, M.K., McCoy, T.J., Krot, A.N., 2006, Systematics and Evaluation of Meteorite Classification, Meteorites and the Early Solar System II, Tucson, Arizona, University of Arizona Press, 679-712 p.

Wilkening, L.L., 1978, Tysnes Island: An unusual clast composed of solidified, immiscible, Fe-FeS and silicate melts: Meteoritics and Planetary Science, 13, 1-9.

Williams, R. J., 1971, Equilibrium temperatures, pressures, and oxygen fugacities of the equilibrated chondrites: Geochimica et Cosmochimica Acta, 35, 407-411.

Willis, J. and Goldstein, J.I., 1983, A three-dimensional study of metal grains in equilibrated, ordinary chondrite: Journal of Geophysical Research, 88, 287-292.

Wlotzka, F., 1993, A weathering scale for the ordinary chondrites: Lunar and Planetary Science, 24 ${ }^{\text {th }}$ Annual Conference. Houston, TX, Abstracts. p. 460.

Wood, J.A., 1967, Chondrites: Their metallic minerals, thermal histories, and parent planets: Icarus, 6, 1-49.

Wood, J.A. 1988, Chondritic meteorites and the solar nebula: Annual Review of Earth and Planetary Science, 18, 53-72. 